University of Louisville ThinkIR: The University of Louisville's Institutional Repository

Electronic Theses and Dissertations

$8-2019$

\title{
Queering black greek-lettered fraternities, masculinity and manhood: a queer of color critique of institutionality in higher education.
}

Antron Demel Mahoney

University of Louisville

Follow this and additional works at: https://ir.library.louisville.edu/etd

Part of the African American Studies Commons, Africana Studies Commons, American Studies Commons, Feminist, Gender, and Sexuality Studies Commons, Film and Media Studies Commons,

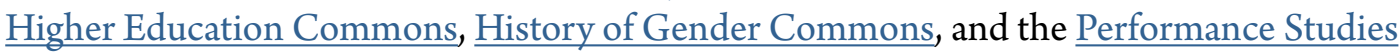
$\underline{\text { Commons }}$

\section{Recommended Citation}

Mahoney, Antron Demel, "Queering black greek-lettered fraternities, masculinity and manhood : a queer of color critique of institutionality in higher education." (2019). Electronic Theses and Dissertations. Paper 3286.

https://doi.org/10.18297/etd/3286

This Doctoral Dissertation is brought to you for free and open access by ThinkIR: The University of Louisville's Institutional Repository. It has been accepted for inclusion in Electronic Theses and Dissertations by an authorized administrator of ThinkIR: The University of Louisville's Institutional Repository. This title appears here courtesy of the author, who has retained all other copyrights. For more information, please contact thinkir@louisville.edu. 
QUEERING BLACK GREEK-LETTERED FRATERNITIES, MASCULINITY AND MANHOOD: A QUEER OF COLOR CRITIQUE OF INSTITUTIONALITY IN HIGHER EDUCATION

\author{
By \\ Antron Demel Mahoney \\ B.S., Bethune-Cookman College, 2005 \\ M.Ed., University of North Carolina at Greensboro, 2007
}

\begin{abstract}
A Dissertation
Submitted to the Faculty of the

College of Arts and Sciences of the University of Louisville

In Partial Fulfillment of the Requirements

for the Degree of
\end{abstract}

Doctor of Philosophy in Pan-African Studies

Department of Pan-African Studies

University of Louisville

Louisville, Kentucky

August 2019 
Copyright 2019 by Antron Demel Mahoney

All rights reserved 

QUEERING BLACK GREEK-LETTERED FRATERNITIES, MASCULINITY AND MANHOOD: A QUEER OF COLOR CRITIQUE OF INSTITUTIONALITY IN HIGHER EDUCATION

By

Antron Demel Mahoney

B.S., Bethune-Cookman College, 2005

M.Ed., University of North Carolina at Greensboro, 2007

A Dissertation Approved on

June 27, 2019

by the following Dissertation Committee:

Dr. Kaila Adia Story, Chair

Dr. Anne Caldwell

Dr. Ricky Jones

Dr. W. Carson Byrd 
Dedicated to the ones I loved and lost during this journey.

Grateful for the ancestors and universe for their guidance. 


\section{ACKNOWLEDGEMENTS}

First and foremost, I must thank my committee: Kaila Story, Ricky Jones, Carson Byrd, and Anne Caldwell. My committee not only challenged me over the past four years, but has been supportive, generous, and kind, making space for me to be the scholar I saw myself to be. Dr. Story, as chair and advisor, exemplified the best of this committee and I could not have asked for a better mentor and friend. I am forever grateful for the Department of Pan-African Studies - the faculty, staff and students — who have provided community and support, especially my incoming cohort family, Saleema and JC as well as Drs. Theresa Rajack-Talley and Joy Carew who were instrumental in shaping our transition and first-year in the program.

My “push” into doctoral studies started long before I entered UofL. So many people inspired and encouraged me along the way. Thanks to all my Florida State University (FSU) friends and family who "aided and abetted" in the push to get me here, especially all the folks at the Center for Leadership and Social Change. My initial scholarship interest was shaped by the first doctoral studies courses I took at FSU with Drs. Tamara Bertrand Jones and Deana Rohlinger after much encouragement from Dr. Estee Hernandez. Furthermore, this study was partially inspired by some of my previous work with Dr. Shawna Patterson-Stephens at FSU. I have also been very fortunate to have met scholars I deeply admire, including Professors E. Patrick Johnson, Marlon 
Bailey, and Jeffrey McCune. Though the encounters were brief, they all offered great advice and encouragement. Also, special thanks to Zeta Alpha Delta Fraternity.

Moreover, I could not have done this without all my friends and family, near and far, who supported me throughout this endeavor. Far too many for me to recognize them all. Nevertheless, I am grateful for the spoken/unspoken, named/unnamed prayers, texts/DMs, calls, and Ms. Cynthia from the airport. My parents-Lee, Gary, Anthony and Karen - for always believing in me. Tony and Xaivian for keeping me grounded and connected. Shout out to my Louisville roommates, Jarrod and Jakia, for making Louisville home, Sunergos Coffee for providing my go-to writing space and fuel, and UofL Multicultural Graduate Students Association, along with Dr. Craig and Ms. Yvette, for being a haven within the graduate struggle. Last but definitely not least, I am grateful for all the black queer folks I've been blessed to be in community with—it's our labor and love that keeps me going. This is especially true of all the participants and subjects of this study. 


\title{
ABSTRACT \\ QUEERING BLACK GREEK-LETTERED FRATERNITIES, MASCULINITY AND MANHOOD: A QUEER OF COLOR CRITIQUE OF INSTITUTIONALITY IN HIGHER EDUCATION
}

\author{
Antron D. Mahoney
}

June 27, 2019

Drawing heavily on Roderick Ferguson's (2012) theory of institutionality, this dissertation constructs a counter-historical genealogy of racialized gender in higher education and U.S. society through the formation of black Greek-lettered fraternities. Ferguson argues that with the insurgence of minority resistance globally and domestically during the mid-twentieth century, hegemonic power took a new form. Instead of rejecting minority difference, power's new network attempted to work through and with minority difference in an effort to absorb and restrict these radical formations within state, capital and academy frameworks - producing narrow or one-dimensional minority subjectivities. Established at the turn of the twentieth century, black Greek-lettered fraternities reflect the impetus and crossroads of power's new archive as constituted through two competing yet complementing social movements - the racial uplift and the American fraternal movements - therefore, working within and against institutional normative logics of race, gender, sexuality, and class. As such, this study employs black fraternalism to reveal power's post-WWII dynamics and its impact on black subjectivity 
within the academy and the broader U.S. political landscape, particularly in relation to black queer embodiment and politics.

This study constitutes a queer of color critique. A queer of color critique centers the queer of color subject, and in doing so, exposes the often-obscured interconnected systems of race, gender, sexuality and class in cultural formations to map the contours of power propagated by state and capital forces. This study finds that as minority difference was institutionalized within the post-civil rights academy, black fraternalism was employed to facilitate and affirm institutional demands for equity and an idealized cisheteropatriarchal black subjectivity, foreclosing on alternative gendered critical possibilities. As such, this study explores the development of black queer fraternal (BQF) formations, so-called deviant forms of black fraternalism that subvert its institutional masculine homosocial logics, to suggests a critical alternative black gender politics, freedom, memory, and normality.

KEYWORDS: Fraternities; Higher education; Institutionality; Masculinity; Queer of color critique; Queer theory. 


\section{TABLE OF CONTENT}

PAGE

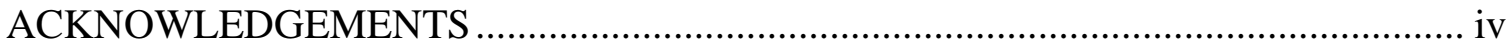

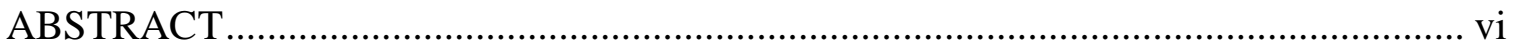

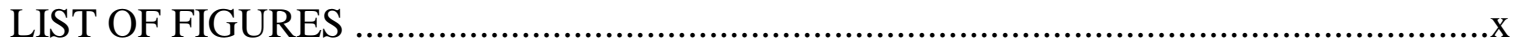

CHAPTER 1: QUEERING BLACK GREEK-LETTERED FRATERNITIES, MASCULINITY, MANHOOD, AND HIGHER EDUCATION ..................................1

Queering Black Fraternities and Institutionality: Situating the Study ............................3

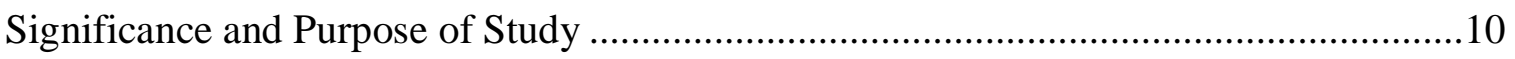

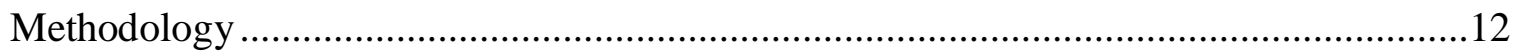

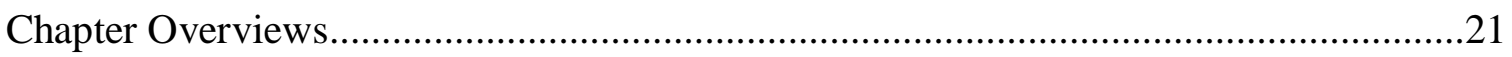

CHAPTER 2: BECOMING MEN: BLACK GREEK FRATERNAL TEXTUALITY

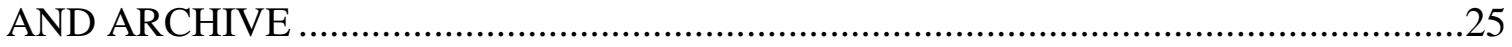

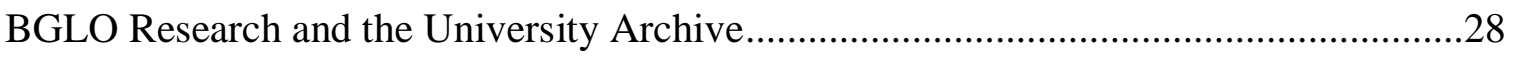

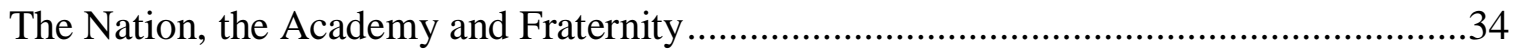

Becoming Men: The Making of an American Fraternal Archive ...................................38

Formulating Black Masculine "Excellence": The Founding of Black Fraternities ...........50

The Black Fraternal Struggle: Gendered Sexuality and Socio-political Consciousness ...56

Black Greek Fraternal Textuality and Archive .....................................................64

CHAPTER 3: THE BLACK FRATERNAL MAKING OF MINORITY DIFFERENCE

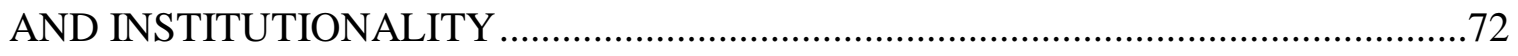

The Biopolitics of Fraternalism in Higher Education ................................................. 73

Archiving Difference: Omega Psi Phi, the AASU and Black Studies ............................78 
The New Black Student and The Black Greek Paradox ..................................................8

The Closing of Critical Universes and The Bureaucratization of Diversity .......................98

A Black Fraternal Will to Institutionality …………….................................................103

CHAPTER 4: HETEROSOCIAL LABOR AND FEMME RESISTANCE:

TRANSFIGURING BLACK FRATERNALISM AND INSTITUTIONALITY

Black Fraternal Homosocial Laboring: Making Gender on Campus ...............................114

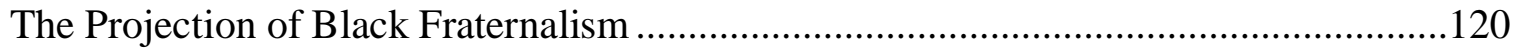

Transfiguring the Institutionality of Minority Difference ………….............................122

Transfiguring the Homosociality of Black Fraternalism .................................................133

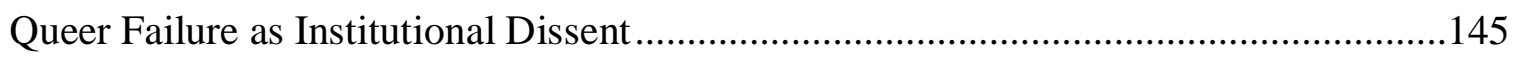

CHAPTER 5: MINORITY DIFFERENCE IN THE AGE OF THE DOWN LOW: MIAKAS, INSTITUTIONALITY AND FREEDOM ……….........................................148

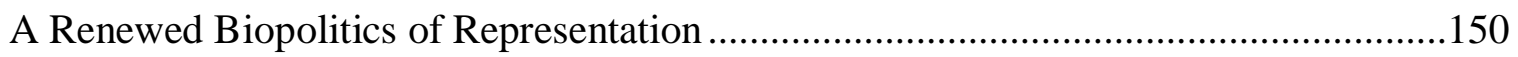

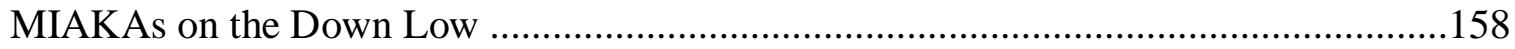

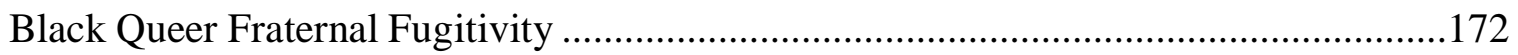

CHAPTER 6: CONCLUSION: SHADE AS A BLACK POLITICS

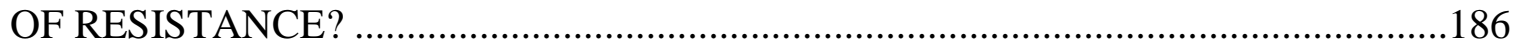

The Limits of Heterosociality and Gender Dissent...........................................................192

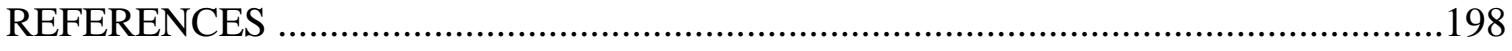

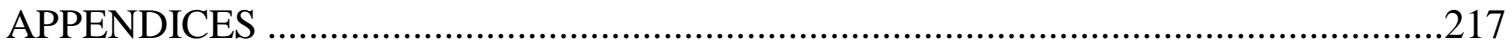

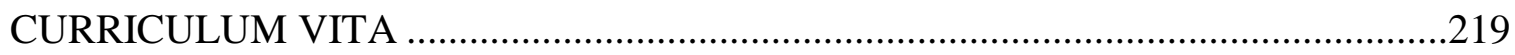




\section{LIST OF FIGURES}

$\begin{array}{lll}\text { FIGURE } & \text { PAGE }\end{array}$

1. Preamble to the African American Student Union Constitution at FSU ..............83

2. Reported Members of the Houston-based Tri-Alpha Chapter of MIAKA ...........161

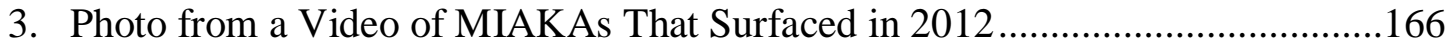

4. One of the MIAKA Pictures That Surfaced in 2007 and Resurfaced in $2012 \ldots . .217$

5. One of the MIAKA Pictures That Surfaced in 2012 ......................................218 


\title{
CHAPTER 1: QUEERING BLACK GREEK-LETTERED FRATERNITIES,
}

\author{
MASCULINITY, MANHOOD, AND HIGHER EDUCATION
}

And the great thing about Winston-Salem State was, of course, if you were effeminate then, of course, you had to belong to the gay sorority, which, of course, patterned itself after the black female sororities. And so that's a whole underground culture that a lot of people don't know about. And this is across the country. So the Delta Sigma Theta Sorority has a lot of gay men who consider themselves Deltas too, even though they did not pledge Delta Sigma Theta, you know, it's a woman's sorority. But there's something about Delta that appeals to a certain gay men or AKA [Alpha Kappa Alpha]. And, of course, AKA was it for me. And yeah, interesting, it was quite interesting, that whole experience. So my gay friends, you know, we just hung out. We identified with what we thought was, I don't know how to say it-fabulous, you know. And so those sororities were fabulous to us. And so we just made our own underground culture. Even at the other HBCUs, we had friends and sorority sisters. So, you know, isn't that something?

—Fred-Rick, narrator from Sweet Tea (Johnson, 2008)

Since their formation at the turn of the twentieth century, black Greek-lettered fraternities have been preoccupied with the conceptualization of black manhood and masculinity. Black fraternities were integral to the New Negro Movement, and as such, part of a larger effort to reimagine and reposition the African American in the political and social landscape of American society (Kimbrough, 2003). As evident in the name of the movement, "The New Negro," conversely, this Renaissance sought to signify a "new" black people in the minds of America - a people of African descent who would defy the stereotypes and distorted images of African Americans perpetuated by a system of white supremacy. However, as Henry Louis Gates (1988) points out, there is a social and political paradox inherent in the "success" of a movement politically and historically 
situated in white liberal ideology. In order to be successful, the "New Negro" must turn "away from the 'Old Negro' and the labyrinthine memory of black enslavement" (Gates, 1988, p. 132), and in many ways, hail the values of white middle-class America in an attempt to be normalized.

Thus, the development of black fraternities at the turn of the twentieth century was a visual and material symbol of African Americans obtaining the status of "New Negro," and since their founding, black Greek-lettered fraternities have been a normalizing institution within black communities—wielding a tremendous amount of political, social and economic clout on college campuses and society at large (Jones, 2004/2015). However, the forms of masculinity presented in black Greek-lettered fraternities are often complex, unstable and contradictory in many cases, requiring substantive reiteration and citational acts (Butler, 1993). Nevertheless, the hegemonic masculinity fostered within black Greek-lettered fraternities consistently stand in opposition to queerness ${ }^{1}$ and femininity—commonly citing the ideas of being virile, attracted to women, and cis-heteropatriarchy as ideal (Dancy, 2011; DeSantis \& Coleman, 2008; Ray \& Spragling, 2012). As a result, DeSantis and Coleman (2008) conclude that it would be almost impossible for an openly gay student to gain admission into a college black fraternity chapter, and based on the social science literature, black gay college students perceive joining black Greek-lettered fraternities as difficult or impossible due to their sexuality (Means \& Jaeger, 2013; Carter, 2013) and those who do join black Greek-lettered fraternities are uncomfortable in fraternal spaces, face

\footnotetext{
${ }^{1}$ I use "queer" throughout this manuscript as an umbrella term for non-normative and/or non-binary forms of gender and sexuality.
} 
differentiate treatment, and/or conceal or compensate for their queer disposition

(DeSantis \& Coleman, 2008; Ray \& Spragling, 2012).

\section{Queering Black Fraternities and Institutionality: Situating the Study}

Given the queer antagonism in black Greek-lettered fraternities, there's something

allusive about the "something" in which Fred-Rick speaks in the opening epigraph—so

much so, Fred-Rick leaves us in a state of wonder: "So, you know, isn't that something?"

Fred-Rick's speculative conclusion is indicative of the rich "tea" 2 he has spilled,

revealing a queer life-world, which at the time, had rarely been acknowledged publicly.

Thus, there's an element of pleasure and desire induced through Fred-Rick's speaking the

unspeakable. A pleasure fostered through the subversion of the gendered and sexual

normativities of black fraternity and sorority life, or black fraternalism ${ }^{3}$, and a desire for a recognition and belonging that transgress the disciplines and regulations of institutionality.

Building on the work of Michel Foucault, Rodrick Ferguson (2012) theorizes what he calls the will to institutionality. Ferguson argues that since the late 1960s and 1970s, when radical student protests on college campuses sought to transform the white cis-heteropatriarchal boundaries of the university, a network of power has attempted to work through and with minority difference in an effort to constitute these radical formations within state, capital and academy frameworks. Thus, redistribution of power was traded for a regulatory representation, securing and extending the functions of

\footnotetext{
2 The term "tea" in black queer communities has come to signify truth or gossip, producing metaphoric phrases, such as "spilling tea" which means to tell the truth or tell the secret (See Johnson, 2008, p. 17). ${ }^{3}$ By black fraternity and sorority life, I am speaking about black Greek-lettered organizations (BGLOs), commonly referred to has the "Divine Nine," a collective of historically black fraternities and sororities organized under the National Pan-Hellenic Council (NPHC). I define black fraternalism as the social and cultural politics of BGLOs, particularly its dominant gender ideology, practice and structure informed by its relationship to state, capital and the academy.
} 
hegemonic power instead of challenging its establishment. Ferguson states, "This was the moment in which power would hone its own archival economy, producing formulas for the incorporation rather than the absolute repudiation of difference, all the while refining and perfecting its practices of exclusion and regulation" (p. 12).

As a result, the absorption of racial and sexual differences within the academy during the 1970s and 80s meant interpreting and administering these differences as single-issue, neutralized subjects. For instance, sexuality was formalized and legitimized within the academy, counter to its more radical movement origins, apart from gender and race and a critique of patriarchy and U.S. nationalism. Thus, Ferguson argues that a will to institutionality places the security and agency of minority difference in the structures of dominant institutions - making the regulatory forms offered by dominant institutions the sole avenue for achieving affirmation, recognition and legitimacy instead of "one item on a menu of interventions" (p. 226). In conclusion, Ferguson postulates, "By what counter-calculus can we maneuver difference for the purposes of rupture" (p. 226)?

Ferguson's articulation of a will to institutionality helps to situate Fred-Rick's experience and commentary on black queer fraternal $(\mathrm{BQF})$ formations ${ }^{4}$ into a broader genealogy of power and difference. E. Patrick Johnson (2008) suggests the formation of $\mathrm{BQF}$ societies were one of the strategies taken by black queer men on college campuses, especially HBCUs, to undermine these institutions' "thinly veiled conservativism" (p. 284) and intolerance of queer-sexuality and gender nonconformity — an intolerance that seem to consolidate in the 1970 s as race and sexuality were being institutionalized within

\footnotetext{
${ }^{4} \mathrm{I}$ use the term black queer fraternal (BQF) formations/culture/groups/organizations/etc to identify a particular set of fraternities/sororities that employ elements - ideas, symbols, performances, and/or structures - of BGLOs and black fraternalism through either real or symbolic relationships to create new distinctive queer bodies and spaces.
} 
the academy. Prior to the 1970s, specifically in the 1950s and 60s, Johnson found HBCUs relatively tolerant of queerness and/or homosexual behavior. For instance, some narrators in Johnson's oral historical study of southern black gay life describe their HBCU campuses during the 1950s and 60s as having a thriving queer social life, including public displays of queerness such as celebrating drag queens at football games. However, the narrators who attended HBCUs in the 1970s and 80s (like Fred-Rick) describe a more repressive sexual and gendered environment.

It is worth pointing out, here, that Johnson's (2008) insights about some HBCUs, during a particular time period, being relatively tolerant of non-normative gender and sexual formations stand in contrast to much of the social science literature that broadly characterize HBCUs as always ascribing to a black respectability ${ }^{5}$ that limited representations of blackness to cis-heteronormativity, including strict gender and sexual codes (Allen \& Jewell, 2002; Gasman, Nguyen, \& Kalam, 2013; Harper \& Gasman, 2008; Patton, 2014; Njoku, Butler, \& Beatty, 2017). Notwithstanding the consistency of these studies, Johnson's findings provide some nuance to HBCU historical perspectives and a basis to understand the effects of institutionality for post-civil rights era historically white and black universities. For instance, since the absorption of minority difference, black queer males find themselves negotiating between the social identities of race and sexual orientation in almost every aspect of college life, including college choice (Strayhorn, Blakewood, \& Devita, 2008; Squire \& Mobley, 2015) and campus

\footnotetext{
${ }^{5}$ Black respectability was coined by Evelyn Brooks Higginbotham (1993) in a study of black women activism in the black church between 1880-1920 in which black women promoted cleanliness, polite manners, self-restraint, sexual purity, and frugality as a strategy of racial uplift in the face of white supremacist controlling and distorted discourse of black gender and sexuality. Other scholars have since noted the pervasiveness of black respectability throughout African American culture and politics.
} 
engagement (Carter, 2013; Means \& Jaeger, 2013; Patton, 2011; Squire \& Mobley, 2015).

This identity negotiation is largely predicated on how these men perceive various environments based on institutional constructions. As such, many black gay and bisexual college students understand, and in many cases experience, black spaces (i.e., HBCUs, cultural centers at historically/predominately white schools, black fraternities, etc) as anti-queer and white spaces as more queer-affirming (though often anti-black). Therefore, black queer males often make choices and decisions about campus involvement based on what identity - either race, sexuality, and/or gender-is most salient and "appropriate" for the intended environment. For example, in studies exploring college choice, black gay and bisexual men who resonated more with their racial identity mainly choose HBCUs and those who had more saliency with sexual orientation overwhelmingly correlated historically/predominately white universities as a “safe place” (Strayhorn, Blakewood, \& Devita, 2008; Squire \& Mobley, 2015).

Therefore, the formation of BQF networks, as alluded to here by Fred-Rick, can be viewed as a result of this institutionality of minority difference, and thus, conversely a critique, or in the tradition of black queer vernacular", a "read"7 of institutional power predicated by state, capital and the academy. Furthermore, the term "reading" can be employed here to connote the relationship between institutionality and textuality in which "institutions are the outcome and locations of imagined communities, with interpretative

\footnotetext{
${ }^{6}$ Black queer vernacular refers to the cultural production and employment of language, or subverted slang, by queers of color often in the formation of counter-cultural spaces and socialites that disrupt hegemonic discursive power and act as a form of cultural resistance (See Johnson, 2003, 2008).

7 The term "read" in black queer vernacular means to critique, or to tell someone off, call them out, or tell the truth about someone or something (See Johnson, 2008, p. 555). For instance, Dorian Corey, from the iconic documentary Paris is Burning, states, "To read is to insult imaginatively, in opposition to the blunt gay-bashing taunts of the straight world."
} 
modes representing the brick and mortar of those imaginations" (Ferguson, 2012, p. 16).

Thus, Fred-Rick's "read" is leveed through his understanding of what the institutionalized "imagined community" 8 should be — gendered and sexually normativeand his ability to speak a truth which disorganizes or reinterprets this institutional text. Hence, I am situating black Greek-lettered organizations (BGLOs), and their black fraternalism, as part of this institutional text, and Fred-Rick and BQF formations, as a counter-calculus, a mode of difference that account for and disrupts a genealogy of (in)difference tethered to institutionality.

In this sense, Fred-Rick's "read" constitutes a form of queer failure. Not only is Fred-Rick "reading" the institutional text subversively, his femme queer identity makes him, and others like him, almost incapable of being hailed by the institutional black fraternal ideology. Jack Halberstam (2011) calls this logic of "success" within a heteronormative, capitalist society into question. For Halberstam, success within a hegemonic institutional framework reifies the broader logics in which institutional structures are defined - in this case, state, capital and the academy. Thus, the type of failure offered by BQF formations, if we accept, can illuminate regulating ideological structures, particularly the disciplinary boundaries of the post-civil rights era university. Therefore, politically, BQF formations constitute "low theory," or what Halberstam describes as "the in-between spaces that save us from being snared by the hooks of hegemony...but it also makes its peace with the possibility that alternatives dwell in the

\footnotetext{
${ }^{8}$ Here, “imagined community" is derived from Ferguson's (2012) interpretation of Jacques Derrida (2004) theorizing of the hermeneutical connection between material institutions and their ideological formations and functions.
} 
murky waters of a counterintuitive, often impossibly dark and negative realm of critique and refusal" (p. 2).

Moreover, Fred-Rick's "read" represents a more developed form-a critique that goes unnamed in a direct sense. Instead, the actual normative structure is exalted, not castigated: "those sororities were fabulous to us." However, it is in this exaltation, the adaption, and the unspoken, or subtle, scrutiny of institutionality that the effectiveness of this critique and rupture of normativity is rendered - what I have come to think about as shade. Here, BQF formations have a disidentificatory relationship with institutionality and BGLOs. José Muñoz (1999) contends that disidentification results from a failed interpellation within the dominant public sphere in which minoritarian subjects employ an identity-in-difference as a strategy of resistance and survival. These identities-indifference work on and against dominant structures. As Muñoz states, "Instead of buckling under the pressures of dominant ideology (identification, assimulation) or attempting to break free of its inescapable sphere (counteridentification, utopianism), this...is a strategy that tries to transform a cultural logic from within, always laboring to enact permanent structural change while at the same time valuing the importance of local or everyday struggles of resistance" (pp. 11-12).

Thus, performatively, BQF formations present a subversive repetition of what Judith Butler (1990/1999) calls a compulsory order of sex, gender and desire, or a (bio)logical determinism. Butler argues that distinction between sex and gender as well as the binary within these modes — male and female, masculine and feminine — are produced through apparatuses of production. Butler denotes that this "unity" of a cultural intelligible sex and gender necessitates desire, in that, desire is perpetuated as 
heterosexual in order to consolidate the binary gender system as "naturalistic" or "authentic." Butler doesn't insist that this repetition must halt. In fact, Butler maintains that this repetition is bound to persist through cultural mechanisms of identity production. Thus, for Butler, the critical question or disposition becomes, "What kind of subversive repetition might call into question the regulatory practice of identity itself' (p. 44)? Therefore, considering BGLOs as cultural apparatuses of a compulsory heterosexual logic, as Butler contends, this also make these very sites contested and "holds out the possibility of a disruption of their univocal posturing" (p. 44).

As a result, in this study, I examine the black Greek-letter system as a normalizing but contested cultural site that operates in conjunction with the institutional power of the academy. As such, I consider the critical possibilities presented in the political and performative disposition of $\mathrm{BQF}$ formations and how they "work on and against" the institutional boundaries and disciplinaries of institutional black Greek-letter fraternities and the academy. This study will, therefore, examine the following questions: How do black Greek-lettered fraternities function in conjunction with the institutional power produced by the state, capital and academy? How might BQF formations "work on and against" the institutional body to reconstitute its power for disruptive as well as reproductive means? What type of logics of race, gender, sexuality and institutionality does BQF formations constitute? Put differently, as Ferguson (2012) implies, "What happens if those [institutional] texts are used to imagine how minoritized subjects and knowledge might inhabit institutional spaces in ways dominant institutions never intended" (p. 230)? With a power regime predicated on a will to institutionality, I postulate $\mathrm{BQF}$ formations as a way to possibly dislocate dominant forms of 
institutionality—altering structures, pleasures and desires—and revealing critical universes.

\section{Significance and Purpose of Study}

Exploring the aforementioned questions in relation to black Greek-lettered fraternities is crucial because it's a first attempt at positioning the development of a black Greek-lettered system at the turn of the twentieth century and its rise to prominence within black social and political circles with the construction of the black normal. Employing black feminist theory and building on the work of queer of color scholars such as Jasbir Puar (2007), Chandra Reddy (2011), Roderick Ferguson (2012), and Hiram Pérez (2015), Erica Edwards (2015) theorizes about the black normal—“the constellation of narratives, images, and state discourses that tie black freedom to the nation-to-empirebuilding project through images and imaginaries of everyday black empowerment within state institutions, an empowerment secured through both sanitizing and pathologizing representations of black sex and sexuality" (p. 143). Therefore, this study is interested in how the black Greek-lettered system, particularly black fraternities, work as an interlocker between the state, state institutions, and state imperialism through their discourse of a regulatory black freedom, predicated on a black respectability and institutionality.

This study is also one of the first critical analyses of black fraternities centered on gender and sexuality. Prior to this study, there has been only one study on black Greeklettered fraternities that employed an analysis grounded in critical theory instead of historical and sociological accounts, that is, Ricky Jones' Black Haze (2004/2015). Black Haze sought to understand the political and social formation of contemporary black 
manhood and its relationship to violence by critically examining black fraternities and state socio-political power. Though Black Haze provided a critical intervention in the scholarship on black fraternities, hazing and identity, it failed to consider gender and sexuality as analytical structures. Therefore, in some ways, this study is both an extension as well as a critique of Jones' earlier work on black fraternities — on one hand, continuing a critical exploration of black manhood and state power, on the other, this analysis centers gender and sexuality and employs critical queer of color theory. In this study's engagement of the black normal and its focus on black gender and sexuality studies, it establishes an attempt to construct a conceptual bridge between two contemporary burgeoning lines of scholarly inquiry_-black Greek-lettered scholarship and black queer studies - that are interconnected through interests in black normativity and nonnormativity but rarely intertwined in meaningful scholarly dialogue.

Furthermore, I am interested in what type of conceptual logic of race, class, gender, sexuality and institutionality is performed through the materiality of BQF formations. Kimberle Crenshaw's $(1989,1991)$ conceptual theory of intersectionality provided a tool for meaning-making to account for how the categories of race and gender are simultaneously considered in legal and judiciary institutions within the U.S., challenging what she calls monocausal paradigms that essentialize blackness as maleness and womanness as whiteness. Crenshaw's conceptual model has since been employed to examine the co-construction of race, class, gender and sexuality and their matrix of domination (Collins, 1990/2000) in a variety of settings and institutions, particularly higher education, illustrating how institutional formations reaffirm differences and social inequality. 
However, Reddy (2011) demonstrates the importance of considering other conceptual models, stating, "I believe we can retrieve different histories and accounts of power" (Reddy, 2011, p. 15) than those articulated solely through an intersectional model. As Charles Mills (1997) defines, concepts are devices that "help us to categorize, learn, remember, infer, explain, problem-solve, generalize, analogize" (pp. 6-7); thus, to consider an optic model based specifically on the configurations of black queer formations within the academy and the black fraternal system would "suggest the importance of historical, political, and epistemological structures that organize how these formations are linked or intersected, and what kinds of logics fasten their coincidence" (Reddy, 2011, p. 16). For instance, what type of conceptual framework might help us to understand institutional power not as a one-dimensional, centralizing force embodied by a particular individual or group, but instead, in the way Ferguson (2012) borrows from Foucault (1978) to describe power as an impersonal "complex and multisited social formation" (p. 7)? How can we best understand the plurality of power relations between the black fraternal subject and the black queer fraternal subject within an institutional context where minority difference is being absorbed in distinct and regulated forms? Thus, as Eve Sedgwick (1990) writes, I'm concerned with how these "certain categorizations work, what enactments they are performing and what relations they are creating" (p. 27).

\section{Methodology}

This study constitutes a queer of color critique. In his groundbreaking text, Aberrations in Black, Ferguson (2004) advocates for a queer of color analysis of liberal capitalist economic and social formations to "help us perceive how the racialized gender 
and sexual diversity pertaining to African American cultural formations is part of the secular trends of capitalist modes of production" (p. 2). Employing the work of Reddy (1997), Ferguson contends that liberal capitalism produces a racist practice that is gendered and sexually regulatory in which gender and sexual differences define racial formations (also see Somerville, 2000). Therefore, a queer of color critique centers the queer of color subject, and in doing so, reveals the often-obscured interconnected logics of race, gender, sexuality and class in cultural formations to map the contours of power propagated by state and capital forces. Thus, as an epistemological intervention, Ferguson states, a "queer of color critique approaches culture as one site that compels identifications with and antagonisms to the normative ideals promoted by state and capital" (p. 3) - making culture a site of material struggle.

Employing Ferguson's framework, institutional black fraternities are positioned as a conceptual "home." Within the hegemonic culture and structures of the university, many higher education scholars have identified BGLOs as institutional counter-spaces for African American students - spaces considered ideal for academic and social survival for black students, particularly at historically and/or predominately white institutions (GrierReed, 2010; Pelzer, 2016; Solorzano, Ceja, \& Yosso, 2000). However, like the "home" concept theorized by Ferguson and Reddy, from literal black homes to black nationalist homes, these black fraternities reject and regulate queers of color. Thus, indicating a social formation composed by the racist logics of liberal capitalism (Ferguson, 2004). Furthermore, black Greek-lettered fraternities provide a social and cultural window into the institutionalization of minority difference within higher education. Whereas Ferguson gives an account for the absorption of minority difference through the 
formation of interdisciplinary studies, such as ethnic and women's studies, similarly, BGLOs, with their absorption into the U.S. colligate fraternal system, offers an account of how institutionality effected black student social and cultural life on campus. Therefore, this project takes up the critical task of examining the U.S. colligate fraternal system, particularly black fraternities, as a cultural and social "home" by "first...attending to the ways in which it was defined over and against people of color, and second, by expanding the locations and moments of that critique of the home to interrogate processes of group formation and self-formation from the experience of being expelled from their own dwellings and families for not conforming to the dictation of and demand for uniform gendered and sexual types" (Reddy, 1997, pp. 356-357).

Operationally, this study employs what Halberstam (1998) calls a queer methodology—or, considering Johnson's (2005) take on queer, a "quare” methodology. Halberstam describes a queer methodology as a "scavenger" method where the failure to adhere to a particular disciplinary coherence brings together eclectic methods to produce knowledge on subjects who have been historically excluded from traditional scholarship. In this sense, Johnson defines "quare" methodology as a specific "scavenger" method that combines the methodological traditions of black feminism and queer studies to emphasize "the diversity within and among gays, lesbians, and transgendered people of color while simultaneously accounting for how racism and classism affect how we experience and theorize the world" (p. 127). Thus, a "quare" methodology employs discursive analysis from queer theory while also accounting for how race, class, gender, and sexual orientation intersect to inform one's social location in ways that are material and performative. Johnson, further, contends that as a queer of color, being of and apart 
from social and cultural homes, a quare praxis must critique oppression from and within the homeplace itself. As such, this study examines higher education institutionality from the place of institutionalized BGLOs while also interrogating the formation of these very structures.

In essence, this is a project of queer time and queer space. By focusing on $\mathrm{BQF}$ counterpublics, an alternative culture that works alongside the university, embedded in but adjacent to the recognizable, new understandings of time, progress, and legitimacy can be resurrected in relation to the knowledge/power regimes of state and capital. For instance, at the onset of this research I frequently referred to BGLOs as "traditional" in relation to $\mathrm{BQF}$ organizations. However, what makes them "traditional," and thus the norm, is tied to their institutional status and adherence to disciplinary knowledges of racialized gendered sexuality—providing them capacity for longevity and legitimacy. Therefore, I come to refer to BGLOs as institutional formations. And, thus, I employ the "queer" in BQF formations to note "nonnormative logics and organizations of community, sexual identity, embodiment, and activity in space and time" (Halberstam, 2005, p. 6). This project then constitutes a counter-historical effort aimed at unsettling the dominant narrative of BGLOs as gendered political entities to reveal institutional power's intent and alternative gendered political formations.

As a result, this study primarily relies on analytic approaches, specifically content analysis or what Stephen Maddison (2000) terms cultural materialism. As such, I make use of close readings of critical theory, popular culture/media and significant literature on BGLOs to analyze, interpret, and speculate the emergence and circulation of narratives on black queer subjectivity and their implications for the formation of black masculinity, 
manhood and institutional will. Furthermore, to fill the information gap pertaining to BQF formations, I conducted qualitative interviews. Unlike institutional black fraternities, there's a dearth of literature on BQF formations chronicling their origins and functions. The reference to these formations in Johnson's Sweet Tea (2008) is one of the rare articulations of these organizations within any type of historical, social or political framework of black queer life, and even within Johnson's work, there isn't an inordinate amount of details or follow up on Fred-Rick's claims. Therefore, I interviewed members of $\mathrm{BQF}$ organizations to get a better understanding of their origin and development.

However, as a queer of color critique of institutionality and black fraternalism, I am not concerned with developing a precise historical account of BQF culture. Rather, I employ interviews from BQF members alongside scholarly and media texts for a cultural materialist approach, as in, though there is a truth and a history in the narratives presented, the narratives are also instances of cultural reproduction or what Ferguson (2004) considers a material struggle — thus, often incomplete, incoherent, and/or contradictory. Given this, through close readings, I attempt to assess the power conditions through which this discourse and knowledge is produced (Maddison, 2000). Riffing off Maddison (2000), "I am not after a big, totalizing history [of BQF culture], but a more detailed, intimate account of relations and structures" (p. 13) between BQF formations, black fraternalism, and institutionality.

To do this, I relied on purposeful sampling for information-rich key informants or critical cases. Patton (2015) states that for in-depth understanding rather than empirical generalizations, information-rich cases are most insightful. In a true queer approach, these interviews were a cross between inquiry methods, ranging from phenomenological 
to historical, and at times investigative. This eclectic approach is warranted given the "down low" existence these organizations have undergone for much of their lifespan. These BQF life-worlds, then, constitute what Foucault calls "subjugated knowledges"the everyday ways of knowing framed by a subordinate positionality that is often unintelligible to those outside their life-world (Halberstam, 2011; Hesse-Biber, 2014; McCune, 2014). Since discrete populations are hard to locate and privacy is paramount, I relied on my own existing networks as a gay member of an institutional black fraternity to identify individuals who met the criteria for the field study. Miner and Jayaratne (2014) state that even though nonprobability samples are not representative of the population of target subjects, convenience sampling, particularly snowball sampling as described here, can be effective techniques in studying sexual minorities given the difficulty of identifying these individuals in the larger population.

Through the snowball method, I reached out to five individuals and ended up interviewing four of them. One individual never responded to my request. I made my request through Facebook messenger based on personal contacts or suggestions from informants. The four study participants each represented a different BQF organization, with what may be considered origins in connection to, patterned after, and/or inspiration taken from three various black sororities. Two of the study participants were founders of their respective organizations and the other two participants were current or former national executive officers of their respective organizations. In the context of this study, I position the interviews as a critical collective case study. Case studies are a qualitative approach used for exploring a particular phenomenon in-depth or holistically within its social, historical, and political context; thus, case studies are usually considered a limited 
method in terms of generalizability given its aim at depth not breath —often resulting in use of one or few subjects (Fyvbjerg, 2006; Stake, 2005). However, Fyvbjerg (2006) contends a case study approach can be ideal and generalizable when employed for falsification, or illustrating a counter-point to invalidate totalizing claims or theories, in which circumstance, conceptually, only a single example is needed. Within this study, the BQF case study provides what Fyvbjerg calls the "black swan" case of institutionality and black fraternal subjectivity, a counter -history, -performance and -politics of conventional institutional arrangements and logics. Therefore, I am relying on only a handful of informants for this study to craft a critical collective case study, or a few cases studied jointly, of BQF formations drawing on their activities/functions, histories, environments, socio-political contexts, subject-object relationships, and populations (Stake, 2005). Furthermore, this critical collective case study is triangulated with the study's discursive analysis to consolidate the study's overall validity.

In order to "travel" into these spaces of subjugated knowledges, I had to build trusting relationships with the participants. Therefore, my intent was not to exploit or employ an imperial disposition to these participants and organizations. Instead, I sought to humanize and validate their experiences within these institutional and normative structures. In this case, I drew from Dwight Conquergood's (1991) notion of coperformative witnessing in which ethnographic research is conceived as "an embodied practice" (p.180) and "intensely sensuous way of knowing” (p. 180). Conquergood posits that the researcher is the instrument but also an invited guest. A co-performative disposition challenged me to position myself alongside the targeted population and work towards relationships that establish open lines of communication (Conquergood, 1991). 
As a result, this methodology is similar to how Johnson (2008) associates the researcher's role to an invited southern dinner guest, thus, as part of southern hospitality, the guest assists in the preparation of the meal "by shelling peas, chopping onions, or setting the table" (p. 9). This approach, therefore, called for a deep self-reflexivity, and where appropriate, I deployed my own experiences of being a black gay male in an institutional black fraternity to provide context, affirmation and/or nuance to not only the interviewees' stories but the overall study's content and critical approach.

As such, I had to be aware of my own positionality, specifically my gender performance, academic background and fraternity affiliation. As a researcher and someone whose gender performance can be described as fairly butch on most occasions, these characteristics could have easily positioned me as a suspicious outsider to participants who embody a more gender-queer disposition. Furthermore, being a member of an institutional black fraternity could have presented possible barriers to trusting relationships given the participants affiliation with BQF organizations. However, what I did not take into full consideration was the duality of the participants' lives - their alternation between the public and counterpublic and how that inform a complex orientation of pleasures, desires, identities and performances. Put simply, they were more than just members of BQF organizations. We shared many commonalities, including membership in the same fraternity as one participant and (working on) a terminal degree as with another, for instance, that not only helped to facilitate trust and disclosure, but also welcomed entry.

To collect the interview data, I utilized an interview guide for one semistructured, in-depth one-on-one interview with each participant. All the interviews 
except one was conducted through video conferencing - the other interview was done by phone. With semi-structured in-depth interviews, I provided a few broad questions to guide the structure and content of the interview; however, considering a co-performative method, this approach provided space for the participant to deviate and be an active subject in the process. Furthermore, as stated previously, it was important for me to share my own background and challenging experiences as a gay member of an institutional black fraternity with the participants. Though there are concerns about researchers oversharing, in this case, this part of my background reveals my research intent and my sensitivity to the nature of this study, and therefore, helped to build trust with the participants. Conversely, Hesse-Biber (2014) contends that when the researcher shares appropriately about their background it helps to reduce notions of power and authority in the researcher and increase reciprocity and rapport with the study participants.

The in-depth interviews were audio recorded and transcribed. The interviews ranged between two to three hours in length. The duration of the field work was approximately six months, starting in August 2018 and ending in January 2019. By December 2018 I had completed the interviews; however, I was invited to a BQF organization's Founder's Day celebration in Atlanta, GA in January which I attended to gather further observations. Prior to the interviews, I got informed consent from all participants by emailing the consent form to each participant to sign and return. All participants were informed that their participation in this study was completely voluntary and they had the right to withdraw their consent or discontinue participation at any time. No incentives were offered for participating in the study. 
The main ethical concern in this field work was privacy. Thus, I assured confidentiality by not using participants' real names in transcriptions, case studies or publications. For the overall dissertation project, the data collected from the interviews support the broader critical analysis of black fraternal life and institutionality. Therefore, I primarily employ the interview data to highlight $\mathrm{BQF}$ formations as a collective experience which provides anonymity for individual participants. Were more individualized references are needed, I removed selected identifying characteristics, such as interviewees' specific location, university name (if applicable), and specific organization names. Furthermore, all electronic and paper files that contain the participants' confidential data is stored on my private, password protected computer and in a locked file cabinet at my home. I received university IRB approval for this study on June 6, 2018 and closed out the study on May 9, 2019.

\section{Chapter Overviews}

Chapter two focuses on the establishment of institutional black Greek-lettered fraternities. Much of the black Greek scholarship extensively, and rightfully so, situates the establishment of BGLOs within the larger context of struggle for racial equality and uplift taking place at the turn of the twentieth century (and throughout the twentieth century). However, most of these accounts fail or inadequately consider the implications of gender and sexuality in the conceptualization of BGLOs as a project of racial uplift. Therefore, in this chapter, I raise questions as to why black Greek scholars have omitted or reduced this analytical terrain and what are the implications for black Greek scholarship. I thus re-consider the history of BGLOs and locate the founding of black fraternities not only within the struggle for civil rights but also the emerging archival 
power of the state and the masculine homosocial logics of American fraternalism. As a result, I consider the social, cultural, and political effects of black fraternities as an archival entity for institutional belonging - forming or informing rules for inclusion, recognition and legitimacy of an ideal black manhood within the academy, state and capital.

With a decline in interest in black fraternalism and a proliferation of BGLO chapters at southern historically white institutions, chapter three turns to the mid- and late-twentieth century to explore this "black Greek paradox" in what Ferguson (2012) entails as the post-World War II "shifts and contradictions of political economy" (p. 12) in the American academy. Ferguson states, "The academy would begin to put, keep in reserve, and save minoritized subjects and knowledges in an archival fashion, that is, by devising ways to make those subjects and knowledges respect power and it's 'laws"' (p. 12). Ferguson outlines in detail what this means academically for post-secondary institutions with the emergence and institutionalization of ethnic and women's studies. However, the same archival power of the academy ordered minority difference within student life or student affairs, producing ethnic and women's cultural centers/unions and minority student development theories. Therefore, I outline what this absorption of minority difference entails for how black student subjectivity is institutionalized within the academy, considering both historically white and black institutions. Furthermore, with black Greek-lettered fraternities as homosocial archival entities of institutional belonging, set at the dawn of the twentieth century, I explore how these organizations affirmed and facilitated the institutional logics of race, gender and sexuality during this era. 
Chapter four explores how a new black student subjectivity, idealized by black fraternalism, shapes the campus environment in the post-civil rights era of institutionalized minority difference. As critical universes are foreclosed and black gender and sexual possibilities are limited, a black fraternal will to institutionality results in a resurgence of black fraternal life and a homosocial laboring that reinforce the logics of minority difference and a cis-heteropatriarchal ideal black student subjectivity. With the emergence of BQF formations, I consider their development and implications for a countercultural, heterosocial femme resistance to black fraternalism and institutionality.

Chapter five moves to the turn of the twenty-first century-like the turn of the twentieth century, a time of great social and political change — to map BQF culture's negotiation and navigation of the interpolative effects of a will to institutionality and freedom. I consider how black gender politics have changed and remained the same with the institutionalization of minority difference and how the media acts as a mediator of institutional effects propagated by the state, capital and the academy. As such, I take up the spectacle of the MIAKA figure, which emerges in the shadows of the down low phenomenon, to ask not, who is this figure, but what does this figure do in relation to black fraternalism, BQF formations, and institutionality.

Whereas in chapter two I consider what this project means for the field of black Greek studies, I attempt in the conclusion (chapter six) to situate this study in contemporary black queer studies. Thus, to make meaning of the genealogy of race, gender, and sexuality forged through and against institutional black fraternalism-I propose shade as a conceptual framework for reading institutionality and black normality 
and formulating a black deviant politics of resistance. I therefore employ shade to summarize, discuss limits, and frame implications of this study. 


\section{CHAPTER 2: BECOMING MEN: BLACK GREEK FRATERNAL TEXTUALITY}

\section{AND ARCHIVE}

In the 1911 Indiana University (IU) yearbook, Arbutus, a white male student named Oliver Ray Melton included in his senior profile a reference to one the first black fraternities established on the campus of Indiana University and in the U.S., Kappa Alpha $\mathrm{Nu}$. In what might be perceived as a humorous slight by his white co-eds towards the African American fraternity, the yearbook insinuates he once dawned a Kappa Alpha $\mathrm{Nu}$ haircut in order to receive entry into a women's only sorority social on campus, stating: "[he] bought a Kappa Alpha Nig haircut one day under the delusion it would secure him an invitation to the Panthygatrie." There are two significant overtones in Melton's profile that characterize the academy and the broader U.S. sociopolitical climate's disposition towards African American men at the turn of the twentieth century. The yearbook profile refers to the fraternity as "Kappa Alpha Nig," as in Kappa Alpha "Nigger" instead of Nu, and he implies that by looking like a member of the fraternity, specifically by mimicking their hair, he would be able to pass as a woman, thus correlating the black fraternity men to women.

On February 4, 2018, the national historian of Kappa Alpha Psi, the successor to Kappa Alpha Nu, Kevin Scott, published a post through the fraternity's official Facebook page highlighting the aforementioned incident, specifically the use of the racial slur "nigger," as an example of "the pervasively racist environment our [fraternity] Founders 
found themselves in while they were establishing our fraternity." However, what was not noted or given attention to in Scott's post, both by him and the presumed fraternity members who commented on the post, was the gendered implications in the reference. In the post, Scott states, "The [yearbook] entry for Oliver Ray Melton showed his lack of character and his poor attempt at humor, by the use of a racial slur," in which Scott goes on to indicate that the fraternity changed its name to Kappa Alpha Psi in 1915 due to white students at IU referring to the fraternity as "Kappa Alpha Nig."

Scott's assessment of the racist campus environment the early members of Kappa Alpha $\mathrm{Nu}$ found themselves in was indicative of the experiences of many of the first black college students attending historically white colleges and universities at the turn of the twentieth century. For instance, on average only one black student graduated every three years from a college or university in the entire state of Indiana from 1861 to 1900 (as cited in Washington \& Nuñez, 2012). Furthermore, by the end of the nineteenth century with the arrival of more racial and gender minorities on college and university campuses previously reserved only for white protestant men, white college men increasingly defined themselves, and subsequently, college student life in opposition to their new classmates, dehumanizing and excluding them from student organizations such as fraternities (Syrett, 2009).

Furthermore, public and scientific discourse of the nineteenth century produced a field of racial science propagated on gendered and sexed differences between the races. Some of these same scientists would later become concerned with sexual perversion and by the beginning of twentieth century link "the question of sex[uality]—with the racial question that rests on it" as indicated in the 1897 publication of Sexual Inversion. As 
such, the sociopolitical ordering of sex, gender, and subsequently, sexuality, served as a basis for scientists in constructing racial stratification once white supremacy could no longer be grounded in theopolitical justifications (Snorton, 2017; Somerville, 2000; Stein, 2015). Therefore, the men of Kappa Alpha Nu being gendered as women is as significant as being called "niggers" - essentially, the two slights are interrelated. The slurs, in fact, give insight into how intersecting nationalist discourses of gender, sex and race shaped the development of black fraternity life. The scientific theories that would have informed Melton's Kappa Alpha Nu inference were in wide circulation through lectures and print media in the late nineteenth and early twentieth centuries, giving credence to which bodies were or were not right for the citizenry (Stein, 2015).

The Facebook post by Kappa Alpha Psi's national historian, then, highlights a trend within what is now deemed black Greek scholarship — an interdisciplinary area of study that emerged at the turn of the twenty-first century focused on the development and experiences of black Greek-lettered organizations (BGLOs). Broadly, some black Greek scholars have posited that the area of study is intended to address the dearth of accessible scholarly research on black fraternities and sororities, particularly given the significant role these organizations and its members have played in twentieth century black politics (Parks, 2008). However, arguably much of the research has been propelled by what Ricky L. Jones (2015) calls the "sex, dysfunctionality, and death" (p. ix) exhibited within black Greek culture.

Assuming both rationales are justified, it is striking that much of the black Greek scholarship doesn't consider or question the gender and sexual normativity perpetuated in and by BGLOs and how this normativity might have been naturalized through the very 
establishment of these organizations. Thus, considering the social media spectacle of the IU yearbook entry, to acknowledge and analysis the gender and sexual implications embedded in this type of racialization, would mean to some extend recognizing the gender and sexual formations in black fraternities as contrived, and not natural at all. It is to reveal that within a history and genealogy that constituted the transition of Kappa Alpha Nu to Kappa Alpha Psi also facilitated a gender confirmation of black men under the normalizing eye of the university. In other words, if in reaction of being called "Kappa Alpha Nig" the fraternity changed its name, how might have the fraternity responded to being referred to as women? This chapter will explore this question and its implications in the broader context of black fraternalism and its establishment within twentieth century American racial and gender politics.

\section{BGLO Research and the University Archive}

Matthew Hughey and Gregory Parks (2011) frame black Greek scholarship by two, often competing, intellectual paradigms. Hughey and Park describe one paradigm as "professional formalists." This paradigm is marked by its bureaucratic tendencies. It consists of knowledge and policy pertaining to BGLOs created within the BGLO institutional boundaries - thus, this type of intellectual process is typically resistant to critical academic inquiry and don't consider its own institutional positionality, constraints or biases. On the other hand, Hughey and Parks recommends a more "public realist" approach that transgress the formal or regulatory boundaries of the organizations to provide a critical, empirical and grounded intellectual process that is relevant and applicable to present-day issues in BGLOs. Hughey and Parks state:

BGLO 'public realists' are interested in (1) how a variety of disciplines may help 
them advance the interests of their organizations and those whom they advocate, (2) analyzing policy goals behind the rules within the organizations to determine if the rules help actualize those goals, (3) critiquing not only the professional formalistic approach but also BGLOs themselves in an effort to strengthen these organizations. (p. 12)

Employing Hughey and Parks framework, Kevin Scott, national historian of Kappa Alpha Psi, and his analysis of the racial hostility that contributed to the founding of the organization would likely be categorized as a professional formalistic approach where the institutional hegemonic ideologies of gender and sexuality are not critically considered. This would likely come to no surprise given Hughey and Parks framework. However, even black Greek scholarship that take a public realist approach have undertheorized connections between the gender and sexual politics of BGLOs and its early and contemporary concerns, such as elitism, de-politicization and hazing.

To further clarify what I mean by undertheorizing gender and sexuality, this does not mean black Greek scholars have not acknowledged nor accounted for the heteronormativity and homophobia present in many institutional black fraternities. More precisely, there have been a lack of critical systematic analysis of gender and sexuality in understanding how relations of power are formed within and through BGLOs. As Patricia Hill Collins (2005) writes, "Sexuality is not simply a biological function; rather, it is a system of ideas and social practices that is deeply implicated in shaping American social inequalities" (p. 6). Collins explains sexual discourse act as a pillar in propagating a regulating black gender ideology which shape hegemonic ideas about black masculinity and femininity that "justify patterns of opportunity and discrimination that African 
American women and men encounter in schools, jobs, government agencies, and other American social institutions" (p. 6).

BGLOs are master structural purveyors of a black gender ideology—reinforcing culturally intelligible gendered sexualities as a racialized norm. Specifically, given their prestige, respect and influence in black communities, the influence of black fraternities' ideal masculinity is not limited to its members. Since black fraternal identity is in part constructed against those who are excluded, black fraternalism affect the lives of those who are not members. Simply take how often non-BGLO members are compelled to address questions like: "why didn't you join a fraternity?" or "what fraternity would you have joined?". Consequently, if black fraternities, and considering their broader impact, black communities at large, are to adopt a more progressive black sexual politics, black Greek scholars must holistically give attention to and challenge naturalized gender and sexual formations in BGLOs. Adapted from Cathy J. Cohen (1999), indicating that black fraternities are homophobic isn't a definitive justification for their ill reaction to a more progressive gender politics; instead, an analysis of their reaction must be situated in an historical understanding of sexual deviance and the production of racialized gendered sexualities in the U.S. In other words, an analysis of sexuality is inextricably linked to the (re)production of gender as we know it.

In The Reorder of Things, Roderick Ferguson (2012) challenges theoretical frameworks of power that are one-dimensional/directional and rely on economic narratives to describe the workings of the academy. Drawing on Jacques Derrida's (1996) theorization from Kant's The Conflict of the Faculties, Ferguson writes:

The presumed autonomy of the university reaches its limit once the university has 
to interact with the public sphere. As Derrida states, 'When, however, the issue is one of creating public titles of competence, or of legitimating knowledge, or producing the public effects of this ideal autonomy then, at that point, the university is no longer authorized by itself. It is authorized...by a nonuniversity instance or agency—-here, by the State — and according to criteria no longer necessarily and in final analysis those of scientific competence, but those of a certain performativity.' Hence, for Derrida the university must perform a certain degree of responsibility to students (i.e., 'the young') and to the interests of the state. (p. 9)

Here, the university is conceptualized as a subordinate apparatus of the state and its students. This conception of the university is similar to how Hughey and Parks (2011) frame the academy in their conception of the public realist black Greek scholar. Hughey and Parks characterize the university as a "customer service" agency in which potential public realist scholars would have to contend to produce meaningful and relevant black Greek scholarship.

However, Ferguson (2012) re-reads Kant to illustrate how "Derrida fails to unpack the full implications of the university's (and Kant's) performance of deference" (p. 9). Ferguson suggests that Kant's theorization of the "lower faculties"-Philosophy and its derivatives - as pure purveyors of truth, unobligated to the state and public as the higher faculties (i.e., medicine, law and theology), is contradictory and misleading. Though Kant ([1798] 1979) downplays their role, he does express the lower faculties imperative to apply critical reason to all academic areas, thus, "to control" (p. 45) the higher faculties through interpretative and evaluative processes. Therefore, Ferguson 
concludes, "Contrary to the presumption that the academy is a mere reflection and derivation of state and civil society, Kant suggests here that the academy — as the laboratory that produces truth and political economy's relation to it — is a primary articulator of state and civil society" (p. 11). Put differently, the lower faculties provide the epistemological grounding for state and civil logics by way of the higher faculties who produce public agents.

Ferguson, therefore, conceptualizes the power of the American academy as one that works as an interlocker between state and capital in which minoritized subjects and radical movements are archived, regulated, and appropriated by the state and political economy's epistemological networks. Drawing again on Derrida, Ferguson (2012) states, "As archives provided homes for those documents, they placed them under certain jurisdictions, not only consigning them to prescribed areas but also gathering them under certain sets of meanings" (p. 19). Ferguson, thus, describes an archive as a reservoir of meaning making, where "in the archive a diverse assemblage of documents were coordinated so that they might articulate an ideal unity...whatever secrets they might contain would have to be managed so that the ideal of the archive would be preserved rather than ruined" (p. 19). In this sense, the U.S. university acts as an archival agent for insurgent modes of difference-ones that rearrange and recuperate existing institutional texts - providing state and capital with methods of representation and regulation (Ferguson, 2012).

Ferguson marks the emergence of this reconfiguration of power from rejection to accommodation with the formation of interdisciplinary studies through the radical antiracist and feminist movements of the 1960s and 70s. These movements established 
ethnic and gender studies and pressured the academy and the disciplines to contend with race, gender, sexuality, class and U.S. nationalism against their construction of the ideal Western man — producing the groundwork for a field of study like black Greek scholarship. However, in archival fashion, these movements were compelled to reference institutional text, or the interpretative modes of the institution, for recognition and legitimacy where "the relationship between institutionality and textuality accounted for a constitutive contradiction within the student movements- their simultaneous estrangement from and appeals to institutional power" (Ferguson, 2012, p. 16). As such, institutional engagement and acceptance has often meant repetition of traditional disciplinary logics that reduce the study of minority difference to single-issue politicswhere race, gender and sexuality are often thought of as parallel intellectual structures of inquiry instead of intersecting - foreclosing on critical universes and making minoritized difference vulnerable to state and capitalist functions (Ferguson, 2012).

Here, I am suggesting that these academic institutional limitations are characteristic of the black Greek scholarship often produced by public realists. As public realists, scholars situated and susceptible to university logics, their black Greek scholarship is at risk of employing one-dimensional analytical frames-resulting in collusion with professional formalists predicated on obscuring or minimizing gender and sexuality as a frame of analysis in black Greek research. Employing Ferguson's theoretical framework also suggests that black fraternities, established on college campuses at the turn of the twentieth century and the functional home of professional formalists, are also informed materially and ideologically by the archival principals of the university. 


\section{The Nation, the Academy and Fraternity}

Though Ferguson (2012) places the apex of power's new archival mode in post1950s when "revolution and liberation struggles throughout the world would test power's archival flexibility" (p. 21), he does recognize that the formulation of these new archival tendencies started to take shape in the nineteenth century, as the U.S. began to advance its nationalist and imperial footing. The motto, "e pluribus unum" (one out of many), represented the epistemic logic that resides as the basis of U.S. archival powers. This logic made unity imperative to an always already heterogeneous society. Ferguson states, "In the context of the nineteenth-century United States, the motto captures the fact that the American ethos was not simply defined in terms of the abolition and expulsion of difference through slavery, genocidal wars, lynching, and rape" (p. 20). Instead, the nation-state constituted a national struggle with difference, particularly racial difference, in which the question of how difference should be positioned in relation to the ideal or universal citizen sustained the American spirit (Ferguson, 2012). Ferguson identifies nineteenth century literature as a site of national cultural struggle with the aim of reconciling national difference, writing, "American literature was supposed to finish writing the American nation-state by helping it resolve the paradox of the many and the one" (p. 20). Ferguson goes on to make two inferences from this acknowledgementone, that literature supported the American nation-state as an archive that made "the many" into "one" and underscored its textual dimension. Consequently, this development produced an American culture that would shape "American social institutions into archival economies" (Ferguson, 2012, p. 20). 
Ferguson (2012) illustrates the nineteenth century U.S. archival logic by in part focusing on the constitutional effects. As the Fourteenth Amendment officially granted formerly enslaved Africans citizenship, the new abject subjects were enrolled under constitutional conditions. This meant national power was reified and extended by "tying the debate over slavery to the debates over new territories" (Ferguson, 2012, p. 24). Hence, in the name of freedom, a management of difference was produced alongside a management of the international. Throughout the twentieth and twenty-first century, the Fourteenth Amendment would serve as citational reference for "subjects differentiated by race, gender, sexuality, disability, class, and ethnicity to contest their minoritized status" (Ferguson, 2012, p. 25) while conditioning them "with a domiciliation that could enlist them in power's archive" (Ferguson, 2012, p. 25). Chandan Reddy (2011) would aptly title this constitutional logic "freedom with violence," one in which these amendments not only absorb and regulate marginalized subjects, but authorize a sanctioned state violence through U.S. globalism and militarism.

Furthermore, with the passage of the Morrill Acts I (1862) and II (1890), Ferguson (2012) contends that the university archival power began disciplining subjects through the category of "excellence." With the initial development of land-grant institutions came schools of agriculture, home economics, engineering and business, with the intent "to uplift poor and working-class whites for the good of an industrializing agricultural economy" (Ferguson, 2012, p. 84). The second Morrill Act, predicated on the state's segregation logic, established land-grant institutions for African Americans in the South. As a result, Ferguson states, "the Morrill Acts sought to professionalize white and minoritized subjects so that they conformed to the ideal of professional, scientific, 
and humanistic service to the nation and so that they embodied national principles of uplift and respectability" (p. 86). Serving the interests of the state and capital, academic excellence becomes a condition of incorporation, where marginalized subjects are surveilled, excluded, and measured as a condition of institutionalization.

In conceptualizing the nineteenth century formation of state archival power, Ferguson (2012) leaves open a considerable gap in terms of unpacking the full implications of the university's performance of archival power. Ferguson outlines American literature and the establishment of professionalizing schools as entrenching instruments of an U.S. archival system - one in which difference is absorbed and disciplined for the consolidation of state and imperial power. However, Ferguson disregards a critical part of the academy's functionality. That is, the university's cocurricular component. If "institutions are also modes of interpretation that are embodied materially, discursively, and subjectively, modes offering visions of community and communal engagement" (Ferguson, 2012, p. 15), then it should be expected that the academy's first archival installation might be within itself —with a student or campus cultural life representative of its interpretative modes.

This co-curricular development is important given the sophisticated twentieth century archival function of the university where "the ethnic and women's movements moved to the heart of this relationship between institutionality and textuality" (Ferguson, 2012, p. 16) by first challenging the student spaces, and in return, producing alongside new academic departments, new cultural centers and admission policies. Hence, it is vital we understand the university's co-curricular formations and how they constitute American social institutions predicated on archival economies. Given the nineteenth 
century emergent archival logics presented by Ferguson, the American fraternity fills the gap in further conceptualizing the university's archival function, including connecting the curricular modes of interpretation with embodied forms that support the U.S. nationalist archive agenda.

Fraternalism has come to signify the U.S. racialized nationalist masculine project and its archival tendencies (Brod, 1995; Connell, 2005; Mechling, 2008; Nagel, 1998). As feminist sociologist Joane Nagel (1998) and others have argued, the development of modern nation-states like the U.S. are intertwined with the production of normative and semiotic masculinity. Through colonial, imperial, and military enterprises, modern masculinity has become a "centerpiece" in modern Western nationalist movements. Respectively, masculine institutions and organizations are established, such as police and military forces and fraternal organizations, that support "the 'micoculture' of masculinity in everyday life [that] articulates very well with the demands of nationalism" (Nagel, 1998, p. 252).

Aligned with the state, these masculine institutions and organizations are framed by a white cis-heterosexual male homosociality. Teresa de Lauretis (1988), in her essay Sexual Indifference and Lesbian Representation, defines "hommo-sexuality"9 as a phallic regime that produces intelligible gendered sexuality where "sexual difference between man and woman...is predicated on the contrary, on a complete indifference for the 'other' sex, woman's” (p. 156). In this framework, the homosexual woman is made legible by being ascribed masculine desire, the gender invert, turning what is considered sexual difference into indifference. Employing this theoretical context, Stephen

\footnotetext{
${ }^{9}$ Drawing on the work of Luce Irigaray, de Lauretis derives "hommo-sexuality" from the combination of the French word for man (homme), and its Latin origin (homo), and the Greek word for same (homo).
} 
Maddison (2000) describes homosocial male relationships, or homosociality, as "a function of what de Lauretis calls sexual indifference and they serve to uphold the integrity of hommo-sexuality, the identification with masculinity as sameness, unity, subjectivity" (p. 71). Therefore, male homosociality works to support the archival function of the American nation-state through a masculine archive of its own. For instance, as Margot Canaday (2009) chronicles, the development of America's bureaucratic and military state during the first half of the twentieth century was accompanied by increasing gender and sexual regulations, standardizing masculinity through the homosociality of military service. Given this association between masculinity and nationalism, in a semiotic sense, the nation founding "fathers" constitute more precisely a band of "brothers." Thus, it is no surprise that only after a few months of signing the Declaration of Independence the first college fraternity was founded in the US, Phi Beta Kappa.

\section{Becoming Men: The Making of an American Fraternal Archive}

The founding of black fraternities has been described by black Greek scholars as a striving for American ideas of "manliness" (Jones, 2004/2015). Though I agree with this framing, what is not addressed is that if black men where striving, or aspiring to, some kind of manliness, then what were they perceived as prior to, or within, the American fraternal system? How does the American fraternal system, then, "make" them men?

The answers to these questions lie in two interrelated discourses that rest at the junction of the U.S.'s question of citizenship at the turn of the twentieth century. As the nineteenth century ended, the U.S. population demographics began to shift as the American industrial revolution produced a migration of Asians, Mexicans, African 
Americans and Europeans. Reflective of the national demographic trends, college campuses in the U.S. were also changing. Formerly all white, all male, and all protestant campuses began to enroll women, Jews, Catholics and a small number of African Americans and Asian Americans (Syrett, 2009). As such, racial anxieties ensued causing white protestant elite men to construct new ways of defining themselves and their "rightful" place as ideal citizens of the nation. At this time, racialized scientific discourse, employing gender and sex differences to reaffirm theories of racial hierarchy, regulated the status of citizenship and manhood as the fraternal subject became the ideal representation of masculinity on college campuses.

As nineteenth century American literature worked to situate American constitutional archival logics, making the many into one, it also prompted a material and subjective embodied archival entity outside of the curricular realm on college campuses. The American fraternal system in part rose out of the literary tradition of the nineteenth century as early fraternal organizations started as literary societies. Between 1760 and 1860 , literary societies were the most popular, and in some cases, the most important aspects of American higher education (Torbenson, 2009). They provided college students with opportunities to socialize and develop experiential skills that were not found in the college classroom. In the classroom, students were expected to be regimented passive learners.

To distinguish themselves, literary societies developed secrete initiations, mottos and badges - setting precedence for Greek-letter fraternal societies (Torbenson, 2009). Therefore, when Phi Beta Kappa was founded December 5, 1776 at the College of William and Mary, it practically operated as a literary society. However, by sponsoring 
briefs, debates and orations on topics such as "the advantages of an established Church" and "the justice of African slavery" (Torbernson, 2009), these literary societies gave voice to what Ferguson (2012) describes as the "writely" formation of American literature as the reconciliatory arm of the American nation-state archival project. Historian Nicholas Syrett (2009) states, "To be Greek was to hearken back to the ancients, to the ideals of the founding of Western civilization; it was also to subscribe to notions of self-improvement through literature and oratory" (p. 25).

Though Phi Beta Kappa was founded in 1776, the American fraternal movement, encapsulating the way we envision fraternities today as social-based organizations, actually began in 1825 . Prior to this time, many of the fraternal organizations established by white college men either died out or became honor societies as did Phi Beta Kappa in 1831. In 1825, Kappa Alpha Society was founded at Union College—establishing the oldest social-based Greek-letter fraternity in the U.S. and marking the beginning of the first era of fraternity development through the mid-nineteenth century. By the 1850s, there were approximately 36 active fraternal organizations (at least two where female organizations that would later become Greek-lettered) with 202 new chapters established at 87 schools initially in the Northeast and Midwest and later the South (Torbenson, 2009).

This initial fraternal movement further illustrates the maturing archival tendencies of the university. As mentioned previously, starting as literary societies, fraternities were established as a counter space to the restrictive curricular learning environments of the time. The college environment was highly paternalistic with the faculty enacting a tight rein over every aspect of the college men's lives-hence, think of college during this 
time as more of a boarding school where students could be punished by administration for a multitude of disorderly and/or immoral behavior. As such, colleges came to expect student protest and as a way to disarm revolting students, institutions regulated, and in some cases, banned secret societies or any type of student group meetings (Syrett, 2009; Torbenson, 2009). As a result, this initial appeal and growth of fraternities were due to their independence and resistance from paternalistic structures (Syrett, 2009).

Fraternities would, however, envelop into the university archival enterprise through a desire for ideal manliness. Here, I am using "desire" as Eve Sedgwick (1985) defines, "to name a structure" (p. 2); in this case, an interpellation through knowledge regimes produced by the academy in its relation to the state. Historian Melissa N. Stein (2015) chronicles in her text, Measuring Manhood, how the nineteenth and early twentieth century academy entwined and constructed ideal manhood with rightful citizenship through scientific discourses predicated on race, gender and sexuality. Around the same time the American fraternity movement was picking up steam and infiltrating college campuses, a new curricular, or scientific, field of inquiry was taking shape round foundations of race.

Prior to the nineteenth century, theories of race were largely based on a religious racialized ideology. This ideology justified European colonization across the globe based on the notion of "divine providence," or in other words, it was destined by God that Europeans "civilize" and govern the world (Zuberi, 2001). By mid-eighteenth century, notions of democracy and independence reigned in the European-American colonies as the British colonies sought independence from England. Therefore, justifications of European domination of Indians and Africans needed fortification—no longer did the 
Great Chain of Being suffice especially as religious theology was beginning to be employed in resistance to slavery by the nineteenth century. Additionally, as a new nation-state, the U.S. needed to consolidate the racial order in state policy (Omi \& Winant, 1994; Wilder, 2013).

Therefore, the development of science and medicine picked up where the Great Chain of Beings left off-relying on developments of evolutionary theories in biology and statistics to reify preexisting ideologies of racial hierarchy (Zuberi, 2001). Accordingly, at the dawn of the nineteenth century, European and Euro-American scientists took a different approach to race research and theory than their eighteenth century counterparts. Whereas eighteenth century scientists framed their work within the Great Chain of Beings, which exemplified a form of Christian monogenism and left open some possibility of human equality, nineteenth century scientists were determine to justify biological distinction between races leaving many of them to adopt a polygenist philosophy and attempt to leave no doubts that Africans and Indians were inferior to Europeans and undeserving of citizenship (Graves, 2001; Stein, 2015; Wilder, 2013).

One way this new racialized ideology manifested itself was through the field of study called ethnology. Stein (2015) describes ethnology as "a field of scientific inquiry premised on the belief that the physical body revealed the intellectual, moral, and political capacities of its owner and, by implication, those of his or her race writ large" (p 30). Drawing on paternalistic theological views, men were ethnology's primary subject of concern. In 1830, five years after Kappa Alpha Society was founded at Union, Charles Caldwell, a medical doctor from North Carolina who established two medical schools in Kentucky (Transylvania University and University of Louisville), published Thoughts on 
the Original Unity of the Human Race, marking the emergence of ethnology in the U.S. (Stein, 2015). Followed by a concession of polygenesis-supporting scientific publications on race, particularly texts such as Crania Americana (1839) and Crania Aegyptiaca (1844) by Samuel Morton (Aegyptiaca with George Gliddon) and Types of Mankind (1854) by Joisah Nott, ethnology inscribed racial difference through the male body based on a science rooted in the racial ideology of the time.

Ethnologists employed skin color, skulls, facial features, strength, reproductive/non-reproductive organs, and even beards as evidence of white superiority. For example, Nott constructed a taxonomy of races based on beard texture - arguing white men were manlier because they were supposedly capable of growing thicker beards. Studies like Nott's wasn't just about justifying white superiority, but determining races' level of civilization and barbarism, and thus, who was best suited to govern or lead armies (Stein, 2015). In this case, black men were akin to women in their inability to embody the constructed corporeal standards of white manhood, and subsequently, citizenship.

Sex, gender and sexuality distinctions between the races where fortified with the discovery of evolutionary theory. Charles Darwin's On the Origin of Species, published in 1859 , consolidated the idea that all humans evolved from a single species (though Darwin incorrectly places that origin outside of Africa)—causing polygenicist racial scientists to reformulate their hierarchal bodily inscriptions. Consequently, this discovery paved the way for social Darwinism, a racial ideology based on an inherent survival of the fittest, and the notion of dysgenesis. As Zuberi (2001) outlines, dysgenesis included three major concerns: 1) degeneration of the quality of population based on the idea that 
upper-class white populations were superior and procreated less frequently than the "less fit" poor and people of color, 2) degeneration of the quality of the population due to the aforementioned racial differences in fertility as well as immigration, and 3) degeneration through miscegenation in which the "fit" white population could become diluted by other races. Dysgenesis became the basis for the eugenics movement which popularized notions of (white) "race suicide," coined by Delta Alpha Epsilon member Theodore Roosevelt (Somerville, 2000).

Through this logic a new controlling image of black masculinity was produced. Black men were believed to have an insatiable primitive sexual appetite, particularly for white women, due to their degenerate status. This primitive logic also structured a racialized physiological matrix of normative gender and sexuality where the white race's triumphant evolutionary progress resulted in the achievement of distinctive binary sexes and heteronormativity (Stein, 2015). According to this matrix, as Somerville (2000) contends, "the children of 'superior' groups embodied phases equivalent to the mature adult phases of 'inferior' groups" (p. 24), making adult African American men and white women equivalent to white male children in this white cis-heteropatriarchal ancestral framework.

By the end of the nineteenth century, sex and sexuality would become chief indicators of evolution towards civilized manhood. Somerville (2000) points out that even though eugenicists were not concerned with questions of homosexuality, sexologists "invoked the concerns of eugenicists" (p. 31) and defined homosexuality as a sign of degeneracy marked by gender inversion, or put differently, an infusion of masculinity and femininity. By the 1880s, American sexologists such as G. Frank Lydston and James 
Kiernan — whose work was referenced by European sexologist Havelock Ellis and were of the first to use the term "homosexual" in print in the US-employed sexual differentiation as a mark of evolutionary development. In this case, the "lower races" were pathologically prone to have deviant gender roles, reproductive anatomy, and sexual behavior whereas sexual perversion in middle- and upper- class whites was seen as symptomatic of being "overcivilized" (Stein, 2015). As Stein (2015) notes, "they [sexologists] emphasized black women's labor, muscular bodies, and supposedly enlarged clitorises, while they interpreted black men's 'hairless bodies' and 'scanty beards' as evidence of the race's low evolutionary stage" (p. 180). Nevertheless, like the eugenics movement, sexology spurred social policy creating a climate of anxiety regarding sexual morality, and thus, produced anti-vice policing to criminalize sexual deviancy (Schwarz, 2003).

Therefore, race and sex scientists codified ideal manhood and its claims to citizenship in the body while distancing whiteness from people of color. Through the university power/knowledge regimes, the interest of the once "rebel" fraternity converged with the university and the state in producing the ideal masculine subject. As manhood was being defined by a corporeal stratification during the first half of the nineteenth century, "one of the things that college - and a fraternity - promised was that it would transform unmannered men into gentleman" (Syrett, 2009, p. 44). The fraternity, then, with its independent spirit, would support the university's archival function through a homosociality that would valorize and manage masculine difference. Fraternities increasingly defined manhood by appearance propagated on class distinction — " emphasized social graces and proper etiquette, sociability, gentlemanly conduct, and 
competition" (Syrett, 2009, p. 54). Furthermore, fraternity men would define being manly through physical appearance, such as being strong, healthy, and handsome — all characteristics associated with a hegemonic masculinity based on genteel Victorian principals.

By the second half of the nineteenth century, with the changing demographics on college campuses and urban industrialization, fraternal manhood reflected the aims of late nineteenth century race and sex scientists. Whiteness became more essential to how fraternities conceptualized masculinity along with wealth, and physical and co-curricular ability (which meant decreasing academic concern) (Syrett, 2009). In fact, physical ability was a way to prove the white race's evolutionary superiority and offset feminizing traits. College presidents endorsed the new American masculinity and saw their campuses as its training grounds. ${ }^{10}$ By the beginning of the 1900 s, fraternity masculinity was increasingly characterized against notions femininity and womanhood and the "lower" races of men who "naturally" possessed a capacity for these gender inversions.

With these developments, American fraternalism found its modern homosocial form. The indifference-forming characterized by the hommo-sexuality of male homosocial desire was held together by the ability to penetrate. In her seminal text, Between Men: English Literature and Male Homosocial Desire, Sedgwick (1985) proposes a model of patriarchy based on a continuum of homosocial desire, where on one end you have "men-promoting-the-interests-of-men," and on the other, "men-lovingmen." As we begin to see in the development of modern American fraternities, male

\footnotetext{
${ }^{10}$ Bowdoin's president, William Hyde, in The College Man and Woman (1906), a book dedicated to Theodore Roosevelt, praised the new emphasis on physical strength in college men development and its ability to curtail effeminacy and asceticism.
} 
patriarchal authority is framed by an abjection of homosexuality — the idea of "menloving-men" looms over all male social bonding, or as Sedgwick puts it, "for a man to be a man's man is separated only by an invisible, carefully blurred, always-already-crossed line from being 'interested in men'” (p. 89). For the fraternity man who was already consumed with his appearance and physical condition (read as suspiciously queer), the emergence of knowledges of homosexual subculture, in which the homosexual was perceived as womanly in early gender inversion models, caused great anxiety. Therefore, to distinguish themselves from "men-loving-men," fraternity men "publically proclaimed their dates and sexual conquests" (Syrett, 2009, p. 192). Women became tools of homosocial formations. They relieved homosexual anxiety by securing the always already crossed line.

Epitomizing the scientific and political sign of the times, fraternity men began to refer to non-affiliated men as "barbs," shorthand for barbarian. The term "barb" suggested the fraternal demarcation between those men who were civilized, and thus Greek-lettered, and those who were not—a connotation with broader colonial and imperial implications. On the world stage, frater Theodore Roosevelt epitomized the connection between U.S. imperialism and manhood through nationalist imperial projects such as manifest destiny and the Monroe Doctrine. Whether it was his speeches and writings, projecting the image of the rugged American cowboy, or his enthusiastic support for interventions in Cuba and the Philippines, he reflected "a racialized, imperial masculinity, where adventurous, but civilized white men tame or defeat inferior savage men of colour" (Nagel, 1998, p. 251). On college campuses, as ethnic, racial, gender, and religious minority representation increased at the end of the nineteenth century, their 
exclusion from fraternities helped to codify white, Christian males' status as heir apparent to ideal American masculinity and manhood—making fraternity membership synonymous with manliness. In fact, the once de facto exclusionary practices of fraternities became de jure by the 1910s as many added constitutional membership codes (Syrett, 2009).

Fraternities would serve as incubators for emerging capitalists. Syrett (2009) states, "Upon finishing their degrees, college graduates were much more likely to reside in urban areas for a least part of their lives than those who had not attended college" ( $p$. 125). As a social network predicated on wealth, fraternities acted as a marker of prestige for both those with and those trying to obtain capitalist success. At a time when the university colluded with the state and capital through the land-grant movement to condition white (and eventually minoritized) subjects to the nation's ideology of excellence, the fraternity became a space within the university to foster and idolize this type of uplift and respectability through its very own masculine homosocial (in)difference-making. Fraternities would facilitate the surveillance, standardization, and exclusion of gendered norms through its selection processes and social capital on campuses. In an era when citizenship rights were commonly articulated as "manhood rights," the masculine "excellence" of the fraternity, where hommo-sexuality indifference was the standard of incorporation, would facilitate a partnership between the state, capital, and the academy that situated minoritized subjects as antagonistic to its ideas.

By the turn of the twentieth century, the once independent, rebellious fraternity movement was a fully functioning spoke in the university archival wheel. By the 1880s, there were 107 non-Greek college students to every one fraternity chapter; compared to 
1980 when there were 580 non-affiliated (Toberson, 2009). As a subsidiary archive, the college fraternity takes on similar qualities as its principle agent — the U.S. nation-state via the academy — a disposition that is contradictory and reconciliatory. The fraternal subject is contradictory in that it "disciplines in the name of freedom" (Ferguson, 2012, p. 19). The initial appeal for men to join fraternal societies rested in their anti-institutional spirit. However, once institutionalized, the disciplinary function of the fraternity was not limited to championing masculine order on college campuses. Fraternity membership became a reliable indicator of another type of indifference, revolutionary apathy. Syrett (2009) states:

While they all engaged in activities that the faculty would have found objectionable, their propensity to participate in the acts of revolution that swept across U.S. colleges between 1776 and 1860 may well have been tempered by the feeling of revolution inherent in belonging to a college fraternity, as well as by the dignity and manliness that fraternity men believed inhered in that membership. (p. 36)

Therefore, the recognition bestowed through fraternalism is a challenge to and investment in institutional structures. The history of the fraternal movement is thus archivedgathered, collected, and given meaning - for the fraternal subject's own discipline and management.

The fraternal archive would, then, act in a reconciliatory fashion to negotiate the incorporation of minority difference into the academy. Just as the academy via the Morrill Act of 1890 and its logics of excellence worked to "resolve the tension between racial hierarchy and democracy" (Ferguson, 2012, p. 86) by bringing minority subjects 
into the state's emerging segregationist racial project, the fraternity would serve a similar purpose with its homosocial masculine regime of excellence. As minority fraternities are established, these organizations were not necessarily created as means to celebrate their difference, but rather because their difference disqualified them as a fraternal subject (Syrett, 2009). As José Muñoz (1999) states, “Counteridentification often, through the very routinized workings of its denouncement of dominant discourse, reinstates the same discourse" (p. 97). As such, they too will work within (and against) the fraternal archival function.

\section{Formulating Black Masculine "Excellence": The Founding of Black Fraternities}

The establishment of black fraternities was not only a college campus-based development. These organizations emerged within a larger social movement for the elevation of black lives at the turn of the century. BGLOs were in part informed by and exemplified many of the ideas expressed in the two interconnected movements of racial uplift and the New Negro. Rooted in racial uplift ideology, the New Negro Movement, with Harlem and its renaissance declared the epic center, was an effort to reimagine and reposition the African American in the political and social landscape of American society through the production of cultural works aimed at raising and changing black consciousness. As evident in the name of the movement, "The New Negro," conversely, this Renaissance sought to signify a new black people in the minds of America - a people of African descent who defy the stereotypes and distorted images of African Americans perpetuated by a system of white supremacy.

However, as Henry Louis Gates (1988) points out, there is a social and political paradox inherent in the "success" of a movement politically and historically situated in 
white liberal ideology. In order to be successful, the "New Negro" must turn "away from the 'Old Negro' and the labyrinthine memory of black enslavement" (Gates, 1988, p. 132), and in many ways, hail the values of white middle-class America in an attempt to be normalized. Kevin Gaines (1996) argues W.E. B. DuBois' double-consciousness represents a form of black middle-class "uplift" ideology where many blacks educated by Eurocentric curricula and institutions "viewed themselves (and other blacks) through the judgmental gaze of whites, even while struggling to break free of falsified white images of blackness into self-consciousness" (p. 9). As reflection of this double-consciousness, BGLOs were created, encapsulating "both black communal values and the trappings of white American elitism" (Washington \& Nuñez, 2005, p. 139).

The development of black fraternities was a visual and material symbol of African Americans obtaining the status of "New Negro." Walter Kimbrough (2003) states that the ethos of the New Negro movement influenced the conceptualization of black fraternities. As such, the period between 1905 and 1930 was the foundational period for collegiate black fraternities, aligning the establishment of black fraternities with the Harlem Renaissance and New Negro Movement. Members of black fraternities were considered part of W. E. B. DuBois's "talented tenth"-an educated, upper-class with professional credentials, skills and economic capital to assist in the political uplift of the broader black race (Kimbrough, 2003). This interrelated emergence was apparent by the number of prominent New Negro leaders, writers and thinkers who were members of black fraternities, including DuBois (Alpha Phi Alpha), Arturo Schomburg (Kappa Alpha Psi), Alain Locke (Phi Beta Sigma), and Langston Hughes (Omega Psi Phi), among 
others, and the reference to BGLOs in Renaissance cultural works (i.e., There is Confusion and The Blacker the Berry).

Though there were a couple of unsustainable black fraternities believed to operate at Ohio State University and Indian University in the early 1900s, Alpha Phi Alpha, founded at Cornell University in 1906, lays claim as the oldest black collegiate fraternal organization. In the fall of 1905, the founders of Alpha Phi Alpha were seven of the eleven black students who arrived at Cornell (Bradley, 2008). Alpha Phi Alpha began as a study/social club in an effort to combat issues of racial isolation and lack of academic and financial support for black students. Soon after establishing the club, some members urged that the club become a literary society denoted by Greek letters. This would eventually lead to a chasm within the group about whether to remain a literary society or become a full-fledge fraternity. Several members of the literary society worked in white fraternity houses and this influenced their desire to become a fraternity. On December 4, 1906, with the support of white fraternities, the institution, and the local black community, Alpha Phi Alpha Fraternity was established.

In 1907, Alpha Phi Alpha would go on to establish a beta chapter at Howard University - becoming the first fraternal organization on the campus of the HBCU that would later be referred to as the "cradle of Black Greek civilization" (Kimbrough, 2003). Five of the eventual nine historic black Greek-lettered organizations would be charted at Howard, including Alpha Kappa Alpha Sorority (1908), Omega Psi Phi Fraternity (1911), Delta Sigma Theta Sorority (1913), Phi Beta Sigma Fraternity (1914), and Zeta Phi Beta Sorority (1920). Two of Kappa Alpha Psi's founders, Elder Watson Diggs and Byron K. Armstrong, would transfer from Howard to Indiana University by fall of 1910 and be 
instrumental in establishing Kappa Alpha Nu on January 5, 1911. Due to the racial derogatory insinuation of Kappa Alpha Nu by whites, the fraternity would change its name to Kappa Alpha Psi in 1914. The remaining members of the "Divine Nine" would be established in 1922, Sigma Gamma Rho Sorority at Butler University, and in 1963, Iota Phi Theta at Morgan State University.

With their roots in the New Negro movement, the black fraternity man would represent the quintessential "race man" through much of the twentieth century. As Mark Anthony Neal (2013) explains, the race man "describes black men of stature and integrity who represented the best that African Americans had to offer in the face of Jim Crow segregation...race men inspired pride; their work, their actions, and their speech represent excellence instead of evoking shame and embarrassment” (p. 169). Since its conception, black fraternalism has always been about service to the black community. This is especially the case given that black fraternalism emerged on historically white campuses where there were few black students and these organizations were an avenue for social and political support and solidarity. Alpha Phi Alpha, being established at Cornell, if not for proximity alone, was influenced by the Niagara Movement of 1905 which would go on to produce the NAACP in 1909. Black fraternities would establish community service, political action and/or philanthropic arms, such as Kappa Alpha Psi's Guide Right Foundation which was established in 1922, dedicated to racial uplift.

Black fraternities would also serve as a vehicle for members to hail the composite body of some of the most prominent and visible race men of all time. Black fraternities would go on to enlist in its membership the likes of Martin L. King, Jr. (Alpha Phi Alpha), Johnnie Cochran (Kappa Alpha Psi), Al Sharpton (Phi Beta Sigma), and Jessie 
Jackson (Omega Psi Phi), among others. Thus, even though every person who share these memberships aren't necessarily political or even "successful" as these men, the black Greek insignia, however, acts as a visual marker connecting individualized bodies with the privileged composite form of black male identity these prominent race men represent. As an optic marker, black fraternities offer its members an almost instant legitimacy, respect and admiration among their peers.

Likewise, at the turn of the century when black men were trying to legitimize themselves on college campuses, they sought (white) Greek fraternalism as affirmation. As Deborah E. Whaley (2010) states, "Participation in the Greek system for Black Americans allowed them to function, in the eyes of White college administrators, as legitimate and recognizable college organizations" (p. 17). In some ways, this was the case even for Howard University who didn't have a black president until 1926. As an archival regime, the Greek system recognized as well as conditioned these men to the masculine and racial order of the day, respectively characterized by homosocial indifference, including phallocentrism and racial separation.

Black Greek-lettered fraternities were crafted in direct relation to white fraternities. Besides being prohibited from joining white fraternities, founders of black fraternities found themselves in direct contact with their object of desire. Michael Washington and Cheryl Nuñez (2005) call into question the early founders of black fraternities' decision to start fraternal societies as mechanisms of racial uplift instead of organizations that might have been more inclusive, and politically and socially, more culturally appropriate. This tension on the question of fraternal organizing is probably best represented in the establishment of Alpha Phi Alpha, where one of the leading 
members of the literary society would disapprove of becoming a fraternity and disjoin. However, Washington and Nuñez conclude, "It is clear that of all the options that lay before them, none could match the appeal of the collegiate Greek-letter fraternity, which as, after all, the paragon of status within the white campus culture" (p. 161). This appeal was fostered in part by these black men's contact with white fraternities. Some of the founders of Alpha Phi Alpha worked in white fraternity houses and tutored white fraternity members (Bradley, 2008). Furthermore, the establishment of black fraternities would be supported by white fraternities in ideas and symbols. White fraternity members assisted Alpha Phi Alpha with their first initiation ceremony and Kappa Alpha Psi's "Loving Cup Sung” is a replica of Beta Theta Pi's (Bradley, 2008; Jones, 2015).

Black fraternities would also emulate white fraternities structurally. Black fraternalism would constitute its own homosociality predicated on a hommo-sexuality archive of indifference. Much of the black Greek masculine archive was about countering the racist depictions of black men that, to some extent, disallowed black men from joining white fraternities. Therefore, for the first half of the twentieth century, black fraternities relied on a masculine logic that challenged black male stereotypes such as the black brute or the gender perverse, and in doing so, devised their own form of sameness. Cynthia L. Shelton (2008) identifies this black Greek hommo-sexuality as strategic essentialism. Shelton writes, "Strategic essentialism differs from essentialism, in that the marginalized group imposes 'essential attributes' on itself and acknowledges that these essential attributes are constructs" (p. 214). Thus, strategic essentialism is a calculated maneuver to counter hegemonic essentialism. 
Black fraternities largely constructed a middle-class masculine personification based on a late Victorian genteel heteronormative patriarchy—an image that would stand in contrast to black primitive notions while aligning them closer to a professional status associated with whiteness. Gaining entrance in a black fraternity during this time often required having light-skin complexion, an elite social class background, and a refined gendered sexuality (Whaley, 2010). For black fraternity members, this fraternal self has typically meant some level of repression of individual identity and demarcation from the black masses (Jones, 2015; Shelton, 2008; Washington \& Nuñez, 2005). Nevertheless, this masculinist formation of respectability politics was seen as imperative to achieving the integrationist and survivalist aims of racial uplift.

\section{The Black Fraternal Struggle: Gendered Sexuality and Socio-political}

\section{Consciousness}

Black fraternities emerged within two sociopolitical movements-the black freedom struggle and American fraternalism (Jones, 2015). Black fraternities, thus, constitute both a counter to and a continuation of these respective movements that in many ways impede on each other's interests. What constituted the parameters of acceptable masculinity in American fraternalism was framed by and against people of color as gendered and sexually deviant/diverse — making the Greek-lettered system a reflection of the national archival domain where inclusion is determined by racial difference and gender and sexual regulation. As a result, black fraternalism is a material field of struggle "that compels identification with and antagonisms to the normative ideals promoted by state and capital" (Ferguson, 2004, p. 3). 
This, black-fraternity-as-cultural-site-of-struggle, is evident in the instability in subjectivity and performance that is in constant need of reproduction and display to reify a coherent, or legible, race man identity. Jeffrey McCune (2014) identifies the deployment of what he calls sexual discretion as one indication of this instability. McCune describes sexual discretion as a historical and epistemological performance-inresistance to the surveillance and management of dominant ideologies of race, gender, sexuality and class. In a socio-political climate where black recognition is predicated on "deviance" or counter-"deviance," the down low has always been the avenue, both the how and where, for black folks to disidentify and make space for more complex desires, pleasures, and formations of community. McCune writes, "Sexual Discretion is as much about the silence in the black community about sexuality as it is about the sexual silences that have always existed but remained unspoken" (p. 9). In this case, the black fraternity not only represents all that is "right" or "on the up and up" about black gender and sexuality, but also serve as an impetus for the low-down sexual passer to subvert its very logic of gender and sexual normality and stability. As Munoz (1999) states, "Passing is often not about bold-face opposition to a dominant paradigm or a wholesale selling out to that form...passing can be a third modality where a dominant structure is co-opted, worked on and against" (p. 108). To summarize, passing calls into question what we consider the inconsiderable.

There isn't much direct evidence of the early experiences of black queer men in the institutional black fraternities. This is in part due to both professional formalist and public realist black Greek scholars pre-orientation with the reproduction of a static heterogendered fraternal identity and the often-discretionary nature of black queer 
subjectivity. However, we know that homosocial structures have historically almost always included non-heterosexual men and/or queer behavior, whether that's all-male boarding schools, military units, or sports teams. Therefore, as we think about the early formation of black fraternities it is beneficial to (re)consider some of its more prominent early known sexual passers and the life-worlds they created within and against the fraternal structure. These men represented the object of homosocial anxiety-an indication of the line always already crossed.

Through his correspondence with artists and other African American bohemians, one of the prominent thought-leaders of the Renaissance and member of Phi Beta Sigma, Alain Locke led an extensive network of same-sex interested men. Locke introduced men whom he trusted to gay literature and potential romantic and/or sexual partners. This network was formalized as a "fraternity of friends" in which "new members" were actually initiated in "the circle" twice a year. Christa Schwarz (2003) states, "With Locke as a pivotal figure, the men involved in the gay network formed an invisible, diverse community which was at the heart of the Harlem Renaissance" (p. 13). Some of the men in Locke's network included Langston Hughes of Omega Psi Phi, and Countee Cullen, a member of Alpha Phi Alpha. There were also men like Harold Jackman, also a member of Alpha Phi Alpha, who was not officially in Locke's network but became associated with it due to his same-sex interests. Despite the dominant ideology at the time which described homosexuality as a degeneracy, Locke introduced a gay-identity to many of the men who expressed same-sex desire. However, Locke's network did not include women, and in many ways, it worked against women in the movement by placing them outside the networking loop. 
Anna Pochmara (2011) contends that Locke's construction of masculinity relied on a Greek model of homosexuality in which Locke deployed Whitmanesque concepts of manhood and camaraderie to signal same-sex desire and eroticism in his writings. Thus, Locke's brand of masculinity is sometimes referred to a queer middle-class identity, in that, Locke remains committed to black middle-class respectability by deploying samesex desire and sexuality covertly without disrupting social perception (Pochmara, 2011). In other words, Locke as the "DL" subject, "disidentifies with what is traditionally labeled gay or bisexual, in other to maintain his role as a respectable citizen, a 'real' man (McCune, 2014, p. 133).

This type of queer disposition was typical for other black Harlem artists and fraternity elites. Schwarz (2003) explains that many queer Harlemites displayed a public image of respectability which often included marriage. Sometimes called "front marriages," these relationships could include one or both parties engaged in marriage to conceal their same-sex sexuality. For instance, Countee Cullen married Yolande DuBois, daughter of W. E. B. DuBois and a member of Delta Sigma Theta, in 1928. Their marriage ended after only six months. She divorced him after finding out he was romantically and sexually interested in men when he embarked on a "honeymoon" with his longtime intimate friend and fraternity brother, Harold Jackman, who was also the "best man" at their wedding. Schwarz states, "Cullen, who fulfilled most of the black bourgeoisie's expectations, got away with relatively few remarks about his failed marriage" (p. 23) - thus, his success and privileged patriarchal network among Harlem elites (i.e., Locke's circle of friends and fraternity membership) made it all forgivable. 
Though Locke was not subverting any specific black fraternity, his network of "friends," which included black queer members of BGLOs, by all means transformed the institutional fraternal homosocial model to create a vibrant black queer life-world. We can see how the sexual passing fraternal subject disrupt notions of a fixed, stable category of fraternal identity. Exploring the lives of black fraters such as Locke and Cullen gives us some insight into how black queer subjects have always appropriated and remixed the fraternal structure to embody more liberating and pleasurable communities, a space of and for queer desire, and shield themselves from public scrutiny, distortion and conformity. Therefore, instead of a closet paradigm of same-sex desire that would epistemologically entrap black sexuality, the down low is employed "as a structure of choice, to best name and represent the creative, generative, and transgressive space for discreet acts" (McCune, 2014, p. 14).

However, there are limitations to this survival strategy. The patriarchal authority of homosocial indifference is left intact (even while being challenged). In other words, as black queer subjects with membership in and engaged with institutional black fraternities that embody the masculinizing homosocial force and black bourgeoisie ideology, they are often as much co-opted by, as they are adaptors of, such logics. There is a price to pay of sorts to participate in dominant male powered conventions - the constant reassurance of acting in the interests of men over women, or the masculine over the feminine. As Maddison (2000) contends, "Retreating from the abjection of public homosexuality and aspiring towards the authority of homosociality necessarily demands the reinforcement of misogyny" (p. 74). Though this misogynistic reassurance could never fully secure the 
queer subject's place in the patriarchal bond, they do become tolerable as in the case of Locke and Cullen who marginalized and objectified women.

As black fraternities mature fraternally, or become more absorbed within the fraternal archive, their commitment to black social consciousness is always already compromised by the indifference-forming fraternal hommo-sexuality. For instance, by the 1930s, black homosocial masculinity looked much like their white counterparts. In his commencement address at Howard University, DuBois himself critiqued black college males' behavior:

Our college man today is, on average, a man untouched by real culture. He deliberately surrenders to selfish and even silly ideals, swarming into semiprofessional athletics and Greek letter societies, and affecting to despise scholarship and the hard grind of study and research. The greatest meetings of the Negro college year like those of the white college year have become vulgar exhibitions of liquor, extravagance, and fur coats. We have in our colleges a growing mass of stupidity and indifference. (as cited in Anderson, 1988, p. 276) James D. Anderson (1988) points out that this critique of black masculine performance contrasts with black college students more socially conscious disposition observed only a few years earlier when students at black colleges were fighting for control of their institutions from northern industrial philanthropists. What can by implied from DuBois' commentary, then, is that black fraternities had some role in distracting students from more pressing issues of the time. DuBois was not alone in his critique. Other prominent black scholars like E. Franklin Frazier (1957) also challenged black “Greekdom” for its elitism, political apathy and capitalist consumption. This indifference to social 
responsibility resemble the apathy that became expected of white fraternities in their modern development.

Other scholars have noted black fraternities wavering commitment to social responsibility and politics throughout the twentieth century (Jones, 2015; Whaley, 2010). For instance, Jessica Harris and Vernon Mitchell (2008) document how Alpha Phi Alpha's level of social activism varied with leadership, stating, "as it grew and matured as an organization, [Alpha Phi Alpha] dealt with changing currents and interpretations of how the fraternal body should be involved with the black community...some had very narrowly circumscribed views, while others saw the fraternity as a catalyst for change" (p. 146). In fact, many of the social change efforts put forth by black fraternities have historically been about proving or assuring black men's manhood within the homosocial framework of the liberal capitalist state. Black fraternities, particularly the first four, have placed heavy emphasis on liberal capitalist purists and engaging in U.S. militarism, such as their establishment of the Central Committee of Negro College Men in 1917 to support black males' involvement in the U.S. war efforts. However, as Jones (2015) contends, "This dedication to American ideals did not change the approach of many Americans to the black man" (p. 46). African Americans who fought in World War I returned to the U.S. expecting greater respect and justice and were met with anti-black rioting and violence in many U.S. major cities. During the radical movements of the 1960s and 70s, BGLOs were openly critiqued by radical organizations for their conservative principals, and in the era of Black Lives Matter, some organizations have taken neutral stances in the politics and protest over state anti-black violence while others have encouraged members to not wear paraphernalia when participating in public 
demonstrations. Black fraternalism, then, produces a microculture of masculinity whose hommo-sexuality constitutes a type of Americanization that attempts to regulate black gender and sexuality for an aspirational universal citizenship (Ferguson, 2004).

The development and continuation of essentialist notions of race and respectability in black fraternities have contributed to their declining politicization. Black fraternities' political agendas are still primarily framed by what Cathy Cohen (1999) calls consensus issues. Consensus issues often reflect a black middle-class cisheteropatriarchal sensibility, and like the founding of black fraternities at the turn of the twentieth century, mark a historical period when black leaders were primarily concerned with a collective representation and institutional access. Though African Americans have made significant gains in terms of institutional access and representation, with members of BGLOs making up a critical portion of that representation, most African Americans still do not have access to any form of institutional power. In a post-modern era of contemporary racism, characterized by cross-cutting issues that are evermore framed by the interwoven lines of race, gender, class, and sexuality that underscore intra-racial differences, it is critical that black indigenous organizations transgress a dominant black gender ideology that inform this unidimensional racial justice framework (Cohen, 1999; Collins, 2005).

For instance, we know black gay and bisexual men make up not only a significant portion of active members of institutional black fraternities, but they also "outwork" their hetero-fraternal counterparts and constitute the "backbone" of many of these organizations (Kimbrough, 2003; Ray \& Spragling, 2012). However, at a time when the Centers for Disease Control and Prevention predicts black gay, bisexual and/or men who 
have sex with men (MSM) could have a fifty percent chance of being diagnosed with HIV in their lifetime (Centers for Disease Control and Prevention, 2016), no institutional black fraternity currently has a program or initiative to address this issue. By not addressing these critical issues, black fraternities, whether implicitly or explicitly, contribute to the secondary marginalization of one of their very own most important and vulnerable subpopulations by not making our humanity valuable enough to mobilize action.

\section{Black Greek Fraternal Textuality and Archive}

In an effort to recognize and secure their manhood in the institutional logics of higher education, black men intervened in the American fraternal system, forging new modes of representation and embodiment. The American fraternal system, a one-time estrangement with the institutional values of the academy, quickly coalesced into its institutional archive through the knowledge/power regimes informed by state and capital around ideal manhood. As a result, the movement for black uplift through fraternalism have had to negotiate and appeal to its prevailing masculine homosocial structuresmanifesting a genealogy of contradictions predicated on indifference-making and (intra)racial distancing.

This archival legacy is evident in the contemporary black fraternal experience. Studies have shown that black fraternal membership contributes to undergraduate members oscillating between conforming to and diverging from white hegemonic ideals of masculinity, represented by liberal capitalist ideas, and more Afrocentric frames, predicated on a racial collective consciousness (Dancy, 2011; McClure, 2006). This negotiating between dominant and minority masculinities also include countering 
attributes seen as white and feminine by being physically strong and dominating, hyperheterosexual and promiscuous, and never being overly refined or academic (DeSantis \& Coleman, 2008). As a result, the predominate form of masculinity produced within black fraternities is constructed in opposition to homosexuality and femininity. In a homosocial logic, the homosexual or queer subject troubles the "necessary" exchange of women, and thus, "are conjured as the treacherous and barren ever present insider-other" (Maddison, 2000, p. 81).

Many black queer college students don't see institutional black fraternities as a viable social option without masking their queer behavior (Means \& Jaegar, 2013). Like the affirming and normalizing possibilities of embodying a fraternal disposition for black men at the turn of the twentieth century, black queer men who end up joining black fraternities often experience a level of social acceptance and status within black communities typically not afforded to non-affiliated black queer students (Patton, 2011; Squire \& Mobley, 2015). However, black queer members are often uncomfortable in institutional fraternal spaces, face differentiate treatment, and/or conceal or are expected to (over)compensate for their queer disposition.

Black queer journalist and member of Alpha Phi Alpha, George Johnson (2017) writes about how he lied about his sexuality to gain membership and once he became a member the pressure to conform did not diminish. Johnson writes, "I hid my identity, keeping my sex life out the spotlight and contained within my own personal circle of gay friends and 'girl friends'... but this didn't stop the rumors, and remained a main point of contention between me and several brothers who felt my suppression of myself still wasn't enough for years." Johnson, like so many of us, then, decided he might could 
prove his worth, "admiring those who somehow existed in high positions within the organization while keeping their identity intact...this ability to navigate hetero-dominated spaces as a leader while being gay was a goal for me, or so I thought.”

If we take up E. Patrick Johnson's (2003) Freudian premise of black heteromasculine male identity formation, "that black heterosexual men are always already 'queered' because they enact (perform) the loss of the one for whom they cannot express desire" (p. 51), Sedgwick's model of homosociality may help us to better understand how the ungrieved homosexual love-object is lost and reviled. In masculinizing homosociality, "homosexual-as-abject becomes deeply functional" (Maddison, 2000, p. 75). To be perceived as not crossing the "always-already-crossed line," the homosexualfemme object must be put to rest from within the subject to perform the type of hyperheterosexuality characterized by homosocial structures. Therefore, homophobia (and misogyny) is constituted not solely through a repressed homosexuality, a premise Maddison (2000) and others resist, but also structurally. The presence of the black queer subject in homosocial fraternal structures, then, "blurs the boundaries between who exhibits phallic power and who bears it: they are demonized and represented as the inimical possibility of male anal phallic penetration" (Maddison, 2000, pp. 81-82).

Furthermore, like the men in Locke's discrete fraternal network, black queer men have employed institutional black fraternal structures as a veneer for more creative and complex communities of gender and sexual desire and pleasure. What has primarily kept me engaged in institutional black fraternity life against its gendered and political constraints has been the ability of my fellow queer brethren to create a space, or a lifeworld, within the contours of the fraternity structures, but often out of view from 
general members, whether that's at fraternity conventions or in online spaces. Indeed, the fraternity offers a degree of escape through its exceptional heterogender guise for many black queer subjects as I can even recall in my early days in the fraternity, before being more openly queer, using "hanging with the frat" has a way to engage in a homosocial that was almost always queer.

Though these practices are a form of heteronormative dissent and black queer world-making potentiality ${ }^{11}$, there is still a management of gender performance and display. The fraternal homosocial pressure and expectation of an appropriate display of manliness, can create anxiety and distancing by black queer members from what is considered inappropriate displays of manliness (i.e. gender nonconforming, femme performance). George Johnson (2017) further demonstrates this when he writes about the push back he received from fraternity members when he decided to embrace his queerness publically, stating "I was requested to remove certain pictures of myself wearing paraphernalia of the organization if I was going to be wearing crop-tops and sunhats...I was asked to minimize my femininity.” As E. Patrick Johnson (2003) writes, "The representation of effeminate homosexuality as disempowering is at the heart of the politics of hegemonic blackness" (p. 51). Furthermore, Maddison (2000) states, "to accede to the power of patriarchal identification - it is to aspire to the sameness of male identity, a sameness secured through misogyny and homophobia" (p. 89). Therefore, the policing of gender performance (both in public and at times in private) and an adherence

\footnotetext{
${ }^{11}$ Potentiality here connotes the distinction between possibility and potentiality in producing anticipatory illumination. Potentiality, unlike possibility, provides some evidence in the present about a future utopia. See Munoz, Cruising Utopia, 2009.
} 
to the patriarchal authority of the fraternity illustrates how as much as we adapt, we are also co-opted by hommo-sexuality (in)differencing.

Reflecting on the hostility he faced when he embraced his queer identity, George Johnson (2017) writes:

I learned that some people in the organization's greatest fear was not white supremacy, nor even a decrease in membership. It was and is the fact that the torch might be passed from our most well-known member, Dr. Martin Luther King Jr., to someone of a queer embodiment. It was that they might risk losing the masculinity they so long fought to protect.

Johnson's revelations reveal the precarity of masculinity in black fraternal formations. Instead of a stable, essential masculinity to protect, black fraternities have aimed to secure a normalized masculinity from within a racialized gendered sexual logic where black "manhood" is insecurable — thus, their fear is, in fact, propelled by white supremacy. The public black queer subject not only disrupts the composite masculine image black fraternities have been constructed against, but also the consensus-oriented politics that image represents, revealing black fraternalism's intersectional political shortcomings.

As a result, the black fraternal structure of homosocial indifference has produced an "exceptional" homosexual fraternal subject, one that is disciplined and distinguished from what is considered the pathological queer of color subject based on racialized norms of class and gender. Entrenched within the heterosexual sexual exceptionalism of statearchived black fraternalism, the queer fraternal subject represents the "excellence" of the black fraternal endeavor and the "exception" to its ideal fraternal self. This dualist 
disposition connotes a homosexual sexual exceptionalism that Jasbir Puar (2007) suggests "does not necessarily contradict or undermine heterosexual sexual exceptionalism; in actuality it may support forms of heteronormativity and the class, racial, and citizenship privileges they require" (p. 9). This exceptional modality of queerness, or homonormativity, then becomes the regulatory agent by which other queers are restricted, or delineated, while also propagating hegemonic racial, national and imperial structures, or homonationalism. Thus, as Puar states, “The queer or homonormative ethnic is a crucial fractal in the disaggregation of proper homosexual subjects, joining the ranks of an ascendant population of whiteness, from perversely sexualized populations" (p. 28).

Institutional black fraternalism, thus, not only hinder intra-racial hetero- and nonhetero-normative alliances, but also intra-racial homo- and nonhomo-normative alliances. Take for instance a 2017 interview conducted by The Jasmine Brand with fashion designer Reco Chapple on being an openly gay member of Kappa Alpha Psi. In the interview, Chapple explicitly talks about the queer antagonism he has experienced as a member as well as his intentions to become a life member ${ }^{12}$. When asked what advice he would give to someone who was openly gay and wanted to become a member, he states:

We are a fraternity of men. I'm a firm believer of the saying, 'When in Rome, do as the Rome do.' We are talking about uplifting the betterment of black men as a whole. You gotta have your shit together.

\footnotetext{
${ }^{12}$ Life membership in a black fraternity typically designates a special class of membership reserved for members with exceptional service to the fraternity, most prominently exhibited through financial contributions.
} 
Chapple's emphasis on manhood - “fraternity of men...betterment of black men as a whole"-works here as a demarcation between the improper and proper queer subjectivity that black fraternalism produces. As a proper queer fraternal subject, you must uphold cis-heteropatriachy by reifying a binary gendered (in)difference — the making of the masculine and the feminine - a difference defined by heterosexuality and a framework that produces the very homophobia Chapple has experienced in the fraternity and reinforces misogyny. Specifically, Chapple's "betterment of black men as a whole," denotes the dissipation of queerness and queer politics to the masculine normative form. As Maddison (2000) states, "Heterosexual, homosocial masculinity identifies real men, who are kept in place by the production of an execrable second term - un-real, perverse, but necessary — desiring and striving towards that ever-elusive real manliness that is the very reassurance of the negation of womanliness" (p. 87). So, to have "your shit together" is a proclamation for a queer "success" 13 that is always already fraught as it renders the queer subject to the institutional disciplinary measures of race, gender, sexuality and class.

As institutions are representation of a textuality, a mode of interpretation, institutionalized black fraternities embody the homosocial order of the archival academy through its Greek fraternal system—-making black fraternities a (micro)masculine institutional archive of its own - both disruptive and recuperative of the institutions in which it's embedded. Since the turn of the twentieth century, this black Greek fraternal archive has been absorbing and disciplining bodies to the logics of state and capital. Ferguson (2012) highlights the first engagement of the academy and its archival power

\footnotetext{
${ }^{13}$ The opposite of the "queer failure" characterized and urged by Jack Halberstam (2011).
} 
with minority difference beginning in the 1950s and 60s with the radical student movements that sought to reform the institutional text of post-secondary education, with the incorporation of these differences taking shape (and being reshaped) in the 1980s and 90s. Interestingly, as these movements were unsettling campus environments, by the 1970s BGLOs would experience a mass expansion due to this minority intervention on historically white college campuses. Therefore, as a "pre-existing" archival entity, we must consider what impact the charting of BGLOs during this critical time might have had on these radical institutional interventions. 


\section{CHAPTER 3: THE BLACK FRATERNAL MAKING OF MINORITY DIFFERENCE}

AND INSTITUTIONALITY

In the fall of 1967, Omega Psi Phi Fraternity became the first black student organization on the campus of Florida State University (FSU). Though they would not be officially charted until August 1, 1970 as a chapter (Chi Theta), the nine men who were initiated through the Tallahassee Chi Omega graduate chapter with help from the Florida A\&M University (FAMU) Upsilon Psi undergraduate chapter not only brought the first black Greek-letter organization (BGLO) to FSU, but the first BGLO in the southeast at a historically white university ("Chi Theta Charter," 2017) — a development which mirrored the establishment of the first black fraternities at the turn of twentieth century. This establishment was both representative and anomalous of the times in the development of minority interventions and archival on college campuses.

Like the men at Indiana and Cornel Universities who formed Kappa Alpha Psi and Alpha Phi Alpha, Omega Psi Phi was chartered at FSU to fulfil an institutional void of recognition, acceptance and legitimacy. However, most BGLOs charted on historically white campuses in the South followed the radical student movements of the 1960s and 70s that worked to reshape campus culture and politics - making space for groups like black fraternities and sororities. Omega Psi Phi presence preceded this major student activism on FSU campus. Therefore, the founding of Omega Psi Phi as the first black student organization at FSU, and first BGLO in the South at a historically white 
university, is a unique development in the broader post-WWII black fraternal and radical student social movements.

In the previous chapter, I theorized how institutional black fraternities constitute archival entities predicated on homosocial indifference and the ideal Western man-a formation that predate the establishment of the post-civil rights interdisciplinaries. Thus, employing the establishment of Omega Psi Phi at FSU as a comparative case study, in this chapter I will examine black fraternities' impact on the radical black student movements and their interdisciplinaries to ask, as Roderick Ferguson (2012), "what networks of power were authorized in our late-modern age, how those networks worked through marginalized subjects and social formations, and how those networks were modeled after the networks built by the human sciences, that assemblage of fields that the ethnic and women's studies movements worked to challenge" (p. 30). To state differently, I am interested in how black fraternalism as a "modeled" archival entity contributed to the configuration of the institutional logics of race, gender and sexuality during this era.

\section{The Biopolitics of Fraternalism in Higher Education}

Ferguson (2012) contends that the origin of the institutional archival power that characterized the mid-twentieth century can be traced to the discursive configuration of “Man.” Employing the work of Michel Foucault (1970, 1977, 1978), Ferguson argues the category of man in Western culture was a late eighteenth century invention grounded in multiple discourses of knowledge. These knowledges formulated the human sciences. Ferguson states, "The human sciences represent the heterogeneous modes by which man was analyzed and produced as a diversity of elements available for critical scrutiny" (p. 
30). This formulation of man incited a type of disciplinary power-one in which the category of man would be employed as a canonical figure by which all other subjects would not be resolved, but instead, judged, differentiated, and reduced to singularity. For instance, in The History of Sexuality: Volume 1, Foucault (1978) famously accounts for the invention of the homosexual personage during the late nineteenth century. Through an expansion of sexual discourses beginning in the seventeenth century, this modern development was characteristic of a proliferation of singular sexualities-demarcating individual bodies. As such, Foucault goes on to conclude deductive power, or the power to seize life, has dwindled since the classical age and have been replaced with a modern power to generate life - a life regulated and controlled by discursive constraints. For Ferguson, then, "Western man would lay the groundwork for disciplining minority difference-making its activation concomitant with its regulation" (p. 31). Put differently, this disciplinary power works through the individuals it produces, attaching agency with regulation, in the way the subject man is obligated to the human sciences.

The formation of the U.S. fraternal system and black fraternal life exemplifies how this disciplinary power produces multiple forms of agency. As discussed in the previous chapter, the advent of modern fraternalism in the U.S. was predicated on the scientific and politic discourse of manhood of the nineteenth century and its homosocial indifference-making. The once independent fraternal subject would then be engulfed into the institutional archive of the university, thus, disciplining and demarcating between desirable and undesirable ideals of manhood and forging new subjectivity and agency in the likes of the black fraternal subject. As Ferguson (2012) writes, "Man and the individual's discursive statuses as the products of and grounds for knowledge help to seal 
the contract between epistemology and power relations" (p. 31). The fraternal homosocial subject, even the disidentifying black fraternal subject, constitutes the object and instrument of institutional power through the subjectivity of manhood, a form of institutional biopower, or a right to life.

Fraternal biopower is representative of the convergence of the two forms of disciplinary embodiment that were conjoined in the nineteenth century in part by the deployment of sexuality. Foucault (1978) argues that beginning with the seventeenth century and the shift from deductive power to generate power (i.e., biopower), two disparate disciplinary procedures took hold of the body in the form of the anatomic and the biological. The anatomic was concerned with the body as machine and its capitalist function while the biological situated the body in terms of reproduction in an era with a growing concern for demography. Foucault states, "This great bipolar technologyanatomic and biological, individualizing and specifying, directed toward the performances of the body, with attention to the processes of life-characterized a power whose highest function was perhaps no longer to kill, but to invest in life through and through" (p. 139).

With these two disciplinary modes, the development of state institutions of power like the university and demographic politics of birth rates, lifespans, and migration characterized this emergent period of modern power-particularly the modern fraternal subject whose nationalist, paternalist, and capitalist homosocial boundaries were largely determined by a racialized gendered sexual logic. To put differently, Imani Perry (2018) contends the deployment of sexuality through sexologist discourse at the turn of the twentieth century made non-normative gender variances recognizable, and with that, "a 
belief in the fundamental non-normativity of some groups...deviant sexuality became definitive of group "otherness"' (p. 70). Thus, the black fraternal subject, even in its abject masculine homosocial state is predicated on the technologies of the anatomic and biological, or what Ricky Jones (2015) might define as economic anxiety and identity fragmentation in the formation of the black male self, and constituted within and against racialized gendered sexual discourse to propose a strictly heteronormative disposition. As Perry states, "The forces of discipline (as well as people reaching for liberation) revolved round the question of deviation from the ideal personhood tied to the European patriarchy category... at the same time, some were not capable of deviating or becoming deviants because they were already essentially so" (p. 70).

The fraternity, similar to Foucault's (1978) citations of the family, the army, the police, and other administration of collective bodies, therefore, acts "as factors of segregation and social hierarchization" (p. 141). Foucault locates the deployment of sexuality in the nineteenth century as the technology to produce a concrete arrangement between the anatomic and biological. In this case, the fraternal subject, configured by the discourses of the human sciences of the time, is given life in the university through its ideal manhood and sexual subjectivity. Therefore, in Ricky Jones (2015) seminal text on black male identity formation in black fraternities, it is the very unnaming of gender normativity that makes the black fraternal subject recognizable and vulnerable, within and to, institutional text.

This makes institutional black fraternal formations quite different than the race, gender, class, and sexual formations that intervened in university life during the 1960s and 70s. The post-WWII radical student movements sought to transform the institutional 
logics, or text, of the university and its universalizing of Western man. The student movements worked to displace the Western man and the epistemology that produced him by inserting "the Black, the Woman, the Asian American, the Chicano, the American Indian, the Gay, and the Lesbian, each one arguing for the end of Man and all that he represented" (Ferguson, 2012, p. 32). These movements, and the interdisciplinaries of ethnic and women's studies they produced, approached the university epistemologically as what Ferguson (2012) calls "writerly" text, "text that could be revised and rewritten" (p. 38).

However, black fraternal formations, as fraternal archive entities of the turn of the twentieth century, are part of the university's readerly function—classical text that cannot be completely rewritten even as contradictory formations within a broader archive. In other words, black fraternal formations consist of both readerly and writerly demands. Black fraternal formations have constituted new subjectivity and agency with the fraternal realm, but their entrenchment in that very system that adheres to the Western man episteme ensures the hegemony of the Americanized state, capital and academy. In fact, the readerly elements that facilitated the archival of black fraternal formations_- "the invocation of logics of identification, the investments in liberal discourses of state and ethical development, the assertions of normativity" (Ferguson, 2012, p. 39)—would be employed by power in the post-civil rights period to address and absorb these more radical student formations as a neo-biopower. Therefore, the establishment of black fraternities on the campuses of historically white universities in the 1960s and 70s, during this time of radical upheaval, is part of the disruption and recuperation of minority difference by the institutional archive. 


\section{Archiving Difference: Omega Psi Phi, the AASU and Black Studies}

In 1967, Tallahassee, the capital city of Florida, had approximately 65,000

residents. A little over twenty percent of Tallahassee residents were black. Tallahassee was not only home to FSU, but also historically black Florida A\&M University (FAMU) with FSU enrollment topping 15,000 and FAMU approximately 3,800 students (Smith, 1994). Until 1958, when a black applicant was admitted to the University of Florida College of Law, Florida public higher education system was completely segregated. FSU admitted its first three black students in 1962 with cautious pleas of tolerance from both the local Tallahassee and campus newspapers (Palcic, 1979). White citizens did not want Tallahassee to be the scene of another integration spectacle as with the University of Mississippi that same year when James Meredith integrated with intervention from the federal government. The Tallahassee Democrat reported that 137 of 234 historically white public colleges in the South had black students at the time and the black students attending FSU had come "quietly" and "without backing or pressure organizations seeking to force issues" (as cited in Palcic, 1979). In 1967, the FSU faculty senate and student government association supported limited institutional integration measures. This was in part due to the perception of prestige, as competitive and aspiring institutions were recruiting and admitting students of color (Palcic, 1979). During the 1960s, the number of black students on white college campuses in the South increased from 3,000 to 98,000 students (Patton, 2005). By 1968, the black student population had grown to 50 students at FSU.

Black students at FSU faced an unwelcoming, alienating and hostile environment. Black students experienced harassment and discrimination in all aspects of college life, 
but particularly from white fraternities. A few of the reported incidents with white fraternity members included jeering black students with confederate flags and an incident where a white fraternity member burned a hole in a black student's shirt at a football game (Palcic, 1979). The harassment from white fraternity members often led to fights with black students. Black students were also barred from white fraternities and sororities. The year prior to the black men establishing Omega Psi Phi on campus, a black student attempted to join a service fraternity and was pledged but never initiated due to the racism within the fraternity system. As historian James Palcic (1979) states, "The incident was a clear sign to several black men that they would not be welcome in any of the all-white fraternities in existence" (p. 76). Omega Psi Phi acted as a social and political impetus, bringing the black students together mainly through parties, but these gatherings of otherwise alienated black students would lead to the formation of a black student union.

Student organizations like black student unions played a pivotal role in the establishment of black studies on college campuses (Rojas, 2007). These organizations acted as mobilizers for black student politics, protest and grievances against the university, organizing that would lead to the establishment of black studies. The political ideology that fostered the formation of black student unions and the framework for black studies arose out of the post-civil rights black nationalist movement. Though the civil rights movement spurred the efforts that lead to the integration of historically white college campuses, many black students and activists became increasingly frustrated with the liberal integrationist ideology after the passage of major civil rights legislation beginning in 1964. Black students and activists believed that social, political and 
economic relief for black people were not happening fast enough, and thus, black folks were not being taken serious by white society.

Furthermore, some black intellectuals and students thought the civil rights movement failed to address institutional change in terms of recognizing black identity and achievements (Rojas, 2007). The black power movement, influenced by black nationalist organizations such as the Revolutionary Action Movement and later the Black Panther Party, honed this institutional critique of American nationalism, liberal capitalism and the civil rights movement to conceptualize the black experience of living in America as a colonized status (Hamilton \& Carmichael, 1967). As a result, to adequately address institutional racism in the US, black power more assertive or militant ideology included a desire for a new black consciousness where African Americans would define and rename themselves, reclaim their history, and galvanize a community with a sense of panAfricanism (Hamilton \& Carmichael, 1967) — thus, radical black nationalists advocated for African Americans to have autonomy in their education.

Black power became the chief organizing ideology for African American students on college campuses in the late 1960s and early 1970s-formative in forming black student unions and instructive for their push for black studies. Fabio Rojas (2007) writes, "Students could be either 'black,' meaning that they identified themselves in opposition to 'whitey,' or 'Negro,' which meant accepting social integration and economic advancement as the primary goals of college education" (p. 33). This type of black student activism was epitomized at San Francisco State College where the Black Student Union initiated the Third World Strikes of 1968 that led to the founding of the first black studies department in the country. Thus, it was in the co-curricular college setting that 
the first interdisciplinaries were formed. As Ferguson (2012) indicates, "during the postcivil rights period, there was a rapid development of various interdisciplines...we might not only include the literal programs and departments of ethnic and women's studies, but also take into account new admissions policies, 'campus cultural centers, [and] minority faculty recruitment and hiring"” (p. 33). Black student unions, then, presented a countercultural space for the reconfiguring of how the university was materially embodied, challenging institutional interpretations of subjectivity and communal engagement.

However, FSU black student activism occasioned a slightly different development than most co-curricular interdiscipline interventions. Instead of being rooted in a radical black nationalist ideology like most interventions of the time, the initial black student mobilization arose out of a black fraternal formation. Omega Psi Phi, formed in the fall of 1967, facilitated some the first social gatherings for black students that allowed black students to discuss some of their common experiences of discrimination and hostility on campus. These students recognized there was a need for some type of political organization to address their grievances, but it wasn't until the assassination of Martin Luther King, Jr on April 4, 1968 that the students were galvanized to form a formal black political organization on campus.

King's assassination sparked riots in several U.S. cities, including disturbances on FAMU campus. At this time, FSU black students became more serious about forming an organization to channel their grievances with the institution. The day after King's assassination, the FSU administration met with members of Omega Psi Phi. It's not clear on whether this was intentional or not, given the fraternity was seen as more of a social than political organization (Palcic, 1979). However, this may speak to a type of 
university recognition or the biopolitics of the fraternal subject. Nevertheless, the administration wanted to field black students' reactions to King's death, and to their surprise, found that black students did not feel welcomed on campus. In fact, in what was considered an emotionally intense meeting, the students presented the university with a list of grievances, including discriminatory housing procedures and harassment from campus security. The university responded to by establishing a Human Relations Committee, investigating complaints, and hiring a part-time counselor to work with black students (Palcic, 1979). Ten days later FSU black students formally formed the AfroAmerican Student Union (AASU).

The ultimate goal of the Afro-American Student Union was to be integrated into the mainstream of campus life, and in order to do so, they made strategic maneuvers to assure that happened. Palcic (1979) found there was a stark difference in the tone and temperament set by the students establishing the union than the grievances expressed days earlier. Palcic states, "To some extent, need to gain approval of the Student Senate and the administration may have tempered the tone" (p. 83). For instance, the AASU preamble more so reflected the students' goal of campus integration than their strong emotional disappointment and displeasure for the university and their subjugated experiences on campus (Palcic, 1979). The students intentionally chose the name "AfroAmerican" instead of "Black," as some of the early leaders of the union note, "We wanted to go through all of those steps that were necessary to become a charted campus organization...We didn't view ourselves as a militant group...We looked upon ourselves as a socially oriented group" (cited in Palcic, 1979, p. 84). The organization was eventually approved by the Vice President of Student Affairs in January 1969. 


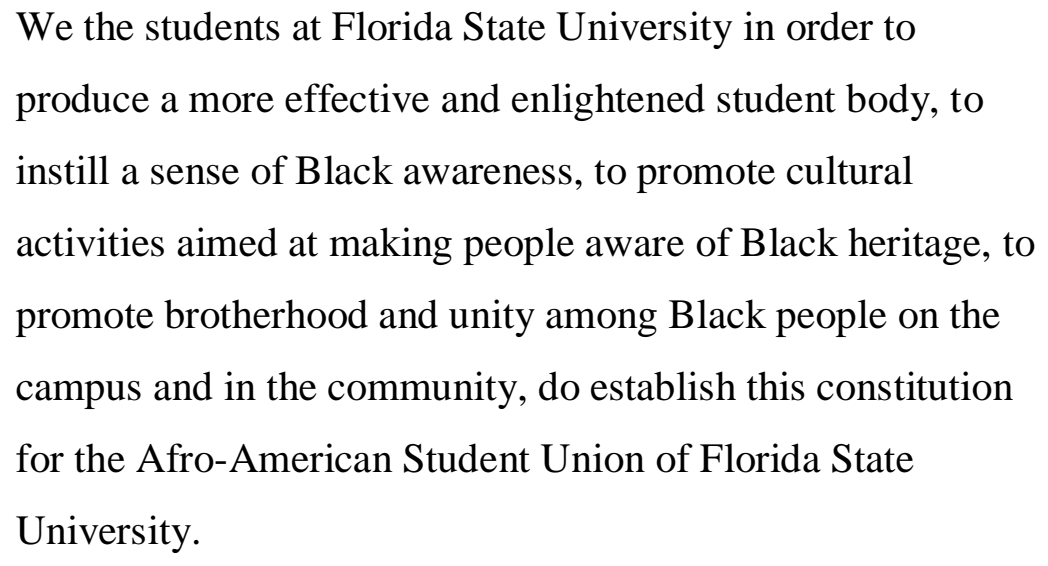

Figure 1. Preamble to the African American Student Union Constitution at FSU. The organization was formally stablished on April 15, 1968 (cited in Palcic, 1979).

The acquisition into the campus logics was vastly different for more radical student groups. During the winter of 1969, when the Afro-American Student Union had gained university recognition, the Students for a Democratic Society (SDS) was also seeking recognition. SDS was seen as a confrontational organization, being more vocal and visible with their campus demonstrations. However, as a more radical group, recognition was denied and the group was barred from meeting on campus. The university president actually got a court injunction to prevent the group from meeting on campus which led to the university employing county police with "fixed bayonets" to prevent any such meeting, arresting several students attending a SDS meeting (Palcic, 1979).

The contrast between the AASU and SDS was also witnessed in their strategies to establish a black studies program. The AASU, under the leadership of Fred Flowers, a member of Omega Psi Phi, proposed the establishment of a black studies program, in which SDS supported and demanded action from the university. As Palcic (1979) states, 
"The Afro-American Student Union employed a strategy different from that of SDS...the ASSU chose to work through sympathetic faculty and administrators to try to accomplish their objectives" (p. 95). The AASU was able to establish a preliminary black studies program, a list of seven courses within various departments was designated as a "program" in the spring of 1969.

The Afro-American Student Union would eventually adopt a more radical black power-oriented perspective and approach — at least in name. As black power became more popular nationally and locally, with a campus lecture by Eldridge Cleaver in '68, the Afro-American Student Union changed their name to the "Black Student Union" though Palcic (1979) found no significant ideological differences in the function of the organization. Though the AASU was established as an avenue for campus cultural awareness and black solidarity, the organization had taken more political and confrontational measures following racist campus incidents in the fall of ' $68 .{ }^{14}$ Nevertheless, the AASU tended to take a calculated or conservative approach, consisting of a more compromising resolve between the organization and the university administration on racially charged issues. As an organization with a clear intent on incorporation into the structures of campus life, the AASU walked a fine line in how it would respond to racism on campus. As seen with SDS, a more radical stance would indeed jeopardize any type on institutional recognition; however, seeking change solely through institutional bureaucracy often meant limited results. Thus, an incorporation with restrictions - both affective and material.

\footnotetext{
${ }^{14}$ After a black student was harassed as football game by a white fraternity member, the AASU presented a list of demands to the university which included banning the play of "Dixie" at football games. The AASU would later suggests that a total ban was not necessary as long as the song was not used as an official symbol of the university.
} 
This more calculated approach by the AASU is indicative of power's new mode. A mode, as Ferguson (2012) writes, "of incorporating difference for the good rather than disruption of hegemony" (p. 34). In this incorporation, black fraternalism plays an integral part. It's at the root of the black student activism, and thus, provides the textual material for organizing and mitigating power effects. I'm suggesting that as an archive entity, the black fraternal formation acted as a prescripted readerly text, or as E. Patrick Johnson (1998) theorizes about the black church, a place "narrated in advance" that disciplines the body. The black fraternity is versed in the canons and orthodoxies of the institution, and therefore, subverts the radical and writerly potential invested in black student activism — making them always already apprehensible for power's affirmation.

To better illustrate black fraternal textuality, we can compare the FSU's black student activist origin with that of a similar institution and black student protests during this time. Joy Williamson (2003) documents the post-civil rights black student movement on the campus of University of Illinois. Though the University of Illinois isn't a southern institution, the institutional context in which black students organized was very similar to institutions like FSU. Black students at the university in the 1960s experienced a campus and a city that was largely segregated and white residents' attitudes and treatment of African Americans resembled that of southern states (Williamson, 2003). What also makes this a comparable case study, is that, unlike southern white colleges and universities, which would not charter BGLOs until 1970s and 80 s, a reaction to the black student interventions, black fraternities and sororities had a presence on the campus before the post-civil rights protests. The first black students attended the university at the turn of the twentieth century, and by the 1940s, there were 
five BGLOs on campus. By 1967, approximately 223 black undergraduate students attended Illinois (Williamson, 2003).

Like the experience of the black students at FSU, African American students at Illinois experienced isolation, discrimination, and overt hostility on campus. As a solution to the isolation, many black students joined black fraternities and sororities. Influenced by the black nationalist and liberation struggle, in 1967, black students formed the Black Students Association (BSA). Again, the choice in name reflected the ideology of the time. Williamson (2003) states, "By the late 1960s, Negro had become a pejorative term and had been eclipsed by Black — a racial self-referent as well as a particular ideology embodying political, cultural, aesthetic, and organizational components" (p. 35). As such, Williamson goes on to write, "The new organization adopted the motto 'We hope for nothing; we demand everything,' linked to the emerging black power movement, and declared itself the organization through which Black students would force the university to recognize and act on Black issues” (p. 47).

The BSA name and motto is a stark contrast to the AASU name and aim predicated on integration and campus recognition. However, the BSA also engaged black fraternalism in its conception. Black fraternalism was seen as a material and ideological threat to the formation of the BSA. Williamson (2003) recalls the internal debate within the BSA on whether a black student could be "dedicated to aggressive social protest and social reform and be Greek at the same time" (p. 48). Though BGLOs were the most powerful black organizations on campus and served as a social outlet for many black students, their relevance didn't translate into the political realm. Williamson states, 
"Consistent with their constitutional mandates, Black Greek organizations did not throw their weight behind BSA or aggressive social protests" (p. 48).

In fact, BGLOs were seen as antithetical, and even saboteurs, to the radical black liberation struggle. Black fraternity members saw BSA as a threat to their power and was hostile towards its formation. As a result, BSA membership became a sort of demarcation between ideal black Greek subjectivity. Dan Dixon, a member of Kappa Alpha Psi and one of the few BGLO members who held a leadership role in BSA, recalls, "Some [BGLO members] said, 'Leave them alone...they failed at everything else. That will be their Greek group, CORE, SNCC, whatever"' (cited in Williamson, 2003, p. 48). When the BSA held their first elections, BGLO members tried to sway the elections in favor of their members to gain control of the organization, by which, black non-Greeks were concerned that BGLO members would taint the BSA purpose. In the end, Dixon was the only black fraternity member elected to a leadership role, and although he was president, being the only fraternity representative Dixon considered his stint in leadership as "in name only" (Williamson, 2003).

The conflict between the BGLOs and the BSA at Illinois brings black fraternalism's writerly function to bear. Historical accounts of the internal workings of the AASU at FSU are limited and scholars have rarely theorized the organizational meaning-making in relation to its connection to Omega Psi Phi. However, the BGLO/BSA conflict at Illinois allows us to speculate the fraternity's impact on the AASU's more conservative approach. In the case of FSU, black fraternalism would continue to inscribe how minority difference was configured within the institution. Even after the AASU adopted a more political and confrontational disposition, including 
changing its name to the Black Student Union (BSU) by 1970, by the mid-seventies the organization would begin to compete with the increased number of black fraternal organizations (three by 1972) for black students' engagement (Palcic, 1979).

Though there is no indication that the BSU at FSU experienced the level of conflict with black fraternities witnessed at Illinois, taking both cases, it does suggest that black fraternal formations' readerly/writierly dynamic, or as Ferguson (2012) puts it, "the simultaneity of oppositional stances and interpellative states" ( $p$ 39), contributed to the contradictory standpoint of minoritized student life. On one hand, black fraternal formations supported the writerly intent of the black student movements, particularly in terms of providing institutional space for black students to counter isolation and build conscious-raising capacity. On the other hand, the homosocial archive of black fraternal subjectivity induced individuals and organizations into institutional logics of recognition, inclusion, and participation - another form of indifference making that moved individuals and organizations away from radical (re)arrangements and assisted power in its "forming and re-forming institutions according to the advancement and regulation of minority difference" (Ferguson, 2012, p. 40).

\section{The New Black Student and The Black Greek Paradox}

The article headline in the December 1983 issue of Ebony magazine read, "Fraternities and Sororities: A Dramatic Comeback on Campus." As indicated in the article, the 1980s was suppose to be a new golden age in black fraternal life after experiencing waning popularity and declining membership in the previous two decades of the 1960s and 70s. This declining support was largely due to the radical post-civil rights student movements as seen at FSU and Illinois that were happening on college 
campuses across the country. As black students adopted a black power sentiment and took a more critical stance towards their universities, BGLOs' relevance and purpose was often called into question for its elitism and apolitical posture, causing students to bypass black Greek participation.

However, there was a paradox to this lack of interest in black fraternalism. As seen with FSU, black students were integrating many historically white college campuses in the South, and as these students were forming black student unions and making university demands for black faculty and students, cultural centers, and black studies, so to came black fraternity and sorority chapters. Walter Kimbrough (2003) states, "Greeklettered organizations emerged soon after on these campuses, almost repeating the history of the groups founded on predominately White campuses" (p. 97). Therefore, at a time when the overall interest in black fraternalism was waning, BGLOs experienced a massive chapter expansion. Kimbrough notes:

Alpha Kappa Alpha (AKA) Sorority never added more than five new undergraduate chapters in any given year prior to 1969 . Yet, with rapid integration of Black students on predominantly White college campuses, chapters of Greek organizations were soon springing up. Between 1969 and 1979, AKA added at least ten new undergraduate chapters per year, with at least twenty chapters in three of those years. (p. 53)

This phenomenon wasn't just experienced with black sororities, black fraternities also benefited from the desegregation of and political movements at historically white colleges and universities in the South. Between 1950 and 1970 there were only ten chapters of Kappa Alpha Psi in its southern region (Florida and Alabama) and the 
fraternity chartered eleven new chapters, all at predominately white institutions, in the 1970s alone (Bryson \& Pruitt, 1999).

If BGLOs were seen as antithetical to the type of movements taking place on college campus, a time when black students were entering higher education more than any other time previously but participating in black fraternalism less frequently, the question must be asked: How did charting BGLOs become a result of black student activists' radical interventions? Furthermore, what dynamics spurred the renewed interest in black fraternalism by the 1980s? One explanation for this development may have to do with the expanded responsibility of the university to non-university subjects. As discussed in the previous chapter, Ferguson (2012) argues that contrary to popular belief, the university was never a preexisting, autonomous entity that only encountered the state and the people through a type of one-direction, deferential relationship. Instead, the university was always already an articulator of state interests and responsible for a non-university agency reflective of an ideal citizenry - making the university an epistemological training ground for the state and capital. With the post-WWII absorption of minority difference into the academy's knowledge regime, the university's responsibility to a "non-university agency" expanded to include subjects previously excluded from the ideal citizenry. As indicated by the student movements of the late $60 \mathrm{~s}$ and 70s, this includes people of color and gender and sexual minorities.

Cultural centers and black studies programs added the university in extending its reach of responsibility, and with that responsibility came a level of regulation. This is best illustrated in the changing definition of what it meant to be a "successfully" black college student. Prior to the 1950 s, what was considered being a "good" or "ideal" black 
college student was predicated largely on academics and survival either within white higher education institutions or within racially segregated communities for many students at black colleges. Therefore, black students saw themselves as students first and did what was necessary to keep the "peace" in order to be academically successful (Smith, 1994; Williamson, 2003). However, with the civil rights movement and the following black power movement, the concept of black student identity changed. The black student was no longer characterized solely by a social and political "sheltering" and academic prowess, but increasingly by a social consciousness and commitment to a black community uplift. Williamson (2003) states, "This new combination emerged parallel to the burgeoning black power ideology, one that included preservation of Black identity, preference for an ethnically centered curriculum, and an orientation toward collective racial advancement" (p. 31). Charles Smith (1994), in his study of social unrest at HBCUs in the late 1960s, also notes the social pressure black students encountered to conform to this new ideal student:

As the expression 'nigger-lover' is an effective deterrent to sympathetic identification with the problems of Negroes among whites, so the expression 'handkerchief-head' is used among present day Negro students to refer to those afraid and unwilling to join the battle for greater civil rights; and is an epithet so powerful that students will go to almost any lengths to avoid its application of them individually or collectively. (p. xix)

The new campus cultural centers, along with black studies programs, then, became the vehicle for the new black student to bridge the divide between campus and the "nonuniversity" black community. Cultural centers acted as homes for not only black college 
students, but in many cases, black nonstudent residents and supported black students in developing community outreach initiatives when there were none provided by the university (Williamson, 2003).

As these interdisciplines - the cultural centers and black studies programs — took form within the university, they had to contend with the institutional readerly function, or how the university acts as an incubator particularly for U.S. nationalist aims. The student movements subverted the university's responsibility function to include black communities, but also expanded its power/knowledge domain. Ferguson (2012) writes, "While the civil rights and black power movements may have objected to the paternal purposes set down by U.S. liberal capitalism, those movements had no quarrels with the intellectual and institutional edict to realize a paternal mission” (p. 135). By encompassing the university's paternalistic mission, the interdiscipines took the mantel of responsibility and reimagined black communities and the agents who would manage them within the logics of the university's nationalist archive.

Through the interdisciplines, concepts such as "grass roots" became a tool for affirming and managing non-university minority difference-bringing into view a new "love object" for the university. These "grass roots" objects circulated "stories of group solidarity, identity, and origin" (Ferguson, 2012, p. 114) and signaled "a movement of unprecedented agencies and dignities at the same time that the object let loose regulations that few people had ever known" (Ferguson, 2012, p. 114). Ferguson (2012) extensively focuses on what this means for the minoritized communities hailed by the institutional logics of responsibility through "grass root" concepts. However, what isn't detailed is the impact this development had on the agents who would largely facilitate narrowing the 
gap between the university and the community — the students who were filling the cultural centers and enrolling in black studies programs - the new ideal black student.

As Ferguson (2012) suggests, notions of responsibility that undergirded the civil rights and black power movements were informed by the knowledge/power regimes of the Western academy. Both movements worked to counter academic discourses that constructed black people, specifically black men, as gendered degenerate and sexually perverse. For the more liberal civil rights movement, this meant propagating a regulated black public persona to meet its integrationist and survivalist tactics. For instance, Marlon Bailey (2013) writes about how in Detroit during the 1940s a widely-known queer black minister named Prophet Jones led one of the largest congregations in the city until the 1950s when the civil rights movement came to Detroit. At that point, civil rights leaders declared that Prophet Jones' sexual perversions would hinder black peoples' pursuit of full citizenship. The movement for black studies, however, was mainly informed by black nationalism as articulated through the black power movement. In black nationalism's contestation of European colonial discourses, black nationalism inadvertently adopted a European nationalist model which consisted of an ethnic absolutism or racial essentialism that obscured differences and complexities within the race (Appiah, 1992; Gilroy, 1993; Scott, 2010). This adoption of a European model of nationalism was fashioned through a historical discourse, or the forming of a type of historiography "grass roots."

The radical student movements were precipitated by a global postcolonial liberation struggle where once colonized nations were forging their independence from their colonial imperialist. This postcolonial struggle was too an indication of power's 
new archival form. As Frantz Fanon ([1961] 2006) warns of the pitfalls of national consciousness, emerging nationalism can be co-opted by neocolonial forces. Fanon explains that the national middle class, or bourgeoisie, typically becomes the chief stakeholder of the ex-colonial nation; however, the national middle class isn't financially capable to carry out the development needed for a newly independent country (due to colonialism) which forces them to turn to outside benefactors or even the "mother country." As the national middle class reliance on outside capitalists grows, so do their wealth and greed, their interest and allegiance to their native nation subsides and opportunities of prosperity are withheld from the people-helping to recreate similar conditions of colonial control. Therefore, in archival power's custom, freedom and management are intertwined as ex-colonial nations are "gathered together into the library of modern nations" (Ferguson, 2012, p. 21).

History also became an archival tool of freedom and management for a neocolonial-affected black nationalism. Historiography has played a significant role in interpreting and producing knowledge to fuel nationalist movements in post-colonial African diaspora. Understanding Africa's pre-colonial past was seen as an avenue to restore the dignity and humanity of a once colonialized people. Therefore, the work of African historians was contextualized under this pretense and early African intellectuals worked in conjunction with nationalist leaders. Hannington Ochwada (2005) states, "The scholarship of the 1960s searched for heroes in the African past" (p. 8). As a result, the overarching criticism of this historical approach is that it has essentialized and romanticized African history and indirectly stripped away its dynamics and complexity 
including, elements such as dictatorial and authoritarian precolonial practices that didn't fit post-colonial socialist agendas.

Also, noticeably missing from these early historiographers' intellectual works were a complexity of sexualities. The glorification of African heroes, chronology, and military activities were inherently masculine and androcentric — helping to produce patriarchal forms of nationalist ideologies and narratives. Furthermore, in an attempt to "normalize" Eurocentric colonial accounts of African sexual morality which typically described African sexuality as wild, out of control or exotic (Gaudio, 2009; Ikpe, 2004; Izugbara, 2004), African historiographers colluded to narratives of "traditional sexuality" in which "a hearty yet wholesome heterosexual appetite stood in proud opposition to the dominant, emasculating colonial discourse" (Epprecht, 2009, p. 1263). Consequently, countering dominant discourse often means working within those discursive boundaries.

As a black nationalist movement, history became a bedrock of black studies and their cultural center counterparts. For instance, when the FSU Black Student Union (BSU) established its cultural center in 1970, their primary objective was "to foster the growth of a pro-black attitude in the Black community through the teaching of African and Afro-American history and culture" (Palcic, 1979, p. 127). With that, the black interdisciplinaries' historical project acted as a "grass roots" endeavor that informed an ideal manhood and responsibility. At the University of Illinois, adhering the pronouncements of blackness as articulated by the Black Student Association (BSA) and its black power ideology, meant conforming to stringent and narrow definitions of blackness for the sake of unity (Williamson, 2003). One of the central ways the BSA demarcated "appropriate" blackness (as opposed to being negro) was through a "Blacker- 
than-thou" philosophy that synonymized black with black manhood, "with Blackness being a reclamation of Black masculinity" (Williamson, 2003, p. 107). Williamson (2003) states, "The emphasis on race pushed issues of gender to the periphery" (p. 107).

This development within the radical student movement was disorienting for some black students, as one black "brother" wrote in a BSA publication about black women, "he was told to respect and protect her, while at the same time he was told that she would effectively castrate him if he displayed emotion and weakness" (Williamson, 2003, p. 107). Like the other black student movements taking place across the country, the black power adherents at Illinois subscribed to and advocated conservative gender roles. In fact, the cultural center at Illinois offered popular courses on black manhood and black womanhood based on black nationalist objectives. As Ferguson (2012) states, "As it inherited the civil rights and black power notions of responsibility, black studies would lift up black cultures only by offering institutional models for disciplining gender and sexual eccentricity" (p. 137). Therefore, black studies programs and cultural centers institutional development placed its ideal agent of responsibility, the black student, within the canonical realm of institutional logics. The new black student was not only community conscious-oriented, but also cis-heteropatriarchal-oriented.

The new black student would take these notions of responsibility and help to formulate an unidimensional black political framework based on consensus issues typically defined by and in correlation with heterosexual cis-black men (Cohen, 1999). As the black nationalist philosophy was transcribed in the formulation of an academic discipline, it carried with it this unidimensional political framework where black studies was dominated by male faculty and heteronormative content. However, black feminists 
challenged this paradigm within black nationalist movements and in the academy. For instance, Michelle Wallace's Black Macho and the Myth of Superwoman (1978) provided a critical analysis of black liberation movements' patriarchal posture. Though her work was well received in feminist circles, it did not get a warm welcome in black studies networks at the time. Black studies scholar Robert Staples published a response to Wallace's work in 1979, entitled "The Myth of Black Macho: A Response to Angry Black Feminists," in which he defended black male patriarchy and dismissed black feminist critiques. Staples' rebuttal was then followed by a response from Audre Lorde ([1979] 2007), who stated, "The black male consciousness must be raised to the realization that sexism and woman-hating are critically dysfunctional to his liberation as a black man because they arise out of the same constellation that engenders racism and homophobia" (p. 64). This discursive exchange illustrates the "grass root" black nationalist influence in the development of black studies and how black feminism aimed to change the discipline's discourse on gender and sexuality.

Nevertheless, black women would go on to forge a movement for black women's studies, a radical emancipatory education centered on the lives of everyday black women, including black lesbians (Hull, Scott, \& Smith, 1982). Akasha Gloria Hull, Patricia BellScott, and Barbara Smith (1982) posit black women’s studies “will not be dependent on women's studies, black studies, or 'straight' disciplinary departments for its existence, but will be an autonomous academic entity making coalitions with all three" (p. xxvii). However, as E. Patrick Johnson and Mae G. Henderson (2005) points out, in a primarily androcentric black studies, sexuality continued to be a contentious line of demarcation within the field given the history of race and sexual deviance within the US. 


\section{The Closing of Critical Universes and The Bureaucratization of Diversity}

As a result, the conceptualization of a new black student foreclosed critical universes in black student life. In E. Patrick Johnson's (2008) groundbreaking oral historiography, Sweet Tea: Black Gay Men of the South, Johnson discovers a vibrant, yet surprising black queer life on the campuses of historically black colleges and universities:

My surprise stems from what I had always experienced as a thinly veiled conservatism on black college campuses, especially with regard to homosexuality or gender nonconformity. Imagine my shock, then, when I learned about basketball stars sleeping with their male roommates...Or, drag queen homecoming queens, college professors 'keeping' young male students, nine-man orgies. (p. 284)

The narrators in Johnson's anthology illuminates a time where there was relatively more gender and sexual variance and affirmation within the life of black college students. Johnson states, "From the narratives presented here, one gets the impression that these institutions were much more tolerant during the 1950s and 1960s than they are today" (p. 285). One narrator who was a student during this time talks about an open queer organization on campus, "...the gay students formed them an organization called the JUGGA, Just Us Gay Girls Association....and they marched on the campus" (Johnson, 2008, p. 288). There was also an indication that the once "sheltered" life of the black college student lent itself to a greater queer acceptance and understanding, with one narrator suggesting:

I think when you live on a small black campus every day, people know. You see these folk every day at breakfast, lunch, dinner. You go to classes with them. 
You just know. And people just kind of knew. And all of us gay kids, we kind of gravitated to one another. (Johnson, 2008, p. 292)

However, post-integration, as minority difference and the new black student and his paternal responsibility to the black community was being canonized within the academy this all changed, as Johnson states, "The narratives of younger men...whom attended college in the 1980s, suggest that things were more clandestine” (p. 285).

Critical universes were further closed through the bureaucratization of diversity in higher education. Whether it was the University of Illinois or Florida State University, the pressure and demands made by black student protests to shift the epistemological and ontological structure of the university was met with an expansion of administrative services. In the wake of the Kent State and Jackson State student demonstrations in 1970, where the national guard and state police, respectively, killed and wounded several students, President Richard Nixon established a Commission on Campus Unrest which would issue a report on campus protests. While the report acknowledges university limitations in addressing the needs of its students and the relevance of student protest, it also establishes "diversity" as a national and institutional value that must be protected from student activists - constructing activists as irrational and criminal to the U.S. archive (Ferguson, 2017). Ferguson (2017) writes, “'Tolerance' and 'diversity' were instead ways of saying 'Society must be defended' - that is, protected from the student, who was understood to be criminal from the start" (p. 23). The report goes on to suggest the adequate manner by which universities should handle student grievances is through an ombudsman method:

The ombudsman is an individual who acts as a mediator and fact finder for 
students, faculty members, and administrators. To be successful, the ombudsman must have both great autonomy and support of the university president... These men and women are sometimes recent graduates. For example, a young, independent, black administrator often serves in the role of spokesman, mediator, and advisor for black students. Because these administrators have the confidence of the students, they can suggest practical modifications of student demands without being automatically branded as 'sell-outs.' They can formalize complaints or proposals and bring them to the attention of appropriate faculty members and administrators. (as cited in Ferguson, 2017, p. 25)

Essentially, while these new administrative services symbolized institutional progress and accommodation of difference, they also worked to curtail and individualize the students' more radical collective institutional critiques.

The establishment of ombudsmen would coincide and be followed by diversity committees, offices and officials. Ferguson (2017) writes, "Folding diversity into the bureaucratic machine and moving it into the administration was one way of mitigating student demands and preventing them from becoming matters of social transformation" (p. 27). Bettina Shuford (2011) chronicles the historical and philosophical development of diversity offices, or multicultural student services, in higher education. Though these entities provided spaces and services for racial and ethnic minorities, institutional transformation was not an essential concern. Shuford identifies three philosophicalhistorical phases of development, beginning with "the Golden Rule," predicated on everyone being treated the same, to "righting the wrongs" of marginalized groups, to the contemporary "valuing differences approach," or multiculturalism. Here, diversity 
becomes as Margaret Andersen and Patricia Hill Collins (2013) contends, "The very term diversity implies that understanding race, class, and gender is simply a matter of recognizing the plurality of views and experiences in society- as if race, class, and gender were benign categories that foster diverse experiences instead of systems of power that produce social inequalities" (p. 8). Indeed, the administrative affirmation of race, gender, class, and sexuality through guise of diversity has facilitated a steady move away from the intended purpose of the radical student movements (Ferguson, 2017).

This bureaucratic pull has also led to an increased specialization in administrative produces. Bureaucratic specialization constituted the "narrowing visions of wholesale institutional change" (Ferguson, 2017, p. 26), and with that, the narrowing of student subjectivity. This specialization took place mainly in the field of student affairs, where many diversity units where housed and operated. During this time, understanding how students change and grow, or student identity development, became a hallmark of the field of student affairs. As practitioners and scholars who would manage and facilitate diversity committees, offices, and initiatives, understanding the new black student was critical. As such, psychologist William Cross's Theory of Nigrescence (1971), which attempted to capture the African American identity shift from negro-to-black in a psychological model, became a foundational theory in both Africana studies and higher education student affairs.

Though Cross's theory was a critical intervention for fields where discourse on black identity was marginal and predominately focused on notions of self-hate, the theory still subscribed to the disciplinary positivist epistemological worldview. Susan Jones and Elisa Abes (2013) state, “This means [identity] development was often presented as a 
linear and sequential trajectory, and in a series of stages, phases, statuses, or vectors" ( $p$. 23). Black identity, then, became essentialized and conceived as a single-self, and consequently, a single-issue mode of difference. In theorizing about new approaches to identity research, psychologist and women's studies scholar, Lynn Weber (1998) outlines how these disciplinary approaches have produced single-self, single-issue identity constructions:

When we say that race, gender, and sexuality are social constructs, not fixed biological traits, we also mean that we cannot fully capture their meaning in everyday life in the way that social scientists often attempt to do by employing them as variables in traditional quantitative research. When race, gender, and sexuality are treated as discrete variables, individuals are typically assigned a single location along each dimension, which is defined by a set of presumably mutually exclusive and exhaustive categories. This practice reinforces the view of race, gender, and sexuality as permanent characteristics of individuals, as unchangeable, and as polarities - people can belong to one and only one category. (p. 18)

The development of Cross's theory, like the development of black studies, created an institutional template for subsequent identity theories, including homosexual identity (see Cass, 1979) and women's identity (see Josselson, 1987)—canonizing race, sexuality and gender as one-dimensional, parallel configurations instead of intersecting formations.

As Judith Butler (1998) and Ferguson (2012) have alluded, the student movements were not solely responsible for the dissemination of essentialist discoursesbureaucratic protocols and metrics have a strong claim in the matter. Ferguson states, 
"Fixed and stable notions of race might thus be understood not simply as epistemological constructions but as administrative procedures as well" (p. 106). In the bureaucratization of diversity in higher education, these theories of identity provided the hermeneutical framework for how institutional entities would be imagined. In student affairs that meant (straight) African American cultural centers, (mono-ethnic) diversity offices, (white) women's centers, and (white) lesbian and gay centers.

\section{A Black Fraternal Will to Institutionality}

This brings us back to the initial questions posed about the reemergence of black Greek life in the aftermath of the post-civil rights student protests. How did charting BGLOs become a result of black student activists' radical interventions? Furthermore, what dynamics spurred the renewed interest in black fraternalism by the 1980s? The paradox of the black Greek resurgence was driven by the paradox of power in this moment, one where "administrative power had to restrict the collective, oppositional, and redistributive aims of difference at the same time that administrative power had to affirm difference to demonstrate institutional protocols and progress" (Ferguson, 2012, p. 214). As previously discussed, with the intervention of the interdisciplinaries came a new black student. This new black student was not necessarily representative of the students who formed the radical protests on college campuses, but an institutional reading, or subjection, of those students. In the interdisciplinaries" "grass root" efforts, the black student was regulated and canonized in student development theories, workshops and courses that produced a one-dimensional subject, ideal for power's calculus. In this sense, the conceptualization of the ideal black student is constituted by what Max Horkheimer ([1947] 1974) might characterize as formalized or subjective reason where 
the black student becomes a form of knowledge, or will to truth. As a "grass roots" endeavor, the black student becomes a means-to-an-end, and thus, "it also becomes fetishized, that is, to have an existence and innate worth that exists separately of the thinker" (Brookfield, 2005, p. 71). Our understanding of the black student within the institutional context becomes a veneer of its actual self. The black student is then conceived as always already a cis-hetero subject, demarcating between rational and irrational subjectivity and social formations. In a post-civil rights era where race, gender, sexuality and class are making critical interventions in university life, this form of subject affirmation is powers attempt to neutralize and work through difference, compelling identification and conformity with not only this new black subjectivity but also its institutionalization.

Subsequently, the chartering of black fraternities was a will to institutionality —an administrative measure to exalt its ideal subject, subvert the redistributive efforts of radical students, and constitute the signs of racial accommodation. Ferguson (2012) writes, "We may call this incorporation of modes of difference and the calculus that seeks to determine the properties and functions of those modes as a will to institutionality" ( $p$. 214). Ralph Bryson and Everharding Pruitt (1999) note that the upsurge of undergraduate chapters of Kappa Alpha Psi during the 1970s was because student affairs offices at predominately white institutions were "quite willing to cooperate in the establishment of chapters" (p. 208). They go on to state, "The need to shed a racist image and the desire to recruit Black students for athletic programs and to qualify for federal funds also a part of the consideration" (p. 208). Chartering black fraternities, then, acted 
as a form of interest convergence in the post-civil rights higher education political climate.

The civil rights era helped to broaden the U.S. democratic archive; to use Charles Mills' (1997) terminology, the social, political and moral contracts were extended to people of color - the explicit de jure subjugation was discredited. However, the terms of the "racial contract" remained intact, or were rearticulated, in ways that a de facto racialization and racism remained unchecked throughout U.S. life post-civil rights, making way for a pattern of "racial contradictions" in which institutions claim to be "color-blind" and "post-racial" without any fundamental change in the social epistemology and ontology that caused the previous explicit systems of racism (Mills, 1997, Omi \& Winant, 2015). According to legal scholar Derrick Bell (1980), one of the ways these racial contradictions were formed was through interest convergence, or the idea that racial progress for people of color could only be achieved at the benefit of whites or white institutions. As an indication of the U.S. archival function, Bell states, "The fourteenth amendment, standing alone, will not authorize a judicial remedy providing effective racial equality for blacks where the remedy sought threatens the superior societal status of middle and upper class whites" (p. 524). The fourteenth amendment has been paramount for minoritized social movements in the U.S. to challenge discrimination and their second-class citizenry. However, as Ferguson (2012) writes about the archival function of the amendment, "Out of the Fourteenth Amendment came a new ethical project for the American nation-state, one that would try to administer difference for the expansion of national power and territory" (p. 24). Here, the resurgence of black Greek life is propagated largely by historically white institutions to 
enhance their economic and nationalist standings. Instead of solely conceptualizing “students as figures of disorder" (Ferguson, 2017, p. 25), with the black student canonized in institutional and administrative logics, the black fraternal subject can now be an alternative architype to the radical black activist-inciting a certain docility in the incorporation of minority difference. In other words, to preserve white power structures, the indictor of institutional inequity would be impressed and enlisted in power's archive.

A change in black Greek discourse also assisted in this institutional reemergence of the black fraternal subject in the wake of the radical student movements. In the 1983 Ebony article, Ozell Sutton, general president of Alpha Phi Alpha and chair of the Council of Presidents ${ }^{15}$, states that the resurgence of black fraternalism is due in part to what we can consider the organizations' (re)articulation of institutional responsibility"The fraternities and sororities have gotten back to their original purpose...to give leadership to the Black community in the struggle for freedom and justice" (p. 93). This change in tone and rhetoric suggest that BGLOs had learned, if not substantively, at least figuratively, in contrast to the radical student movements they were seen as out of touch. As Sutton goes on to indicate, "Black Greek groups have been viewed as non-caring, social activity-prone organizations that don't have a great deal of concern about the wellbeing and welfare of those who haven't obtained our level, either economically or educationally" (p. 98).

Taking Sutton comments alongside Ralph Bryson and Everharding Pruitt (1999) insights, this change in rhetoric can be read as an attempt to appeal to the sensibilities of the new black student and acquire the institutional pleasure of belonging - the same

\footnotetext{
15 The Council of Presidents is an executive committee comprised of leadership from each BGLO.
} 
pleasure that originally enticed the founders of black fraternities. The bureaucratization of diversity had created a demand for the institutionalization of difference - making black fraternities an object of institutional desire. Therefore, BGLOs resurgence, as Ferguson writes (2012), "hinged on the promise of permanence" (p. 223) which "requires subjects that treat the administration as a matter of libido" (p. 223).

This institutional desire and pleasure that marked the reemergence of BGLOs coalesced around institutional ideals of manhood, similar to the founding of black fraternities. Through the black fraternity's homosocial indifference-making, fraternities could extend these institutional pleasures and desires to its members. Black fraternity members would be affirmed as the ideal new black student. The black fraternal subject in its conceptualization would meet all the demands of the administrative and institutional terms of responsibility and diversity as set by nationalist discourses that idealized cisheteropatriarchy and essentialist notions of community. Therefore, as Ferguson (2012) points out, while challenging the foundation of higher education, the post-civil rights student movements ushered in new "nonuniversity" agents under the per view of institutional responsibility, and thus, "political organizations and academic programs devoted to minoritized subjects would arise in the postsixties environment, disseminating both life-enhancing and regulatory aspects of responsibility, producing an ironic kinship with the disciplinary universes of dominant Western institutions" (p. 112). What becomes obvious in the black fraternal will to institutionality is that their institutional presence, or even love-affair, places the focus on responsibility outside of the academy, letting the university "off the hook" for the discontent experienced by minoritized students that led to the student movements. 
The black fraternal will to institutionality represents the university as an archive entity attempt to normalize minority difference. The black fraternal will to institutionality signifies the incorporation of race and gender predicated on a compulsive heterosexuality. Judith Butler (1990/1999) states:

The institution of compulsory and naturalized heterosexuality requires and regulates gender as binary relation in which the masculine term is differentiated from a feminine term, and this differentiation is accomplished through the practices of heterosexual desire. (p. 31)

Just as the academy is legitimized in this post-civil rights era through a bureaucratization of diversity, employing BGLOs as bureaucratic documentation-race, conversely, is legitimized within the administrative realm through a regulatory practice of gender coherence. Therefore, black fraternities as institutional agents can compel a type of erotic abuse, particularly for black queer subjects, where instead of looking to an “internal sense of satisfaction" (Lorde, [1978] 2007, p. 54) those desires are displaced or misdirected towards institutional formality. It is important here to remember Audre Lorde's warning of the erotic trappings of institutional logics, such as marriage, religion, and as so, the academy. A will to institutionality is, then, considerably about distinguishing between the legitimate and illegitimate as well as the formality and informality of difference — granting formalized difference the permanence and protection of the institution all while disqualifying the informal and constituting the margins as an uneven field of play (Ferguson, 2012).

This process of institutionality would not be complete without the convergence of capital. As Ferguson (2017) states, "Through neoliberal multiculturalism, capital and 
academy presented themselves as the real achievements of student and social protest, producing products and constructing brands that bore the masks but not the substance of movement ideals and visions" (p. 28). With the black fraternal subject affirmed in the university archive as the ideal, regulated form of minority difference, BGLOs became an object of capital's desire in forming its own legitimacy and integrity as institutions in a post-civil rights and global economic period. Black fraternalism has long seen achieving capitalist pursuits has an indication of its members' rightful place in American masculine homosociality.

For instance, in 1968, Richard Nixon in his presidential campaign introduced the concept of black capitalism in the mist of black urban unrest and black nationalist calls for self-determination in their antigovernment protests and communist leanings. Ferguson (2012) points out how certain radical student activists detested the idea of black capitalism for its "ability to reroute minority affirmation away from the critique of institutional seductions and toward the hegemonic appeals of liberal capitalism" (p. 55). The advent of black capitalism marked power's new configuration —one in which the state and capital redirect radical aims and affirm minority difference for their interests. Supporting the black capitalist movement would be various black fraternal figures, including Kappa Alpha Psi member Wilt Chamberlain and Alpha Phi Alpha's The Sphinx Magazine in which contributors between 1969 and $1973^{16}$ discussed the merits of black capitalism in its various forms (i.e., separatist or integrationist approach).

Therefore, as capital sought to expand its economic reach to new forms of difference brought to bear by the social movements of the 60 s and 70 s, capitalist

\footnotetext{
${ }^{16}$ See The Sphinx volume 56(5), February 1969; volume 56(1), February 1970; and volume 59(3), May/June 1973.
} 
institutions also needed to work with and through these forms of difference. Taking its cue from the academy, capital turned to BGLOs in the 1980s to articulate its accommodation of difference. As Watch the Yard, a multimedia company dedicated to black collegiate and fraternal culture, writes, "Black fraternities and sororities were so popular on television in the late 80 s and early 90 s and everybody was trying to get a piece of their marketing power...even McDonalds.” In a 1989 commercial for McDonalds, a line of black fraternity "pledges" can be seen reciting and stepping to the McDonalds menu to an assortment of onlookers, particularly noticeable women admirers. Here, capital's commodification of black culture reinforces the black fraternal subject as the ideal black collegiate, propelling the black fraternal hetero-homosocial appeal while equating it with the BigMac. This ad and others like it, makes the McDonalds menu a work of a cultural "labor" that obscures the commodity exchange value and legitimizes companies by exalting intelligible forms of minority difference-as Ferguson (2012) suggests, reifying race and gender as part of capital's domain of articulation.

Black fraternalism's will to institutionality affirms and consolidates Ferguson's theory. By exploring power's new mode through the deployment of the black fraternal subject, new elements of power's calibration of minority difference is revealed. The cocurricular is brought closer to view in understanding how the academy conditioned minority difference to bring it in relation with state and capital. Black fraternal subjectivity, then, represents the life-giving and regulating force of a "freedom" or "excellence" bestowed by institutional logics — limiting the ways in which blackness is recognized and celebrated. As Ferguson (2012) writes, “This will to institutionality suggests that minority difference can achieve effectiveness and agency by investing in 
dominant institutions, making institutionalization a historical necessity rather than one item on a menu of interventions, suggesting that minority difference can only be achieved through the forms that dominant institutions offer" (p. 226). Therefore, before unruly forms of subjectivity can be dismissed, we must take in to consideration a will to institutionality—its negotiation and rupture possibilities. 


\section{CHAPTER 4: HETEROSOCIAL LABOR AND FEMME RESISTANCE: TRANSFIGURING BLACK FRATERNALISM AND INSTITUTIONALITY}

Queerness is that thing that lets us feel that this world is not enough.

— José Muñoz, Cruising Utopia (2009)

When asked about the campus climate as a black gay student at an historically black college and university (HBCU) in the 1980s, Timothy, a narrator in E. Patrick Johnson's (2008) southern black gay historiography, states:

I mean, no one was out then apparently. No. Unt un...it was definitely negative. I did not want to come out to anybody, except for just my network of friends. And we would even kind of watch how we behaved in public settings such as the cafeteria or the library, things of the nature. We would try to keep on the DL so to speak. (p. 298)

A lot had changed in terms of the campus environment for black students from when there were open gay groups marching on campus and homecoming queens in drag (Johnson, 2008). By the 1980s, the critical interventions forged by the radical student movements had resulted in power's new archival conception, foreclosing on the possibility of previous critical universes that allowed room for more diverse racialized gendered practices.

Race, gender and sexuality were integrated into the university through the interdiscipines, and thus, under the academy's grammatical conditions. Therefore, the 
legitimacy and affirmation extended by the university came with a certain formality in the subjectivities produced that limited the redistributive effects of the movements. As Roderick Ferguson (2012) states, "The administrative university adapts to modes of difference by attempting to normalize them" (p. 224). Indeed, a will to institutionality has helped to configure race, specifically black subjectivity, as a single-issue mode of difference. This institutional configuration is evident in much of the contemporary literature on male-identified black queer college students on campus. Whether it's at HBCUs or historically/predominately white institutions (PWIs), black queer male students find themselves navigating and negotiating the heteronormative and homonormative co-curricular spaces of the academy (Blockett, 2017; Carter, 2013; Harper \& Gasman, 2008; Patton, 2011, 2014; Patton \& Simmons, 2008; Means, 2017; Means \& Jaegar, 2013; Mobley \& Johnson, 2019; Squire \& Mobley, 2015; Strayhorn, Blakewood, \& Devita, 2008; Strayhorn \& Tillman-Kelly, 2013).

Specifically, black queer male students contend with the remnants of dominant notions of the ideal black student, or a cisheternormative black (hyper)masculinity, perpetuated by institutional black cultural entities, such as cultural centers at PWIs (Strayhorn, Blakewood, \& Devita, 2008; Strayhorn \& Tillman-Kelly, 2013), institutional practices at HBCUs (Carter, 2013; Mobley \& Johnson, 2019; Patton, 2011, 2014), and black Greek-lettered organizations (BGLOs) (Dancy, 2011; Means \& Jaegar, 2013). Therefore, like Timothy, black queer male students often practice sexual discretion as a means of survival by finding "efficacy in the act of being 'unmarked' rather than marking oneself through public confession" (McCune, 2015, p. 13). Furthermore, black queer male students are often rendered illegible to co-curricular entities dedicated to LGBT 
outreach at PWIs due to their white queer interpretive mode largely predicated on “outness” (Blockett, 2017; Squire \& Mobley, 2015).

Black fraternalism has, thus, consolidated these institutional configurations of minority difference through their will to institutionality. Since BGLOs popular reemergence in the 1970s and 80s, black fraternalism has acted as a thermostat for racialized gendered norms for black students - a mechanism for achieving the status of ideal black student and legitimizing institutional forms of minoritized difference. Black fraternities have served as a masculine homosocial archival entity that confers a certain regulating gender indifference, agency, desire and pleasure. Therefore, in this chapter, I will take up Ferguson's (2012) challenge to explore and consider formations that disrupt dominant forms of institutionality and recapture critical universes. Ferguson writes, "Now is the time to scrutinize this will to institutionality if we are to create alternative forms of agency and subjectivity not beholden to the logics of state, capital, and academy" (p. 226). To do this, I will locate the critique of a black fraternal will to institutionality in the deployment of black queer fraternal (BQF) formations that took shape in the 1970s and 80s and how this cultural development disturbed "the expectations and systems of intelligibility put in place by disciplines and institutions" (Ferguson, 2012, p. 230).

\section{Black Fraternal Homosocial Laboring: Making Gender on Campus}

Black fraternal culture changed greatly since its early conception; the 1970s and 80s brought about a more flamboyant and outwardly expression of black Greek culture. Long from the modest fraternity sweater and pin, BGLO members filled campuses with Greek-lettered t-shirts, audible calls, visual hand signs, stepping, campus plots at many 
HBCUs, and more sophisticated public pledging rituals (Kimbrough, 2003). As for the latter, pledging took a renewed interest in hazing, for what Walter Kimbrough (2003) suggests, "the elaborate practices were given newfound meanings, especially since chapters were now on predominately White campuses that were confused by the actions of the pledges" (p. 55). The 1983 Ebony article marking the "comeback" of BGLOs highlight this aspect of black Greek culture with a picture of a Phi Beta Sigma pledge line (in height order) dressed alike, carrying bricks with their heads bowed from Howard University with the caption: "Students who want to join fraternities and sororities are subjected to a variety of embarrassing and sometimes belittling situations" (p. 96).

For black fraternities, this newfound meaning in pledging practices included a physicality and violence deployed to demarcate a black manhood distinctive from whiteness and femininity (Jones, 2015; Dancy, 2011; Scott, 2011). As discussed in the previous chapter, this counter-cultural black masculine logic is not solely produced through social movements, but is aided within the administrative university where blackness is essentialized and queerness is aligned with whiteness. According to Ricky Jones (2004/2015), violence became a mechanism for constructing a counter politicohistorical framework of American manhood, or a black masculine homosociality —in other words, black men deploy violence as a way to be "cool," "hard," "down," and "real" in the face of adversity. During the 1970s, there were severe physical hazing incidents at Bradley University, University of Florida, and the first hazing death at the University of Pennsylvania in 1977, to name a few (Parks, 2015). From 1977 until 1990 there were approximately 31 recorded cases (Jones, 2015). 
During this time, there would also be a rise in auxiliary "sweetheart" groups. For black fraternities, this consisted of female affiliate programs — such as Alpha Angels, Kappa Sweethearts/Kittens, Que Pearls/Debs, Sigma Doves/Shadows, and Iota Sweethearts - who were "responsible for tasks such as serving as hostesses at fraternity parties, fulfilling brothers' community service obligations, acting as cheerleaders for intramural sports, and fund-raising" (Stombler \& Padavic, 2005). These groups are probably best known by their depiction in Spike Lee's School Daze (1988), a big screen adaptation of black Greek life where the fictional black fraternity (the Gammites) included a sweetheart group (the Gamma Rays). ${ }^{17}$ These auxiliary groups didn't become popular until the late 1960s and 70s due to the decline in BGLO membership (Stombler \& Padavic, 2005). Therefore, the rise of these groups are a direct result of the "black Greek paradox" discussed in the previous chapter. With an increase in chapters at PWIs and a decline in membership, auxiliary groups were a way to supplement chapter initiatives that might not otherwise have had enough membership.

We can think of the formation of black fraternity auxiliary groups as well as hazing as forms of homosocial laboring. Black fraternities, as a masculine homos ocial archive, reproduce a homogenous male heterosexuality underscored by logics of state and capital (discussed in Chapter two). This masculine homosociality is predicated on the objectification of women and abjection of homosexuality so that "power is retained within the structure by securing bonds of common interest between men, while the whole matrix serves the necessity of economic reproduction through the importance of

\footnotetext{
${ }^{17}$ Scholars have noted that early Spike Lee films, including School Daze, have objectified black women as plot devices to construct notions of the ideal black man, or in the case of School Daze, an ideal black homosocial masculinity. Furthermore, though the Gamma Rays were technically a sweetheart group, Lee constructed them as a composite interpretation for black sororities. See Wallace (1994); Whaley (2005).
} 
fatherhood and heterosexual procreation" (Maddison, 2000, p. 74). As such, masculine homosociality works to procure capital through patriarchal networks in which men are able to acquire social and cultural power.

Aligned with the capitalist motives of homosociality, the presence of an inordinate hazing and black fraternal auxiliary groups is part of the always necessary repetitious display of a particular heterosexuality and misogyny required of a homosocial male gendered (in)difference-making. This display works against the inconsistences and instabilities of homosocial formations. As Maddison (2000) states, "In order to participate in dominant power men must continuously represent their credentials, and more importantly, represent distance between themselves and the always-already present possibility that they will act discontinuously with their own gender interests...not continuously displaying power of women [or the femme], and not redemonstrating the already implicit understanding of male authority, is continuously conjured as latent homosexuality" (p. 74). Therefore, as Judith Butler (1993) might suggest, hazing/violence is then a performative link between the materialization of an ideal black male body and a normalized discourse of racialized gendered sexuality. Furthermore, sweetheart programs functioned primarily in the interest of men and the fraternity's patriarchal system (Stombler \& Padavic, 2005). ${ }^{18}$ The process of hazing and sweetheart groups, then, in their laboring, assisted black fraternities in fulfilling the institutional responsibility that came with their will to institutionality—an obligation to minority nonuniversity subjects and regulation of race, gender and sexuality.

\footnotetext{
${ }^{18}$ Stombler and Padavic (2005) note black fraternal "sweetheart" organizations provided black women with a channel for community service and some degree of social status, agency and sisterhood not found in white fraternal auxiliary groups.
} 
Black sororities also included male auxiliary groups, such as Men Interested in AKA (MIAKA)/AKA Cavaliers, Delta Beaus, Zeta Knights, and Sigma Gamma Rho Rhomeos. Sigma Gamma Rhomeo is believed to be the oldest of the BGLO auxiliary groups, founded in 1936; however, there have been no substantial research on these groups and the significance of their origin and purpose is less understood (Stombler \& Padavic, 2005). To some extent, it can be assumed that these groups served a similar purpose as their fraternity counterparts. However, the inverse gender relations would suggest differing power dynamics than their fraternity counterparts. Based on my targeted research, black sorority auxiliary groups seem less common, or at least less formal or public, than the fraternity sweetheart groups. For instance, in my review of Florida Agricultural and Mechanical University (FAMU) yearbooks from the 1970s, almost all the black fraternities included female auxiliary groups whereas no auxiliary sweetheart groups were pictured for the sororities.

Though black sorority auxiliary groups were more allusive, their possibility does provide some context and precedence for the foundation of $\mathrm{BQF}$ formations, particularly the formations I will examine in this study that originate in the Tallahassee (FL) community. For instance, two of the BQF members who I interviewed participated at one point in black sorority auxiliary groups, and though there were gay men in these groups, the organizations were not queer-they operated in a similar fashion as fraternity sweetheart groups. Therefore, BQF societies constitute a distinctive yet overlapping genealogical trajectory with and apart from BGLOs' auxiliary programs. Interestingly, BGLOs terminated and/or disassociated from all auxiliary programs in 1988, around the 
same time they eliminated pledging and adopted membership intake programs (MIP) due to hazing. ${ }^{19}$

Before moving forward, allow me to make a few caveats, or a reminder, about methodology. This project seeks to render a counter-historical genealogy of black fraternalism through a queer of color critique of institutionality in the U.S. academy. Therefore, in the spirit of a queer of color critique, an analysis that "disidentifies with historical materialism to rethink its categories and how they might conceal the materiality of race, gender, and sexuality" (Ferguson, 2004, p. 5), I am particularly interested in BQF cultural formations for the underlining power dynamics they support, reveal, and interrogate in terms of black fraternalism and institutionality. As such, my exploration of $\mathrm{BQF}$ culture in the following chapters are not chronological nor complete histories of BQF formations - as that is not necessarily my goal with this project and its parameters. Rather, I employ interviews from BQF members alongside scholarly and media texts for a cultural materialist approach, as in, though there is a truth and a history in the narratives presented, the narratives are also instances of cultural reproduction or what Ferguson considers a material struggle — thus, often incomplete, incoherent, and/or contradictory. Given this, through close readings, I attempt to assess the power conditions through which this discourse and knowledge is produced (Maddison, 2000). Riffing off Maddison (2000), "I am not after a big, totalizing history [of BQF culture], but a more detailed, intimate account of relations and structures" (p. 13) between BQF formations, black fraternalism, and institutionality.

${ }^{19}$ BGLOs ended pledging in 1990. 


\section{The Projection of Black Fraternalism}

Black fraternalism became an integral part of power's calculation of minority difference through economic, political, and academic institutionalization-making it part of and parcel to institutional textuality. Like a projector mapping an image from a film reel (or text) onto a screen, black fraternalism is compelled by, thus works on and against, the master tape of the institution. Therefore, in the age of institutionalized minority difference, black fraternalism projects the ideal imagined minoritized community within the U.S. academy. An imagined community informed by institutional modes of interpretation—its textuality—including Western modernity, archival, and administrative specialization.

I like the idea of "projection" here because it signifies institutionalized black fraternalism's employment of an imagined community as an orienting devicesuggesting ways of being (direction), or regulation, to those represented by the community. However, projection also connotes im/possibility. Impossibility in that the imagined, institutionally oriented community isn't actualized, or put differently, it doesn't accurately encompass the plurality of minority forms. Minority archival is always already insufficient. Conversely, projection makes space for what Ferguson (2012) calls critical possibilities:

By 'critical possibilities' I mean the potential of those cultural forms to offer accounts of institutional modes — not simply the disfranchisements and betrayals of institutions, but also the rules of inclusion and anatomies of recognition and legitimacy; not simply how we are entrapped, but also how we might achieve provisional forms of freedom and insurgency. (p. 15) 
We can then think of these critical possibilities as a politics of transfiguration. In his seminal text, The Black Atlantic: Modernity and Double Consciousness, Paul Gilroy (1993) deploys black music as a countercultural formation of modernity that resist, adapts, and transgress the ideological bifurcation of modern textuality. Gilroy contends that within this countercultural formation there is a normative function which constitutes a politics of fulfilment: "the notion that a future society will be able to realize the social and political promise that present society has left unaccomplished" (p. 37).

Conceptualized as part of the black uplift movement at the turn of the twentieth century, black fraternalism, in its institutional state, encapsulates a fulfilment politics defined by its integrationist efforts and "excellence" orientation that challenge but invest in institutional structures for legitimacy and recognition: "It necessitates a hermeneutic orientation that can assimilate the semiotic, verbal, and textual"' (Gilroy, 1993, p. 38). It is this politics of fulfilment that makes black fraternalism susceptible to a will to institutionality.

The politics of transfiguration, the "sibling dimension" of fulfilment, however, represent "critical possibilities" ability to reorder institutional logics and the repressive nature of its choices of subjectivity_legitimate/illegitimate, formal/inform, recognized/unrecognized. Gilroy (1993) states, “This [politics of transfiguration] emphasizes the emergence of qualitatively new desires, social relations, and modes of association within the racial community of interpretation and resistance and between that group and its erstwhile oppressors" (p. 37). Gilroy goes on to say, "This is not a counterdiscourse but a counterculture that defiantly reconstructs its own critical, intellectual, and moral genealogy in a partially hidden public sphere of its own" (pp. 37-38). Like Jeffrey 
McCune's theory of sexual discretion (2015), Gilroy situates a politics of transfiguration as a historical and genealogical racial mode of resistance where alternative modes of community, solidarity, and individual self-fashioning have been "created under the very nose of the overseers" (p. 37). Therefore, understanding the politics of transfiguration helps us to locate the critical possibilities embedded within (and under) black fraternalism's institutional communal projection, as a "politics of transfiguration strives in pursuit of the sublime, struggling to repeat the unrepeatable, to present the unpresentable" (Gilroy, 1993, p. 38). Put simply, a politics of transfiguration suggests the projection of institutional text can be manipulated as well as upheld.

\section{Transfiguring the Institutionality of Minority Difference}

Fred-Rick's revealing of the BQF lifeworld in Johnson's (2008) Sweet Tea, and discussed in chapter one, is indicative of a politics of transfiguration as he incites the pleasure and desire in "struggling to repeat the unrepeatable, to present the unpresentable." However, as Sara Ahmed (2015) has characterized affective discourse, "These short sentences depend on longer histories of articulation" (p. 1). If Howard University is considered "the cradle of black Greek civilization," then FAMU and Tallahassee might be considered the home of its reordering.

One of the first formations of a $\mathrm{BQF}$ society is believed to have taken shape in the spring of 1974 on the campus of FAMU. According to a study participant, this development was spurred by the post-civil rights era radical social movements, as he states, "In the 60s, the 70s, that is, you know, when the gay movement got to FAMU and it started to become more open." Here, "open" is relative—-to live "abroad," as the interviewee characterizes being "out," was still very much taboo. However, the "arrival" 
of the gay movement and this "new" level of tolerance on campus was symbolic of the queer fraternal conception. A conception which is believed to have originated when a lesbian activist from New York became a member of the FAMU chapter of Alpha Kappa Alpha (AKA) and assisted a group of black queer men in forming an underground AKAinspired society. Whether lore or actuality, the lesbian AKA's New York origin signifies a geographical territory that is synonymous in our collective memories with contemporary queer liberation movements. Besides the Stonewall riots, some of the first campus LGB student organizations where formed in New York through movement actors' involvement in and association with local national lesbian and gay activist groups (Beemyn, 2003).

The spillover effect narrative of the lesbian AKA from New York is further solidified in how the queer male AKA underground society took shape. These queer fraternal societies would initially resemble the New York house/ball culture. As the participant explains:

It was like a house at first. It wasn't more of a sorority. It was a house. If you seen Pose that's how the chapters started. And so if you wanted to be in the pretty girl house you went for AKA. And if you wanted to be in the real girl house you went for Delta [Sigma Theta]. But it was the houses that were competing.

Another participant also associated house/ball culture with the start of BQF societies: It's more of a social network bonding benefit amongst gay men, really similar to like how gay houses are. It's kind of where, you know, part of the culture comes from too. Emulating that but just putting a Greek twist to it. Throw in some colors and a crest and putting a process together from things we collect and hear and see. 
Houses here are in reference to queer house/ball culture, recently made popular by the FX TV series Pose (2018) and the iconic Paris is Burning (1990). The origin of ball culture goes back to the turn of twentieth century and the Harlem Renaissance. Initially organized by white gay men, Harlem drag balls were interzone pageants, interracial spaces located in black communities, where it was common to have participants and patrons express queer desires (Roberts, 2007; Schwarz, 2003). Frank Roberts (2007) states, "The lavish, carnivalesque drag balls became spaces where racial taboos were broken through sexual and gender nonconformity." Balls would later be organized and supported by black and Latinx queer houses that formed under the socio-political climate of 1970s and 80s. Roberts writes:

These contexts included a spiraling decline of the city's welfare and social services net, early gentrification of urban neighborhoods through private redevelopment, decreases in funding for group homes and other social services targeting homeless youth, a sharp rise in unemployment rates among black and Latino men, and a virtual absence of funding during the Reagan era for persons newly displaced and/or homeless as result of HIV/AIDS.

These conditions forced many queer black and Latinx individuals to form alternative kinship networks, or houses, that reformulated familial structures to provide support for the ballroom community. As Marlon Bailey (2013) suggests, houses' kinship structure and gender performances interrogate normative, or (bio)logical, constructions of gender, sexuality, family and community.

New York and other urban-based houses typically found in the north -east and west derive their names from couture designers or aspirational mottos and symbols 
(Bailey, 2013) — in many ways constituting the recognized with the unrecognizable to blur the lines of legibility. Thus, harnessing and displacing the power endued to the formal by the unintelligible. Naming in house culture, and subsequently BQF culture, takes on the properties of a postmodern type of mimicry found in some postcolonial African diaspora cultural formations. In these formations, hegemonic (colonial) symbols are appropriated by the minoritized "other" as critique of empire, state, capital and institutional protocols, making visible modalities of difference and how these symbols function for and against the other-not by rejection of the other (Mahoney, 2019). In other words, binary classifications are challenged by presenting minoritarian life through dominant channels. In the case of male BQF organizations, their formation, centered around black sororities, worries the lines between and within what constitutes "fraternity" and "sorority."

These BQF houses were initially structured like their New York counterparts with house "mothers," who were typically the oldest member and led the house, with the second oldest member responsible for membership. By the late 1980s/early 1990s, these BQF underground houses would change organizationally from a house structure to a more sorority-like model. The impetus for this change seem to be the establishment of houses at Florida State University (FSU). It was then that the "pretty girl" house at FAMU would be referred to has the house of beta alpha and its FSU counterpart the house of zeta omicron - all in reference to their respective AKA undergraduate chapters. According to a study participant, it was around 1988 when the AKA houses from FAMU and FSU came together as a centralized body and developed a more formal organization. Before this the AKA house at FAMU was primarily concerned with the performative and 
supportive elements of the fraternal house culture, as the participant states, "We were over here kicking and grinning and mirroring their [AKA's] steps and strolls and helping them [AKAs] with their steps and strolls." However, the expansion to FSU led to the first house chapter to form a fraternal infrastructure based on the sorority. This included elected officers, protocols, sorority-patterned rituals, and independent aims disassociated from their sorority namesake. Eventually, these BQF groups established chapters across the southeast, as a participant states:

They went to Morehouse to start another chapter. They went to University of Florida. They went all to central Florida, south Florida - they went all over Florida....They put chapters in South Carolina, chapters in Mississippi, New Orleans. Wherever they met at those prides and black college reunions and stuff and freaknic, that's how they got chapters.

This would be around the same time that Fred-Rick, the narrator from Sweet Tea (2008), would have been in college and a member of his "pretty girl" house. According to some of my participants, it is believed that the Delta houses followed a similar trajectory as the "AKAs"- becoming more centrally organized ${ }^{20}$ and expanding chapters by the mid- to late-1980s. Furthermore, during this time, BQF societies expanded beyond the representation of the two original sorority-themed houses - AKA and Delta — to include all BGLO sororities, and ultimately, female BQF formations based on fraternities ${ }^{21}$.

\footnotetext{
${ }^{20}$ One participant suggests that the Delta houses at one point adopted Delta Beaus as an organizational "cover" to centrally organize. This suggests that perhaps BQF groups at times employed auxiliary programs to make space and place for their queer desires.

${ }^{21}$ I do not address or directly theorize female BQF groups in this project. My primary focus is male BQF groups.
} 
Nevertheless, for much of the 1980s and 90s, the basis of these organizations remained their underground orientation and performative tradition.

The competition amongst these various BQF groups were largely drawn over recruitment of members. The different groups appealed to potential members through their sorority-gender-queer performances which often took place in the private, counterpublic spaces of dorm rooms, off-campus homes, and particularly night clubs. One participant states:

I'm from Tallahassee and these organizations were founded in Tallahassee. So it, it was normal for us. It's almost like, if you think back to what 19-0-8 or 19-13, you know, where Delta and AKA came on Howard. It was normal for them. But [not] at other places where it had not been established as of yet...so that was the case. I mean, I was uh, I was 18 before I graduated high school...I was clubbing before I graduated, before I even turned 18, because back then the club was Club Park Avenue, or CPA, and they never locked their door and so all of the young kids would go in through the back way. So I was very cognizant of the gay Greek letter organizations prior to me thinking about joining one or even thinking about founding my organization.

Another participant describes what it was like to first witness BQF culture in the club, stating:

They knew how to act on campus, when they went on campus they were astute. They were involved in SGA, involved in the band. You never really could tell until they got in character... When I went in that club that night... I saw people on campus that I thought was straight. I saw Ks, Deltas, Zetas [Zeta Phi Beta], and 
Sigma Gamma Rhos, boy Ques [Omega Psi Phi], I saw the reverse of FAMU campus and Florida State campus. ${ }^{22}$

The "reverse" gendered performances the participant is referring to, are the primarily black queer males, enacting a black sorority subjectivity through calls, hand signs, steps and strolls - many of those black Greek outward expressions that became popular following their reemergence in the 1970s and $80 \mathrm{~s}^{23}$ Stepping ${ }^{24}$ is specifically important to enacting a black sorority subjectivity. Deborah Whaley (2010) contends stepping is a cultural tool utilized by black sorority women to achieve gender autonomy and construct a public identity. Through stepping and other similar dance forms like strolling, black sorority women foster intra-sorority community and identity while displaying sexual confidence and exploiting "the contradictions of femininity, sexuality, and diasporic identities as historical actors in the everyday life" (Whaley, 2010, p. 80). As a result, stepping/strolling can be considered a gender signifying device—a mediated construction that provides a performative criterion for sorority "realness" and BQF world-making in the underground sorority culture.

Drawing on Bailey's (2013) theory of realness derived from the ballroom community, sorority "realness" enacted through stepping/strolling provides a framework of embodiment, self-presentation, and performance that allow black queer males in $\mathrm{BQF}$ culture "to capture the authenticity of particular gender and sexual identities" (p. 55). Members are able to refashion themselves — construct and rehearse - the femme sorority

\footnotetext{
${ }^{22}$ Both accounts given by the two participants here would have taken place in the mid- to later 1990s at Club Park Avenue (CPA) which no longer exist. CPA's former building is now Avenue Eat \& Drink restaurant. When it was in operation, Sunday night was CPA's gay night.

23 "Boy ques" connote butch females who embody members of Omega Psi Phi.

${ }^{24}$ Stepping and strolling are performative dance forms comprised of sophisticated body movements and chants with eclectic roots in West/South African dance, modern dance, military drilling, hip hop and gospel.
} 
embodiment not necessarily to be judged, as in the case of ballroom performances, but definitely to attract potential members. As another participant explains:

So when I was originally introduced to these organizations, they were introduced to me almost as if they were men imitating aspects of sorority lifestyle, you know female organizations. Hmm then that appealed to me only because I did not see myself mirrored in the image of the men that I saw in the other organizations, the, I guess the "traditional" male fraternal organizations on campus [FAMU] or even at Florida State across the street.

Further evident in the participant narratives is the visual and spatial epistemologies of race and gender scripted in institutionalized minority difference. Bailey states, "Realness as a theory of quotidian performance offers a way to understand, primarily, how....all gender and sexual identities are performed. Ballroom members use performance to play a greater role in how they are interpellated—seen—as particular gender and sexual subjects" (p. 56). Within the post-civil rights era academy, the "laws" that have produced the coherence of an intelligible black male subjectivity-one exemplified by the ideal black fraternal subject — manifested through the archival of minority difference. This institutional archival established "causal or expressive lines of connection among biological sex, culturally constituted genders, and the 'expression' or 'effect' of both in the manifestation of sexual desire through sexual practice" (Butler, 1990/1999, p. 23). In other words, sexuality, or a compulsive heterosexuality, became an indicator for the "appropriate" legible gendered behavior to be performed on campus and in campus organizations like BGLOs. Therefore, it is important to note how one of the participants refer to the "reverse" gendered performances in the club through the prism of straight, not 
straight. Conversely, the gay night club, as E. Patrick Johnson (1998) has theorized, can be a deconstructive space to reconfigure the personal and communal boundaries erected by pre-scripted places like the college campus. The darkened, ambiguous space of the gay night club obscures the institutional gaze of the campus environment.

As indicated by the study participants, many BQF members were your ideal involved black student on campus - members of SGA, band, resident assistants, and even members or aspiring members of BGLOs. Therefore, they could perform the black heterogender necessary to be recognized, or seen, according to the university institutional text. Accordingly, Bailey (2013) writes, "Bodies are located in and viewed through a frame or visual epistemology that determines what is considered 'real' through naturalizing discourses that render the body as a true text" (p. 56). This spatial and visual dichotomous gender performance practiced by many BQF members, then, calls into question the authenticity of institutional forms/text of minority subjectivity and the archival power that has informed them. As Butler (1990/1999) posits, "The very notion of 'the person' is called into question by the cultural emergence of those 'incoherent' or 'discontinous' gendered beings who appear to be persons but who fail to conform to the gendered norms of cultural intelligibility by which persons are defined" (p. 23).

Interestingly, the BQF culture is sometimes referred to has "neoclassical bodies" amongst its members which may consciously or subconsciously signify their reconfiguration of "new" bodies distinct from the ideal black fraternity body brought to view by and against Western notions of modern manhood.

As such, the deployment of black sorority life forms in BQF culture has more to do with constituting what Bailey (2013) calls a "technology of the self” within (or under) 
the academy's institutional domain than it is ever about wanting to be in or be a AKA, Delta, Zeta or Sigma Gamma Rho, as one participant states, "We didn't get our glory or gratification on campus. We let the girls have that. Our gratification and glory came from the bar scene." Technology of the self defines the communal labor practices black LGBT communities employ to self-fashion individual and collective gender and sexual identities that subvert culturally intelligible gendered forms and foster black queer worldmaking. As Bailey theorizes of ballroom members' technology of the self, the black sorority embodiment, presentation, and performance in BQF culture becomes a form of work through which BQF members attempt to refract the violence to which black gender and sexual minorities are subjected in the university.

The institutional violence here is akin to what Erica Edwards (2012) suggests as the violence of a black charismatic leadership. Parallel to the archival of minority difference in the academy, Edwards contends notions of black leadership embodied in the civil rights and black nationalists' movements was too "archived," primarily through the media. This archival reduced understandings of legitimized black leadership to racialized gendered charismatic scenarios that reify gender and sexual normativities. Consequently, there are historical, social and conceptual violences associated with these institutional conceptions of black leadership in terms of its erasure of the ontological and epistemological leadership forms produced by black gender and sexual minorities.

Likewise, the absorption of minority difference in higher education created an environment where queer people of color were historically, socially, and conceptually made invisible, illegible, and inauthentic in the context of the ideal black student. 
As a result, the individual and collective self-fashioning of BQF culture is predicated on disidentification aimed at restoring black queer subjectivity in the “imagined community" of campus life. Disidentification is a form of minoritarian performance of identities-in-difference — a survival strategy. As José Muñoz (1999) states, "These identities-in-difference emerge from failed interpellation within the dominant public sphere. Their emergence is predicated on their ability to disidentify with the mass public and instead, through this disidentification, contribute to the function of a counterpublic sphere" (p. 7). By adopting and adapting a portion of what constitutes the projected ideal minoritized community (black fraternalism), the portion of that idealization that recovers the femme-homosexual object lost in the conception of black heterogender masculinity (black sorority subjectivity), black queer males are then able to use "majoritarian culture as raw materials to make a new world" (Muñoz, 1999, p. 196). Stated differently, in a homosocial logic as Maddison (2000) has theorized from Teresa de Lauretis (1988), if in order for sexual desire between two women to be made legible, one must be read as or made masculine, then the inverse of that, sexual desire expressed between two men, one would infer a femme reading or making. Muñoz writes:

The concept of worldmaking delineates the ways in which performance-both theatrical and everyday rituals - have the ability to establish alternative views of the world. These alternative vistas are more than simply views or perspectives; they are oppositional ideologies that function as critiques of oppressive regimes of 'truth' that subjugate minoritarian people. (p. 195)

BQF formations employ the aesthetics of black sorority life - the look, the moves, the sounds, the language — for a black queer fraternal world-making that is oppositional to an 
institutional black fraternalism based on a homosocial logic where gender presentation, performance and expression dictates sexual desire. In doing so, a black queer fraternal world-making reveals the institutional racialized gendered projections for what they are- projections (not real).

The ability to "play in magic" as one participant describes BQF culture's

disidentification with "the principles and thoughts and concepts of sororities of the divine nine body," is produced through performative iterations and reiterations which disavow "that which majoritarian culture has decreed as the "real"” (Muñoz, 1999, p. 196). In a Butlerian (1990/1999) sense, BQF disidentification is a subversive repetition of culturally intelligible gender where "the parodic repetition of 'the original'... reveals the original to be nothing other than a parody of the idea of the natural and the original" (p. 43). Put differently, with BQF members' ability to embody a naturalized feminine black sorority subjectivity, BQF culture calls into question and disfigure the (bio)logics of sex, gender, and sexuality upon which its agency and the black fraternal subject's agency rest. A subjectivity (and agency) that's not "natural," rather constituted through its institutional cultural intelligibility. As Maddison (2000) states, "Heterosexual femininity is a function of masculine authority...this is something that de Lauretis's term sexual (in)difference recognizes, that cultural authorities produce one kind of identity, in relation to which all others are complementary, supplementary, functional” (p. 70). The BQF femme, then, makes black fraternalism's masculine homosociality dysfunctional.

\section{Transfiguring the Homosociality of Black Fraternalism}

If the embodiment, self-presentation, and performance within $\mathrm{BQF}$ culture are a technology of the self for individual and collective refashioning, then this 
disidentificatory performance is predicated on a co-productive labor. The black queer reiterations of institutional black fraternalism, that is BQF culture, constitutes its institutional opposition not only in the world it creates, but also in how that world has come to be. From the time of their original conception and throughout much of their complicated history and contemporary formations, BQF culture has been, interestingly, in part shaped by the involvement of black sorority women. Not just in the sense of idealization, but through real relationships with BQF members and organizations. For instance, when I asked one participant if there was any type of relationship between his organization and the sorority his organization is patterned after, he responded, "Yes, I mean concretely...we get our information from somewhere."

As previously mentioned by another participant, black sorority women seem to have been heavily involved in the early BQF house formations, particularly as it relates to BQF members and sorority members working together to develop steps/strolls and even assisting sororities with campus pageants. However, this tradition appears to have continued and evolved, as participants talked about more recent encounters with black sorority women, including women participating in BQF organizations' membership intake/pledge processes or BQF members being invited to informal sorority socials, exclusive to sorority members. One participant might have best described the relationship between black sorority women and BQF members, stating:

There have been situations where... it is an invitation to some [black sorority] members to participate in the MIP [membership intake process] process. So when, you know, the gay Greek letter organizations, may invite some of their female counterparts into their process, selected ones they know are cool or not 
going to go back to [report to their sorority] nationals or whatever...So it just depends on the level of friendship, the level of professionalism, the level of, um, even the level of secrecy that you have with those individuals. Now if you are talking about older members that have been in these respective organizations for the past 50 years and they sit on the national board, they're not, you know, they're not going with that.

Another participant actually describes a situation where older, senior members of a black sorority did get whim of BQF activities with local sorority women:

It was my partner...talking about his mother getting a call from one of her sorors in Tallahassee about some interactions with women in Alpha Kappa Alpha at FAMU with men, you know hmm, and making them dress up and do all these things. And I can see how that could possibly be something that occurred.

Though not all the BQF members I interviewed were willing to talk about black sorority women's contribution in their organization, they do acknowledge that black sorority women have played a role in their respective organization's conceptualization. All the interviewees suggest black sorority women were involved in their organization's initial founding; however, from here the level of engagement by black sorority women varies from organization to organization. Some participants go further to express a continued more complicated relationship with black sorority women as expressed in the aforementioned comments. Nevertheless, BQF culture seem to be a selective, or possibly open, secret in black sorority life, with some members at the local undergraduate level actively engaging with BQF groups and more senior members and/or national officers often aware but disapproving of such relationships and behavior. 
As for the latter, this anti-BQF sentiment by sorority leaders can be in part characterized by black sororities' public respectability disposition. The other ideological avenue from which sorority leaders likely view BQF culture, and inform their distain, is that of appropriation-black queer men "stealing" their sorority likeness. The appropriation argument, however, is always already complicated by some black sorority women's co-productive labor and/or complicity in BQF formations. Furthermore, as argued throughout this project, an appropriation framework doesn't capture the complexity of power's archival dynamic. Therefore, I want to unpack the respectability angle to better understand why some black sorority women might engage in BQF culture against their sorority's standards, wishes and beliefs.

Like black men, formation of the black sorority at the turn of the twentieth century was twofold — part social and political "uplift" and part intervention into the white hegemonic standards of womanhood. The sorority, within the heteronormative prism of black fraternalism, was a vehicle for black women to publically assert their claims to an American femininity and womanhood they have historically been excluded. The public persona and expected characterology of black sororities and their members intrinsically ascribe to a patriarchal femininity ${ }^{25}$ associated with American fraternalism. Regarding the gendered disciplining of black sorority life, Whaley (2010) writes, "Fraternals are a social form predominately characterized by single-sex socialization and organization, but there is a dominant ethos of heteronormativity and heterosexual courtship encouraged within the fraternal framework as a whole" (p. 27). As such, for

\footnotetext{
${ }^{25}$ Patriarchal femininity is thought of as a complementary femininity to patriarchy. A femininity that is normative and reify patriarchal ideas of male authority.
} 
black sororities, respectability includes emphasis on a normative femininity ${ }^{26}$ that resonates from their archival in the fraternal system and works to regulate and police culturally intelligible orientations of sex, gender and sexuality. This feminine regulation not only produces a gendered binary, but as Rhea Hoskin (2019) states, "it is also characterized by ascendency of masculinity over femininity" (p. 3). Thus, this fraternal patriarchal femininity is performative and subjectable to a masculine homosocial gaze and desire. In other words, the ideal sorority woman inherently through her symbiotic relationship to the ideal fraternity man helps to demarcate fraternities from "men loving men" to "men promoting the interests of men."

Therefore, in the context of an institutional black fraternalism, I consider the engagement between black sorority women and BQF males as a form of heterosocial laboring to constitute a femme resistance. As detailed in previous chapters, black fraternalism was incorporated into the academy through the homosocial archive of the American Greek-lettered system, and thus, this structural interpellation helped to arrange its corporeal logics of race, class, gender and sexuality. To be recognized and made legible within the university's knowledge/power matrix, and consequently, American society at-large, black fraternalism adopted a cis-heteropatriarchal authority, one where a masculine indifference meant a rejection, regulation and subjection of the feminine. A rejection of the femme-homosexual male, and for black queer males who do join black fraternities, the femme is regulated, particularly in public display, to form a homosexual sexual exceptionalism that regularly supports the privileged social and political delineations structured by fraternalism. The black female sorority subject, then, as the

\footnotetext{
${ }^{26}$ Normative or hegemonic femininity refers to the social, political and cultural rules and regulations of an ideal femininity within the context of patriarchy.
} 
ideal black fraternity male counterpart, is feminized to produce a normative gendered system within black fraternalism and for the always already anxiety reducing function of masculine homosociality. Or, as Maddison (2000) suggests, "The sharing of, or competition for, sexual conquest of women, the sharing of the action of subordinating, being the glue of homosociality at the same time as producing homophobic reassurance that the crossing of the always-already crossed line has been resisted" (p. 73).

As a result, there is an underlining femmepobia induced by the structural desire of institutionality, or a will to institutionality, and fraternalism. Hoskin (2019) defines femmephobia as the "systematic devaluation of femininity as well as the regulation of patriarchal femininity" (p. 2). The relationships forged between some black sorority women and black queer males in $\mathrm{BQF}$ culture is predicated on a resistance to femmephobia. For homosociality is fundamentally about forced social bonding based on a masculine authority that centers a male heterogender- "the possibility of male homosexuality lies on one side of the homosocial arrangement, policing the terms of bonding - protecting the conditions of intimacy, while women lie on the other side, the currency of exchange with which men effect their transactions with each other" (Maddison, 2000, p. 85). Hoskin contends, "Contemporary femme scholars use femme to describe femininity that veers from any one of patriarchal ideals, whether it be normative Whiteness, cisnormativity, heteronormativity, able-bodiedness, the cult of thinness or sexual appetite" (p. 2). Furthermore, what Hoskin doesn't acknowledge here is the significance of black and women of color feminism that has historically employed femme embodiment and performance as a critical intervention and praxis into 
mainstream white feminism and black liberation projects. Drawing on the work of prominent black and women of color femme scholars, Kaila Story (2017) writes:

[Audre] Lorde, [Laini] Madhubuti, [Leah] Piepzna-Samarasinha, and [Sydney] Fonteyn Lewis all contend that not only is the Black and feminine an ancient identity of strength, power, and divinity, but they also stress that the contemporary manifestations of a Black femme identity are based on a Black feminist tradition of recovering and resistance that seeks to undermine the racist and heteronormative assumptions that choose to see femininity as inherently White, and power as inherently male. (p. 412)

Then, as a femme resistance, black sorority women and black queer males perform heterosocial labor, a type of gender dissent that collapses the structural normative matrix that situates these two subjects at odds within an institutionalized black fraternalism. Maddison (2000) states, "Heterosociality rejects the unification of patriarchal sameness sustained through the manifestation and abjection of others; rather, the possibility of heterosocial bonds acknowledges the violence of such sameness and attempts to act discontinuously with the hegemonic unity of interests expressed in manliness as an instrument of authority" (p. 93). By working together in a femme resistance, black female-queer male (dis)identification, defy the logics of masculine homosociality in black fraternalism while (re)defining, or denaturalizing, what it means to be femme, and consequently, masculine.

For instance, Whaley (2010) argues that for black sorority women, particularly members of AKA, the step show stage and the unsanctioned underground pledge processes are spaces where women challenge the respectability feminine politics of the 
sorority. Though sorority stepping has elements of sexual and cultural containment"where the women recreate malignant perceptions of gender and sexuality" (Whaley, 2010, p. 78) - there are also elements of femme resistance. Whaley states, "The women are controlling the image, taking on the mask of femininity and at times dislodging it; some performers ridicule femininity, while others use it as a rhetorical device to demand gender recognition, or womanhood" (p. 79). As for new member intake, some "Old School Pledgers" (OSPs) employ hazing in unsanctioned, underground pledge processes to "make" women into respectable sorors ${ }^{27}$. In outlining this paradoxical ideology, Whaley states:

This exhaustive list [membership criteria detailed in the AKA manual] is strongly tied to behavior mandated by the politics of respectability, that is, the ascription to upright and nearly angelic behavior, especially in the public sphere, at all times. Pledge sessions become the privatized stage to instill and test the character traits, where sorors and pledges become willing, even if ambivalent, actors.

Respectability is not something inherent or necessarily already there in all members; it is something that is often taught or strengthened through disciplining practices during the pledge process. (p. 107)

Whether stepping or pledging, these women often take a "dis-respectability" approach on the performative and underground stages—actions unsanctioned and/or seen as unfavorable by national officials and their standards of femininity — to shape AKA's more respectable public image. With that, this dis-respectability reveals a hegemonic

\footnotetext{
${ }^{27}$ The connotation "soror," which means sister, is sometimes used to delineate between black sorority women who pledged, or participated in underground hazing, versus those who are just "members" and only engaged in the official membership protocols sanctioned by the sorority national headquarters (Whaley, 2010).
} 
femininity that is also "taught or strengthened," not a natural gender difference, and some women's ability to disidentify with these normative standards through a defiant femme praxis.

What is interesting and relevant here in the context of $\mathrm{BQF}$ culture, is that, it is around sorority stepping/strolling and pledging, spaces and practices where women have challenged sorority mandates and ideology, that black queer males and sorority members appear to have had the most contact and engagement. As previously stated, a participant claims, "We were over here kicking and grinning and mirroring their [AKA's] steps and strolls and helping them [AKAs] with their steps and strolls." In discussing the establishment of his organization in the late 2000s, another participant noted how his organization founder, a black queer male, and a member of Zeta Phi Beta, bonded over the potential of pledgeship. The founder of his organization was initially pledging Phi Beta Sigma at a historically white institution in the South, when the fraternity brothers found out he was gay and started treating him differently. According to the participant, "He ended up not staying through the initiation process. A close friend of his was his RA who was a member of Zeta Phi Beta at the time...In humor, she said, 'Well, you know, if you were my friend, or you were on line for me, I'd pledge you.'” It was from this initial interaction, and eventual bond with the Zeta Phi Beta member, that his BQF organization was formed.

Social bonds between black queer males and black females are not uncommon on college campuses. In fact, Terrell Strayhorn and Taris Mullins (2012), in their study on the experience of black gay undergraduate males living in campus residence halls, found that one of the primary sources of support for black gay male students in the (black) 
hetero- and (white) homo-normative college environment were black heterosexual female students. Whereas black gay male students were often ostracized by their black heteromale peers, meaningful relationships with black female students were usually welcomed and mutually beneficial. Along with assisting black gay students navigate the hostility of the campus, Strayhorn and Mullins state, "They tended to establish meaningful interpersonal relationships with Black women, talk with them about their gay relationships, seek as well as offer advice about men's behaviors, and hang out with them in their rooms" (p. 154). Therefore, there is no reason to believe that these type of heterosocial bonds wouldn't extend beyond the interpersonal and into the structural realm of black Greek life.

Additionally, these type of heterosocial bonds, whether desired or actualized, have manifested in other forms of heterosocial labor in the collegiate context during the post-civil rights era of institutionalized minority difference. In the 2018 documentary, When the Beat Drops, choreographer and director, Jamal Sims, explores the underground world of black queer dance culture known as J-Setting. J-Setting specifically references the Prancing J-Settes, a popular female dance team that accompanies the Jackson State University marching band, and more broadly, describes a type of dance style found in HBCU collegiate marching bands' female dance troupes called bucking. HBCU marching bands might not seem like a masculinizing homosocial formation in the likes of black fraternalism. However, historically many of these bands started as all-male regiments, with some of the first women joining in the 1970s. And today, they remain androcentric with socialized gendered roles, such as all-female auxiliary dance troupes 
and all-male drum major corps. ${ }^{28}$ Maybe more importantly here, as institutional organizations, these bands are material manifestations of institutional logics of race, gender and sexuality.

In the opening of the documentary, Anthony states, "I tried the whole thing of doing what they say boys should do," as he reflects on his passion for dance and the masculine homosocial barriers that limited his ability to practice his passion. Anthony, a former black queer college student and member of a HBCU marching band, with its gendered configurations, was unable to express himself in the way he desired, both on and off the band field. However, it was through his admiration, or disidentification, with the black women in the band dance line, that he was "having these feelings in the inside," a longing for a self-expression that reconstituted the femme, its power and pleasure, lost in the architecture of an ideal black masculinity. It is this type of regulation and longing that Anthony and many other black queer males created the queer dance art form, JSetting/bucking, a heterosocial labor that originated in the underground black gay club scene of the early 1990s in the South.

Like BQF culture, J-Setting was not only a type of femme resistance for black queer males, but it also evolved from a black female dance culture that challenged the hegemonic femininity ascribed to their roles. As one female Prancing J-Sette states in the documentary_ “It's what every girl wants to be and every boy wants" - indicating the symbiotic role of dance lines as a model patriarchal femininity, objects of a heteromasculine desire and a regulatory passive femininity. However, bucking, which gets its name from its resemblance to horse kicks, is not ya mamma's majorettes, or a modern

\footnotetext{
${ }^{28}$ Some of the first female drum majors for HBCU bands were selected in the early 2000s. However, it is still rare. FAMU selected it first female drum major in 2018.
} 
genteel feminine form of dance. Bucking is athletic (read as masculine) and includes a mix of power, grace, sass and sexy, or as one Prancing J-Sette describes, "it's hardcore and edgy." Thus, like black sorority women, HBCU band dance lines simultaneously invest in and challenge hegemonic notions of femininity through performance and dance. This type of performative femme resistance and defiance, as I have argued in this chapter, provides a foundation for black hetero-females and black queer-males to bond over and/or in a co-productive black femme ${ }^{29}$.

In When the Beat Drops, the culmination of black heterosocial labor is realized at J-Setting competitions where the mostly black queer male teams compete in front of former HBCU dance line member judges - co-producing a femme culture that defies masculine homosocial logics. Examining the heterosocial bonding and labor found outside of black fraternalism helps us to make better sense of BQF culture. Whether its residence halls, marching bands, or in the case of black fraternalism, black women and black women's femme culture, has always been an avenue for support, bonding and material for a black queer male technology of self and queer world-making — constituting the black heterosocial as what Treva Ellison (2019) defines a black femme praxis, "the sociality of 'living in the flesh,' its pains and pleasures, and collective practices of mutuality and recognition beyond what is beckoned by state surveillance and criminalization" (p. 14). In defiance of the regulations, expectations and (in)differencemaking of masculine homosocial structures, black queer males perform a heterosocial

\footnotetext{
${ }^{29}$ My thinking about a co-productive black femme was enhanced in part by a talk given by Jeffrey McCune on "The Market of Black Effeminacy" at the 2018 Race Sex Power Conference in Chicago. McCune discussed dialectic-femme relationships between straight black women and queer black men.
} 
labor through a very real or desired disidentification with black women where true masculinity and femininity is dislocated from a (bio)logical determinism.

\section{Queer Failure as Institutional Dissent}

Ferguson's (2012) will to institutionality reminds us that power operates not only in the realm of repression but also in desire for affirmation. Through the knowledge regimes of the university, a black fraternal will to institutionality helped to secure, legitimize, and formalize minority difference within the university according to its edicts and regulations of race, gender, and sexuality. As a result, black fraternalism and its homosocial masculine structure came to represent the ideal black student—projecting an imagined minoritized community that upheld institutional, state and capital power dynamics while foreclosing critical universes and possibilities. As such, BQF culture is, as Ferguson suggests, a negotiation with and struggle against "the steady closure of critical universes brokered in a time of affirmation" (p. 226). The "hybrid transformations" of BQF culture, then, are formations in response to the white capitalist cis-heteropatriarchal logics that undergird state power (Muñoz, 1999).

As $\mathrm{BQF}$ culture attempts to move beyond the grasp of institutional arrangements of affirmation, they take to the underground for a politics of transfiguration, one that insist that institutional affirmation is always already insufficient in securing black life. Thus, when Ferguson (2012) questions the reliance on institutionalization as a means to achieve effectiveness and agency, "suggesting that minority difference can only be achieved through the forms that dominant institutions offer" (p. 226), BQF culture employs the performative, a heterosocial type of labor to radically undermine black fraternalism, its homosocial practices, and its institutional reinforcement of gender 
sameness and hierarchies. BQF culture illustrates how when incorporation into dominant institutions are the only route to a "liberated" minority difference, the body often becomes the place of institutional confinement. BQF culture, then, represents as Gilroy (1993) states, "Artistic expression, expanded beyond the recognition from the grudging gifts offered by the masters as a token substitute for freedom from bondage, therefore becomes the means towards both individual self-fashioning and communal liberation" (p. 40).

In a system where this type of queer behavior is considered pathological, unruly, and disrespectful, BQF culture, nevertheless, is a utopianism that reimagines and reveals the hidden fractures of an institutional black fraternalism. The BQF utopia, in its disidentificatory performance, undermines institutional logics of legitimacy, formality, and thus, legibility, by shifting the power relations between the recognized and unrecognizable. The femme heterosociality of BQF culture blurs these institutional fault lines. Or, as Ferguson (2012) contends about the possibility in alternative forms of minority difference, BQF culture's employment of black fraternalism disseminates and circulates "minority culture and difference that do not place them [neatly] within dominant systems of value" (p. 230); it disturbs the texts that engage minority difference and use those texts to "imagine how minoritized subjects and knowledge might inhibit institutional spaces [and bodies] in ways dominant institutions never intended" (p. 230).

BQF culture constitutes a constructive institutional indecisiveness. It is neither legitimate nor illegitimate, formal nor informal, and thus, "disturb the expectations and systems of intelligibility put in place by disciplines and institutions" (Ferguson, 2012, p. 230). Those who engage in BQF culture deploy the institutional aesthetics of black 
fraternalism to both fulfill an institutional pleasure and desire as well as a deep personal erotics. As Audre Lorde ([1978] 2007) contends, the erotic as in the "yes within ourselves," the pleasures of life defined outside of dominant institutions, and in this case, an erotic not in the service of an ideal man or manhood. Therefore, BQF culture, especially in its underground state, doesn't constitute an exception to the norm nor a direct opposition to the norm - two approaches that inherently reify the norm. Instead, BQF culture subverts the choices imposed by institutionality and undercuts it logics of normality to form a world of critical possibilities of minority cultural life. In the vein of Jack Halberstam's (2011) exploration of the undisciplined, “These alternative cultural and academic realms, the areas beside academia rather than within it, the intellectual worlds conjured by losers, failures, dropouts, and refuseniks, often serve as the launching pad for alternatives precisely when the university cannot" (p. 7). As such, the gender dissent, or queer failure, characterized by BQF culture, also suggest an institutional dissent. 


\section{CHAPTER 5: MINORITY DIFFERENCE IN THE AGE OF THE DOWN LOW: MIAKAS, INSTITUTIONALITY AND FREEDOM}

Freedom is not a place; it's a state of being.

—Neil Roberts, Freedom as Marronage (2015)

In spring of 1994, Delta Phi Upsilon Sorority of Men filed for incorporation in the state of Florida, becoming the first publically organized black Greek-lettered organization for queer men. By the early 2000s, Delta Phi Upsilon would change its name to Delta Phi Upsilon Fraternity. However, with its origin rooted in BQF culture circa 1985 on the campus of Florida State University, Delta Phi Upsilon's incorporation and subsequent name change, in many ways, encapsulate the crossroads - tensions and dissentions about legitimacy, sustainability and agency-BQF culture was/is inevitably presented: to institutionalize or not? In the late 1980s, as BQF underground culture began to expand beyond the boundaries of FAMU and Tallahassee, Delta Phi Upsilon took the public organizing route, a strategy that other $\mathrm{BQF}$ organizations would not embark until the late 1990s/early 2000s, including Men of DISTINC (1997), KOSIS (1997), DASMOR (2000), The Academia Society (2006), Men With Purpose/Mu Omega Rho (2009), Zeta Alpha Delta (2013). As cliché as it may sound, a will to institutionality, is fundamentally about, to be or not to be, or even how to be, in the age of institutional affirmation of minority difference. 
The incorporation, and subsequent naming, of Delta Phi Upsilon illustrates "its implications within and its rebellion from the conformist affirmations of U.S. institutions" (Ferguson, 2012, p. 175). Particularly, it makes clear the homosocial masculine archive of the American fraternal system and the academy. To be recognized and legitimized within its institutional framework, you must play by its institutional rules and regulations - even for a black queer fraternity. Therefore, a "sorority of men," for the sake of legibility and gender indifference, must become a "fraternity." As Roderick Ferguson (2012) has documented, for Delta Phi Upsilon and other BQF formations, their incorporation "points to the inability of institutions to accommodate the plurality and complexity of minority cultural practices even while nominally affirming minority difference" (p. 176). Delta Phi Upsilon faced the fate of institutional normality that other queer racially minoritized subjects have faced when entering the system of American fraternalism. Yeung and his associates $(2000,2006,2009)$ have profiled the experience of members of Delta Lambda Phi (DLP), a national multiracial gay fraternity. In an effort to mainstream DLP in the masculine homosocial fraternal world, members of DLP have tried to downplay differences between gay and heterosexual-based fraternities by defying gay stereotypes and presenting a desexualized and defeminized public image and performance. As a result, fraternalizing often means "to naturalize gender difference and invite complicity with homosocial mechanisms" (Maddison, 2000, p. 85).

Therefore, to gain subject status, or to "be" institutionally, black queer males and $\mathrm{BQF}$ culture would have to succumb to the essentializing racialized gendered protocols of the state, capital, and the academy, "a maneuver that could only read the unruly breadth of minority formations as unlawful occurrences" (Ferguson, 2012, p. 176). In other 
words, to be institutionally legit, $\mathrm{BQF}$ culture would have to perform a gender coherence and propel a set of nationalist logics framed by "fraternity" that indicts their very gender incoherence and plurality. As such, in this chapter I will attempt to map BQF culture's negotiation and navigation of the interpolative effects of a will to institutionality. If the "freedom" of institutionalization is considerably limited and constraining, then what would compel $\mathrm{BQF}$ formations to adopt such a strategy? Further, would there be alternative maneuvers? Or, as Ferguson (2012) suggests, "In the compromised terrain of culture is precisely where we might find alternatives to how culture is narrowed in regimes of affirmation" (p. 175).

\section{A Renewed Biopolitics of Representation}

At the turn of the twentieth century, systems of the academy colluded with state and capital to produce discourses that propagated an ideal citizenry. These discursive incitements were driven by changes in the social, political and economic landscape of the US. In the face of an industrializing and diversifying country, racialized discourse of gender and sexuality positioned nonwhite populations as inherently unfit for citizenship rights and exploitable in a capitalist society. Ethnologists and sexologists considered sexual perversion — homosexuality, gender inversion, onanism, prostitution, etc —as innate corporeal qualities of the "lower races." Melissa Stein (2015) states, "Scientists interpreted sexual perversion in the 'lower races'-typically, African Americans as well as immigrants from Asia and southern and eastern Europe - as further evidence of their physically and morally degenerate nature and thus their propensity for 'vice' (p. 174). In this sense, "defected" human bodies, or races, constituted a threat to the wellbeing of the U.S. national body. 
Vice commissions, accounts and spectacles, which often played out in the press, acted as scripting devices, writing the pathology of sexual deviance on to the black (collective) body while attempting "to insulate middle-class whites from real and presumed gender and sexual nonnormative practices of African Americans and Asian Americans" (Ferguson, 2004, p. 14). For instance, the often cited 1893 article by St. Louis physician Charles H. Hughes, entitled, “An Organization of Erotopaths” in which Hughes writes:

I am credibly informed that there is, in the city of Washington, D.C., an annual convocation of negro men called the drag dance, which is an orgie of lascivious debauchery beyond pen power of description. I am likewise informed that a similar organization was lately suppressed by the police of New York city. In this sable performance of sexual perversion all of these men are lasciviously dressed in womanly attire, short sleeves, low-necked dresses and the usual ballroom decorations and ornaments of women, feathered and ribboned headdresses, garters, frills, flowers, ruffles, etc., and deport themselves as women. Standing or seated on a pedestal, but accessible to all the rest, is the naked queen (a male), whose phallic member, decorated with a ribbon, is subject to the gaze and osculations in turn, of all the members of this lecherous gang of sexual perverts and phallic fornicators.

Among those who annually assemble in this strange libidinous display are cooks, barbers, waiters and other employees of Washington families, some even higher 
in the social scale — some being employed as subordinates in the Government departments. ${ }^{30}$

Though his claims were unsubstantiated, relevant here is Hughes correlations between race, the "lascivious debauchery," and the interrelated forms of surveillance and criminalization of a black sexuality. As Stein (2015) notes, "His description of the scene blends disruption of sex and gender with markers of primitive ritual and savageness" ( $\mathrm{p}$. 197). Therefore, what makes one a "deviant" or a behavior "deviance," is based on a specific arrangement of looking. Deviant or deviance is ascribed through disciplinary modes of power framed by nationalist ideologies, or what C. Riley Snorton (2014) recognizes as a biopolitics of representation, "the scopic will to identify, reproduce, and subjugate bodies and populations through symbolic systems and structures" (p. 7). In other words, within these structures, deviance situates what is ideal and who belongs in the nation while obscuring the structures therein. We can think about the advent of black fraternalism at the beginning of the twentieth century as part of this representational biopolitics by which the subversion of these racialized gendered discourses codified its masculine homosocial fraternal archival.

This type of biopolitics of representation would become even more significant and sophisticated in propagating racism at the turn of the twenty-first century. The postWWII archival of minority difference configured new social relations of race, gender, sexuality and class in an ever-expanding U.S. imperialism and global capitalism. As Patricia Hill Collins (2005) notes of this "new" racism, these revised configurations of previous logics are framed by new global capitalist relations. Collins states, “The

\footnotetext{
${ }^{30}$ [Charles H. Hughes], "Postscript to Paper on 'Erotopathia,'-An Organization of Colored Erotopaths," Alienist and Neurologist (St. Louis, Mo.), vol. 14, no.4 (Oct 1893), p. 731-32.
} 
increasing concentration of capital in the hands of fewer and fewer corporations distinguishes the contemporary global capitalism from its nineteenth-century counterpart" (p. 33). This change in the structure of the global market effects the distribution of wealth and poverty which disproportionately affect people of color and of African descent, particularly gender and sexual minorities. For instance, postcolonialtransnational feminist theorist Chandra Mohanty ([2003] 2006) points out that women are central to the functioning of a capitalist global economy. In such cases, women from economically developing nations, typically poor, working-class, immigrant/migrant women, are frequently exploited as labor in industries ranging from sex trafficking to tourism. Mohanty also reminds us that social movements like feminism are too objects of global cultural exchange. She warns that Western feminist discourse sometime “reproduce particular 'globalized' representations of women" (p. 486) that objectives and marginalizes Third World women.

Similarly, Marlon Ross (2005) interrogates the epistemological conceptualization of "the closet" within the U.S. gay and lesbian social movement as well as queer theory. Ross postulates that the closet paradigm has a "perverse" effect on people of color. Ross states, "Significantly, historians and theorists of queerness stake their claim to academic centrality largely through the concept of the closet, as they argue with great rigor and sophistication that the binary between closeted and uncloseted sexual desire is a primary determinant of modernity and modernism" (p. 161). As such, Ross posits that the closet paradigm (i.e., coming out), rooted in a white history and a white corporeal subjectivity, privileges a queer experience endowed with whiteness by placing it central to all other queer experiences - making it the modern standard. Thus, the experiences of the queer 
people of color are regulated to the margins in ways that perpetuate distorted, essentialist ideologies that position Western urban, upper and middle class, white experience as "civilized" and "developed" and Africans and Asians as "primitive" and "undeveloped." Ross concludes, "The 'coming out' or closet paradigm has been such a compelling way of fixing homosexual identification exactly because it enables this powerful narrative of progress...but also more fundamentally as a doorway marking the threshold between upto-date fashions of sexuality and all the outmoded, anachronistic others" (p. 163).

Furthermore, the incorporation, and subsequent regulation, of minority difference, whether feminist or queer, into state and capitalist institutions, provides a measure of archival integrity (i.e., "e pluribus unum") that facilitates U.S. global interventions predicated on a U.S. exceptionalism. Considering the affirmation and legitimacy of U.S. Cold War initiatives, Chandan Reddy (2011) explains, "The reformist state advanced individual civil rights as a way to restore its claim to political universality against growing antiracist antagonisms, as it sought to become hegemonic across a globe afire with heterogeneous anticolonial struggles" (p. 21). In other words, the state advanced civil rights and a universalizing subjectivity with its own fortification and Cold War, and later, War on Terror, geopolitics central. As discussed throughout this project, the university was essential to propagating this universalizing subjectivity-the ideal black student would be oriented by the black fraternal projection to become the idealized black citizen - making black fraternalism a type of minority exceptionalism: regulating and distinguishing black bodies while upholding state logics of "excellence" and "exception." As a result, "new" racism often subjugates while advancing minority difference, and in the era of colorblind ideology, gender and sexual difference prominently frame 
racial inequity. Cathy Cohen (1999) argues that contemporary black politics, once primarily framed by consensus issues, are now challenged or forced to grapple with cross-cutting issues which underscore intra-racial differences of gender, sexuality and class. Cohen suggests that an advanced marginalization best characterizes this era of race relations. With an advance marginalization, exceptional minority subjects "who are close to the edges of dominant power, where access and involvement is decision making actually seem possible, confront incentives to promote and prioritize those issues and members thought to 'enhance' the public image of the group, while controlling and making invisible those issues and members perceived to threatened the status of the community" (Cohen, 1999, p. 27). Thus, "deviant" gender and sexual minorities in black communities face a type of secondary marginalization, or what Paul Gilroy (1993) may call neo-nationalism, where they become the objects of management and control for black elites. In turn, black elites blame, shame and even punish those less privileged subgroups (i.e., the black underclass) based on their gender difference or nonheteronormativity (Ferguson, 2004).

Furthermore, the advent of and reliance on mass media has also changed how racism operates at the dawn of the twenty-first century. Collins (2005) contends mass media is a vehicle for how racial "ideologies are created, circulated, and resisted" (p. 34). This includes both dominant and indigenous ${ }^{31}$ media sources acting within the logics of a biopolitics of representation outlined in this section. Dominant, or popular, media typically minimizes the "other" by constructing what Ronald Jackson (2006) calls "the utopic American self'- the ideal citizen based on nationalist ideology, white subjectivity

\footnotetext{
${ }^{31}$ Cohen (1999) suggests that marginal groups often rely on indigenous sources of information due to limited access and representation in dominant media forms.
} 
and order. Jackson states, "The Black body has become a text in which all behaviors are visual and discursive representations to be read as alien, unless those bodies are complicit in almost every sense with dominant cultural norms" (p. 55). Or, as Snorton (2014) suggests, "Popular media serves a mediating function between the sovereign, the citizen, and the others" (p. 26)—serving as a disciplining and surveilling mechanism of black bodies for the constitution of a white normality. And, though indigenous institutions can be a counter balance to popular media iterations, they often work within, if not complicit with, dominant media's racialized logics by policing black sexuality to conjure more respectable public depictions.

Within these new and revised structures and relations of racialization, mass mediatized spectacles of presumed deviant black gendered sexuality have become a vehicle for relaying, releasing and reproducing societal anxiety and order in times of drastic social upheaval. Indicative of these twenty-first century conditions was the development of the black sexual phenomenon known as the down low (DL). Many pundits and scholars have taken up the DL phenomenon, figure and experience in analysis and theory. ${ }^{32}$ The DL discursively emerged in the early 2000s, like the discourse of and similar to the "Organization of Erotopaths" at the turn of twentieth century, linking, as Snorton (2014) states, "black sexuality with duplicity" (p. 3). Snorton goes on to say, "Both in the psychology of reception and the politics of circulation, the down low reflects contemporary anxieties about the nature of citizenship, national values, and social norms" (p. 9). With the DL in the media, blackness was once again, under evolved

\footnotetext{
${ }^{32}$ Beginning with D. L. King's salacious expose, On the Down Low (2004), many commentators and academics have challenged the premise of the DL, including, but not limited to, Keith Boykin (2004) and Jeffrey McCune (2014).
} 
circumstances, constructed and positioned as innately queer — strange, abnormal, and threatening to the national body and those normative black bodies in its proximity.

The DL, as a discursive site of multiple meanings, locations and practices, typically signified a group of black men who "secretly" had sex with other men while performing a type of black heterogender practice. Put differently, they defied the masculine homosocial — crossing the always-already crossed line — as well as hegemonic queer logics of "coming out." Instead, Jeffrey McCune (2014) posits, “The DL acts as an epistemology — a knowing and doing outside of the common eye, or more aptly the scenes of surveillance" (p. 6). As such, McCune reframes the DL as a positionality by which black men whose behavior and performance doesn't align with the dominant ideal of black masculinity find solace and meaning in a covert space and place — subverting ideas of black masculinity and white queer identity.

However, how the DL was presented in the media was quite different. Snorton (2014) states, "Down-low melodramas most often recirculate racial, gender, and sexual myths that produce down-low men as either morally corrupt predators or victims of a pathological culture (i.e., blackness) that repudiates queer identities" (p. 4). Melodrama here is in reference to the various types of popular media that take up certain excessive and expressive discursive "drama" to make a moral point. The media frenzy behind the DL figure was propelled by its potential public health risk to the nation based on unsubstantiated correlations to HIV/AIDS transmission rates - diverting attention away from state policies and structures that inadequately addressed HIV/AIDS among women, people of color, and the poor. Snorton contends, "The down-low figure is one exemplar among many contemporary and historical characters, such as Bigger Thomas, "Willie 
Horton," and Nushawn Williams, which re-presents — that is, reframes and representsblack masculinity as dangerous, prone to trickery, promiscuous, and contaminated while also framing white masculinity and sexuality as less susceptible to such problems" (p. 9). In the next section of this chapter, I want to consider another deviant black male figure that emerged in the shadow of the down low at the turn of the twenty-first century - the MIAKA. Though the scope of circulation maybe less expansive as the DL figure, the MIAKA figure in many ways support DL notions of black sexual duplicity and threat, particularly as it relates to logics of institutional minority difference. Therefore, like Eve Sedgwick (1990), and Snorton who follows, I want to understand how the category of MIAKA via the DL works within and against the archival power of the academy, "what enactments they are performing and what relations they are creating" (p. 27). By understanding the MIAKA media melodrama, we can better comprehend the terrain in which BQF culture has had to navigate and negotiate a will to institutionality.

\section{MIAKAs on the Down Low}

On March 6, 2007, the local Houston news station KHOU, covered a story that was brewing on the internet's blogosphere. Pictures had been posted of young black queer males supposedly from Texas Southern and Prairie View A\&M universities posing and embodying what was seen as Alpha Kappa Alpha (AKA) Sorority's signature recognition symbols — colors, hand signs, masks, and maybe most disturbing to viewers, their feminine disposition. The group was identified as MIAKAs, or Men Interested in AKA. A Nashville NBC affiliate later ran another story about MIAKAs at Tennessee State University, reporting:

A local student was 'outed' as a MIAKA, which stands for Men Interested in 
AKA's. The student was reportedly so embarrassed by having his secret life exposed, he stopped going to class and has threatened a defamation lawsuit. There are rumors on campus that other male sorority members will be 'outed' in different ways in the days ahead. (cited in Farrow, 2007)

After the national coverage, what ensued was a national quest to "out" and persecute all MIAKAs and those alike—not just on black college campuses but it was alleged that AKA national headquarters was preparing to take legal action against the group. Starting earlier that year, the pictures circulated on various blogs, which were believed to have originated on a personal blog, but quickly migrated to public forums on BET.com, BlackPlanet.com, and MediaTakeOut.com, where the pictures picked up major traction and attention. The attention was largely criticism of the group, not so much for its AKA ties, though that was a significant gripe, but for their public queer deviance. As BET journalist and Africana Studies scholar Tara Lake (2007) writes:

As the debate raged, one thing became clear: The controversy was less about the sanctity of AKA and more about homophobia. A self-proclaimed Omega Psi Phi member posted, 'I can care less about being politically correct. Homosexuality is wrong and it is tolerated too much, especially on our Black campuses.' One AKA proclaimed, 'God is not pleased with this.' Others called it 'sick.'

Lake goes on to report that Alfrances Sharpe, a 70-year-old 1958 Tennessee State University AKA initiate, was "livid" when she saw the MIAKA news, but she acknowledges, "Yes, these groups have been around for a long time, but they were never public." Another comment posted in the BET forum by someone believed to be a 
member of AKA might have best captured the overwhelming black public sentiment. The writer states:

My confusion lies with the following....1. In an age where our black men (and race) face many challenges regarding a historical lack of identity (it's been stolen from us from the time our ancestor's feet touched the U.S. shores) this action (creating the MIAKA's and an unofficial and unrecognized chapter/organization) has and will to further set back the 'cause' as now some of our males are consciously choosing to identify with a women's organization? Why would you, and others who think like you choose to do this? 2. If you are pursuing the further establishment of gay rights why not start a gay male fraternity and/or trans-sexual sorority? 3. If you truly respect and think you understand the foundation and principles on which Alpha Kappa Alpha was founded you will remember and honor that it is for women (in addition to other principles) only. (cited in "MIAKA," 2007)

This string of comments illustrates the MIAKA figure's connection to the DL narratives under the evolved logics of contemporary racism. Snorton (2014) contends that the "down low" is a contradictory discursive treatment—-simultaneously, a way of knowing and not knowing the "low," or the debased, demarcated by the public/private divide symptomatic of a black sexual hypervisibility. Thus, to know in private is a way of protecting black subjectivity from surveillance and exploitation. As Snorton suggests, "they gesture toward the way black sexuality is already figured as down low" (p. 14). On the other hand, to know publically induces national and intraracial anxiety about black subjectivity as an immoral conspirator and sexual threat to a respective black and queer 
normality as informed by institutional minority difference. Therefore, these comments showcase an advance marginalization where the black underclass is shamed in an attempt to manage and control not only them, but also a black public image.

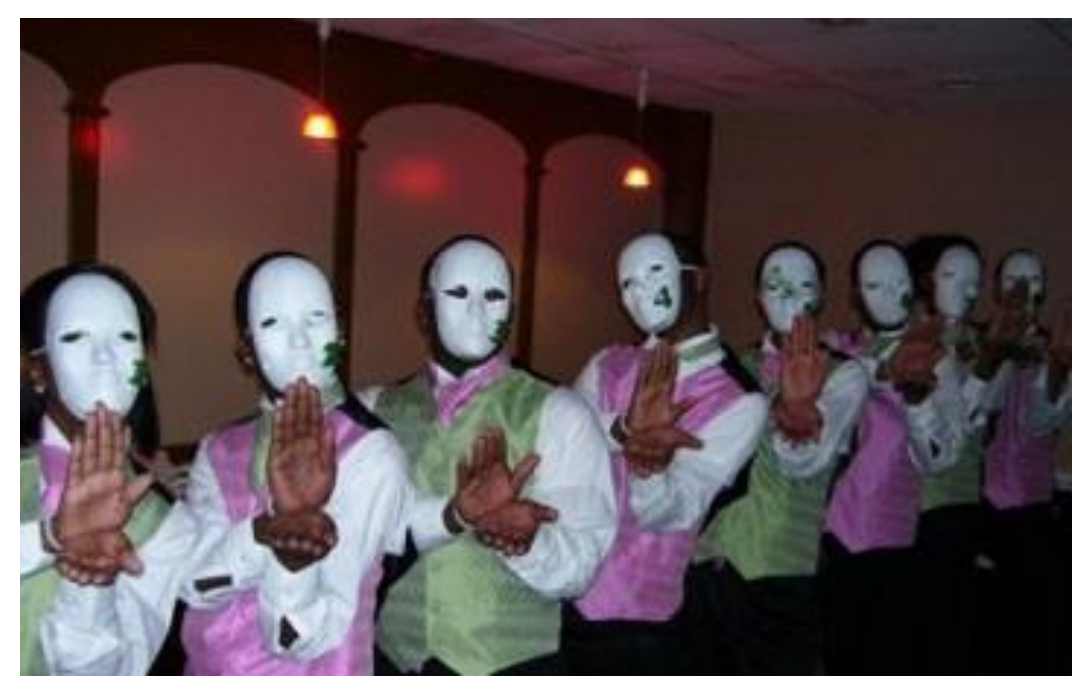

Figure 2. Reported members of the Houston-based Tri-Alpha chapter of MIAKA ("Star Jones Responds," 2012).

As mentioned in the previous chapter, MIAKA originated as an official male auxiliary group for AKA. However, in 1979, MIAKA became Cavalier Fraternity, Inc. as the sorority and auxiliary group severed ties with each other and the auxiliary became independent (West-Savali, 2012). Other BGLO auxiliaries took similar steps toward independence or ceased in 1988 when the National Pan-Hellenic Council (NPHC), the national governing body for BGLOs, disbanded all sweetheart groups. Nevertheless, some AKA chapters continued to associate with MIAKA and/or its moniker in some form. The Alestle, a Southern Illinois University student-run paper, reported in 2003 that the Epsilon Iota chapter of AKA hosted a Mr. MIAKA Pageant (Phillips, 2003). 
Furthermore, all the BQF participants of this study made it very clear that MIAKA — in both its historical and more recent mediated presence—was/is not associated with their respective organizations. Some participants did offer theories of where the MIAKA figure that circulated in the media came from, such as defunct or rogue chapters of sweetheart groups or of previous iterations of $\mathrm{BQF}$ chapters before they became more formalized. Others described MIAKAs as males who actually want to be or emulate AKAs without any organizational distinction; therefore, demarcating BQF organizations who maybe inspired by or patterned after black sororities, heterosocially, but never want to be or see themselves as members of a particular black sorority.

Who the MIAKAs are in the mass-mediated figures - or better put, who they belong to-remain unclear. However, what is obvious, is that "MIAKA" has become a "dirty" word for both the general public and within BQF culture. This is ironic, given that, because of the media hype surrounding MIAKA, most people who know anything about BQF culture, generally, associate it with MIAKAs. Therefore, I am not interested in determining who MIAKAs are, or who they belong to. As stated before, I'm interested in what "MIAKA" as a mediated figure does in terms of black fraternalism, BQF culture, and institutionality.

Evident in the reactions to the MIAKA figure in the media, an air of disgust permeates. People, particularly black folks, are disgusted by the sight of MIAKAs: "This is sick!" Sara Ahmed (2015) helps us think about the emotive qualities of disgust and its crucial role in situating power relations. For Ahmed, "gut feelings" are not definitive of disgust, "Or if disgust is about gut feelings, then our relation to our guts is not direct, but is mediated by ideas that are already implicated in the very impressions we make of 
others and the way those impressions surface as bodies" (p. 83). Ahmed thinks about disgust as "bad taste" - for the subject to experience an object in bad taste the subject must come in contact and possibly be consumed by the distasteful object. Thus, Ahmed states, "The inter-corporeal encounter of incorporation or ingestion hence involves the perception of 'badness' as a quality of something only in the event that badness fills up, as it were, the mouth of the one who tastes" (p. 83). Disgust is projected onto an object through a bodily proximity; a contact that is read as offensive and sickening. As a result, disgust as an affective material draws us in - a "seeable and knowable as stranger-thanme" (Ahmed, 2015, p. 83) — as well as pull us away, an involuntary recoil of repulse. Ahmed states, "Pulling back, bodies that are disgusted are also bodies that feel a certain rage, a rage that the object has got close enough to sicken, and to be taken over or taken in" (p. 86).

Disgust then is not simply an idiosyncratic inner state; instead, "it works on bodies, by transforming or 'working on' the surfaces of bodies” (Ahmed, 2015, p. 85). Disgust is informed by our social locations within social-historical structures. What is disgusting, is that which is abject, or as Ahmed (2015) writes, "To be disgusted is after all to be affected by what one has rejected" (p. 86). Here, as discussed in previous chapters, we can think of the MIAKA figure as representative of the homosexual-femme, the one who has been lost due to a black fraternal homosociality, and only reclaimed in an underground $\mathrm{BQF}$ heterosociality. Therefore, what makes the MIAKA figure disgusting, sickening ${ }^{33}$ even, is that it always already comes from within-disrupting what is, for what could be.

\footnotetext{
${ }^{33}$ I use sickening here to denote the duality of the term. On one hand, queer people of color are sickeningas-in-abject in relation to modernity and Western human subjectivity. However, queer people of color
} 
Furthermore, Snorton's (2014) contends that DL narratives resonate in the national conscious not for any primary risk of HIV/AIDS transmission, but instead, these narratives play on "the particular anxieties produced by the mutually reinforcing discursive processes of stigmatization that circulate under the signs of 'black' and 'queer' (p. 66). Like the DL figure, the black homosexual-femme MIAKA is stigmatized before they are ever "infected." "Infected" here being the "appropriation" of AKA—seen as a nefarious disposition. Improvising on Snorton's claims, in this sense, the "appropriation" of AKA becomes an additional physical proof of an already stigmatized body. Ahmed (2015) states, "It is not that the abject has got inside us; the abject turns us inside out, as well outside in" (p. 86). In other words, the feeling of disgust and its recoil by the subject is a result of the instability in the subject's normativity, and thus, institutional insecurity. To ensure that black fraternalism, and the ideal black embodiment it denotes, is not what is always already present — that it is a part of and not apart from the norm — disgust and its reaction is par pro cursu $^{34}$.

Through the mass-mediated melodrama, the MIAKA figure becomes a border object — it reconstitutes the norm by its very threat. Ahmed (2015) states, "Borders need to be threatened in order to be maintained, or even to appear as borders, and part of the process of 'maintenance-through-transgression' is the appearance of border objects" ( $\mathrm{p}$. 87). As an emotive predicated on contact, the dominant media makes the private (that which is below), public, and in doing so, brings the "disgusting object" in proximity, or in contact, with idealized national subjects (that which is above). Put differently, as

often reframe and employ the term to mean sickening-as-in-unapologetically fierce, to work (or werk) on and against normativity. Thus, as E. Patrick Johnson (2005) has argued, black queer vernacular often constitutes a queer of color critique of both discursive and material sustenance.

${ }^{34}$ Meaning, "Par for the course" in Latin. 
discussed in the previous chapter, this public proximity risk "contaminating" a projected institutional minoritized community via black fraternalism. Ahmed states, "The pulling away from the object keeps the object at the centre of attention, as a centring which attributes the affect of sickness to the very quality of the object" (p. 86). As mentioned previously, the coverage of MIAKA in the national press has not been as expansive as the DL figure; however, the limited national coverage has resulted in a proliferation of discourse in the blogosphere-keeping the deadly object alive and constituting an effect of a continuous "pulling away" in a border-making maneuver.

Therefore, not only does disgust take over the consuming subject, the contributing object is also painted ${ }^{35}$ with disgust. This may explain why even members of BQF organizations reject the MIAKA figure. One is disgusting by proximity to disgusting, and therefore, distancing reflects some struggle for affirmation and protection, or aboveness. Ahmed concludes, "Disgust at 'that which is below' functions to maintain the power relations between above and below, through which 'aboveness' and 'belowness' become properties of particular bodies, objects and spaces" (p. 89). As a result, I consider the mass-mediated MIAKA figure and the material a/effects of disgust it generates as an agent of institutional alignment. Through its border-making properties, it distinguishes above bodies, or valued bodies, from below, the devalued, while "pulling" bodies toward institutional logics of recognition.

\footnotetext{
${ }^{35}$ I use painted here to describe how the disgusting object becomes disgusting through the experience of the subject. I also use painted to connote a spatial configuration and valuation of disgust - signifying the lower regions of the body "associated both with sexuality and with 'the waste' that is literally expelled by the body" (Ahmed, 2015, p. 89). Similarly, in queer vernacular, to be painted is associated with bottoming, in that, a "top"- - the one who penetrates in anal sex - can be painted - by the waste of the one who is penetrated which is considered "disgusting." Therefore, in some ways, I am suggesting a reworking of Ahmed's metaphor of disgust. Instead of degustation, disgust might be better theorized (at least in this case) as penetration from below - that which is "the bottom" penetrating that which should be on top, or above.
} 


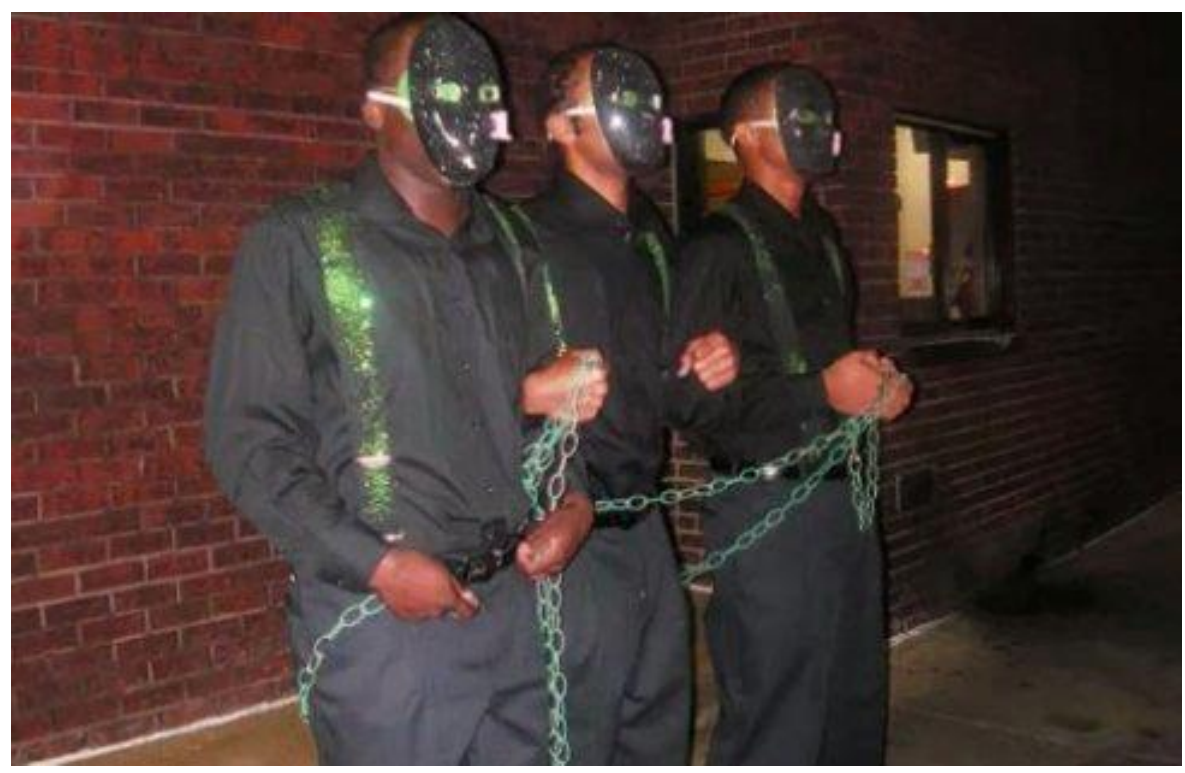

Figure 3. Photo from a video of MIAKAs that surfaced in 2012 (Kohli, 2012).

Let's consider the MIAKA melodrama resurgence in June of 2012. The catalyst of this reemergence was a video of alleged MIAKAs during a probate or new member show that circulated online. Journalist Kirsten West-Savali (2012) writes, "This video, showing 'MiAKA men' imitating the calls, signs, attire and external mannerisms of the ladies of AKA, was accompanied by persistent rumors that MiAKA was threatening to sue Alpha Kappa Alpha Sorority for inclusion based on the grounds of gender discrimination." This time, the video and rumor of a potential lawsuit by MIAKAs against AKA seem to have originated from the blog/forum website KollegeKidd.com. Though there has never been any evidence of a lawsuit by MIAKA against AKA for discrimination, this did not stop several prominent media outlets and personalities from running the story, including, but not limited to, The GRIO, The Huffington Post, Ebony, Madamenoire, Atlanta Black Star, Philadelphia Inquirer, and several black radio stations. Erin Ryan (2012) reporting for Jezebel writes, "In none of the reports did any news outlet quote a source or attorney from MiAKA." In fact, most of the reported 
stories referenced the KollegeKidd website which offers no proof of a lawsuit, just speculation, stating:

There may be a big lawsuit in preparation against the oldest and most renowned sorority founded for African American women...Men interested in Alpha Kappa Alpha Sorority, also known as MIAKAs, are threatening to file a lawsuit against Alpha Kappa Alpha Sorority, Inc....The group of men, whom all are homosexual, are alleging homophobia and gender discrimination by the sorority. ("MIAKA Threatens," 2012)

Furthermore, many of the 2012 stories reused pictures from the 2007 MIAKA stories in their publications, and with the recycled pictures came some familiar responses. The Grio reported the following responses to the MIAKA story from various outlets:

'It is terrible! Everywhere I go in Chicago I've seen was more gay black 'flamboyant' men than any other race! My heart hurts at this sad epidemic... where does it really leave the black family dynamic/community...'

'The black woman is being taught to accept the behavior by the 'agenda.' Hence why many black women have homo sexual men doing their hair. They have homo sexual male friends. And then we have a lack of black men being proper fathers and role models for our young men.'

'Then you take the first black president and get him to verbally support this life style, and you now have made a huge impact on the minds of millions of young black people. This is a system that was started long before President Obama got into politics, but he is now being used to get the black community on board with the 'agenda.' (West-Savali, 2012) 
High profile BGLO celebrities also weighed in on the public controversy. On June 8, 2012, member of Kappa Alpha Psi, political commentator, and professor, Marc Lamont Hill, shared the KollegeKidd blog on Twitter and stated:

'I'm not disputing their claims of homophobia-I don't know enough about that context—but I think AKA's principle objection is gendered.'

'I don't think it's discriminatory for a sorority to be able to only accept women. Same with Frats...'

'I think MIAKA is fine. We [black frats] have 'sweethearts' 'pearls' etc... Nothing wrong with the male version. But joining [AKA] is another thing' 'I don't see why they don't just pledge Alpha [Phi Alpha]!'36

The following day, Star Jones, former executive officer of AKA, attorney, and talk show host, took to Twitter to address the issue:

'Shall I start with what the hell is a MIAKA?'

'Just because you're INTERESTED in \#AKA doesn't make you an \#AKA. I'm interested in basketball...but my free throws suck. \#getAgripJoinaFRAT'

'Tell the MiAKAs (how hilarious) the former 2nd Supreme said don't waste your money on a lawyers retainer; you have no case! Oh..and \#DUCES.' 37

With these comments, we can see how the "disgust" with the MIAKA figure is not solely about "appropriation" or MIAKAs trying to join AKA, which remain an uncorroborated claim. Instead the primary "disgust" is about the black homosexual-

\footnotetext{
${ }^{36}$ During Hill's twitter dialogue, he also suggests that he would have no problem with qualified transgender men joining BGLO fraternities.

${ }^{37}$ After Star Jones' response, the Tom Joyner Morning Show, a syndicated black radio program, covered the story with an interview with someone who was supposed to be a MIAKA. The interviewee was not a MIAKA, however, he had attempted to join the Academia Society. Needless to say, he offered no insight about a potential lawsuit and was essentially made fun of and used to reinforce the masculine homosociality of BGLO fraternities.
} 
femme male subject themselves. The illegitimate bodies of the MIAKAs explains why even highly intelligent individuals like Hill and Jones didn't even question the legitimacy of the lawsuit and its sources. The MIAKAs actual embodiment justifies their deviance - the AKA “appropriation" and membership accusations - obscuring the implication of institutional structures and knowledge/power regimes that have facilitated the abjection of the black homosexual-femme. Thus, the MIAKA figure is not only a social threat to a nationalist and black masculine homosociality—one comment specifically condemns black heterosociality — but with the rumored litigation, it's also a legal threat - poised to "penetrate" and/or "contaminate" the ideal black social and structural bodies. The "pull" of disgust, then, keeps the MIAKA figure in the news and blogosphere, overwhelmingly indigenous media, in order to reify an institutional black normality. Hence, the resounding calls for MIAKAs to "just join" or "start your own" frat — if even possible to join, these resolutions would accompany institutional regulations of embodiment. More broadly, as an agent of institutional alignment, the disgust of the MIAKA figure frame im/proper bodies and suggest through what channels those proper bodies are achieved.

What was not lost in the MIAKA coverage, however, was the spectacle's political timing. The MIAKA stories broke about a month following Barack Obama's May 9, 2012 announcement supporting same-sex marriage- - becoming the first siting U.S. President to do so. Rightfully, some LGBT supporters found the timing very suspect: 'I find it no small coincidence that during such a pivotal moment in this nation's history, when President Barack Obama and black faith leaders are publicly fighting against homophobia, joined by coalitions of black people coming together, this story emerges 
again' (cited in West-Savali, 2012). Here, similar to the countless other historical tropes of black sexual danger, we can consider a blatant deployment of the MIAKA discursively as dangerous and deviant — a deterrent, particularly to black political action and social change at a time of advance marginalization.

However, if we consider the melodrama of the MIAKA figure and its emotive a/effects of disgust as an agent of institutional alignment, there are deeper implications. The consolidation of institutional structures and logics through the "pull" of disgust also reifies a type of homo-normativity and -nationalism that centers policy support for samesex marriage over more deviant forms of sexual politics (read as blackness) - a politics and performance of those who are situated outside of state sanctioned, normalized white, middle- and upper-class, male homosexuality (Cohen, 2004). In other words, the contrived threat of the MIAKA figure helps to compel and propel institutional understanding and absorption of minority difference. Both black and queer minority (in)difference, along with their respectability politics, make the MIAKA figureconnoting race, gender, class, and sexual difference-“disgusting," and in doing so, further their respective essentialist political agendas and extend state protocol, power and reliance. Moreover, the spectacle of the MIAKA overshadows the actual precarity of black queer life under the very structures the spectacle works to reinforce.

The MIAKA spectacular constitutes what Snorton (2014) considers the glass closet of black sexuality. Considering the critique of those like Ross (2005) of queer studies" “raceless paradigm," Snorton draws on Sedgwick (1990) and W. E. B. DuBois (1903) to re-formulate "the closet" metaphor of queer liberation. Snorton deploys DuBois' interlocking racialization theories of the veil and double-consciousness to extend 
queer studies' poststructuralist discursive rendering of the closet, predicated on speech acts of silence, to include the visualization of difference. Snorton states, "For DuBois, then, the veil is a metaphor for the sociogenic experience of blackness; it positions double-consciousness as a critical optic for black people in negotiating the condition of hypervisibility" (p. 22). Thus, Snorton subverts institutional logics of minority difference to theorize race and sexual difference nonexclusively_disrupting the parallel constituting of race and sexuality to "work through multiple axes of oppression" (p. 23). As a result, Snorton posits that "the closet" is transformed from a space of concealment to a site of confinement, display and observation when blackness is considered. Snorton writes, "My formulation of the glass closet thematizes that very narrowing in and the claustrophobic feelings produced by technologies for surveilling and producing blackness as an object of sexual knowledge" (p. 23). Therefore, the spectacle of the MIAKA, much like that of "An Organization of Erotopaths," works to confine blackness as well as queerness through and to the logics of institutionality.

In the previous chapter, I began to construct institutional black fraternalism, metaphorically, as archival text, or film, that is projected like an image on a screen. I proposed that institutional black fraternalism is an idealized "projection" of black subjectivity—an imagined minoritized community framed in part by, but definitely within, the archive of the university and its knowledge/power regime. Therefore, to be seen as an orienting device of normality, the imagined minoritized community must be "projected" from its archival film, the master tape of the university, in which it is embedded. Furthering the archival film projection metaphor, I suggest the hypervisibility 
of black sexuality, the glass closet if we will, constitutes the lamp (light)/glass through which black fraternalism's institutional film runs and is projected.

For black sexuality to be conceptualized as a glass closet is to understand "there are often, if not always, elements of distortion and projection when working with glass" (Snorton, 2014, p. 15), in that, black sexuality is always already perceived as deviant and queer. The MIAKA and other DL narratives reverberate throughout the media and other cultural production sites as hidden "truths" about blackness. As Snorton (2014) states, "In this sense, glass is not merely a metaphor but it is shaped by and embedded within our daily materiality" (p. 15). Since its conception, black fraternalism has worked against the glass nature of black sexuality, particularly that which suggest queerness, by adopting a nationalist masculine homosocial disposition-one that represses the homosexualfemme subject. Therefore, as an institutional archival entity, the idealized image of black fraternalism is projected through and against what it means to live behind the hypervisibility of the lighted glass. Snorton states, "There is no identity without mediation, which the concept of glass helps us to understand directly by demonstrating the complex and even contradictory ways visuality structures our perceptions of others and ourselves" (p. 17). The spectacle of the MIAKA and its glassy "disgusting" material, then, reinforces the idealized image of black fraternalism and its institutional logics of normality.

\section{Black Queer Fraternal Fugitivity}

The "pull" of the MIAKA spectacle towards institutionality, a reinforcement of its will, is evident in the development of BQF groups. Even before the MIAKA spectacle went national, there were concerns in the BQF community about surveillance and 
negotiating a black sexual hypervisibility. One study participant recalled a time BQF groups were called out on a local radio program in Tallahassee around 2005, stating: "Because now even though you may have known in the back of your mind and known because you know somebody told you, but now that it's been publicly aired that okay, 'there's the boy AKAs, the boy Deltas, the boy Sigma Gamma Rhos'...everybody was on blast." Other participants spoke of the 2007 and 2012 MIAKA spectacle as a galvanizing force in how their organizations and other BQF groups would structure themselves and position their organization in relation to the university. One participant compared the aftermath of the MIAKA spectacle to corporate restructuring: "It's like a big fortune 500 corporation. Like ING the retirement cooperation. When the crash happened, the recession, and they changed their name, they are like Voya or something. Similar concept. But actual change on the inside."

Though these organizations historically have been inspired by and/or patterned after various black sororities, in their public form these groups have made substantial efforts to move beyond their sorority connection and establish new traditions and practices. All the men I spoke with did not see a sorority-like model for their organizations sustainable largely due to reputation and legality in the wake of the MIAKA scandal. Some groups even began the process of restructuring before MIAKA surfaced in the media, and others, like Delta Phi Upsilon, claim to have never modeled themselves after a black sorority. Nevertheless, there are BQF groups that now forbid their membership from any type of BGLO sorority emulation and have rid their infrastructure of anything that resembles a BGLO sorority. For others, though they no longer structurally identify with any BGLO sorority, they do pay homage to their 
heterosocial beginnings in the history, folklore, and revamped traditions and cultural practices. This includes, as discussed in the previous chapter, sometimes complicated continued relationships with black sororities (particularly at the local level). For instance, some interviewees talked about the use of "soror," meaning sister, as an organizational honorific for greeting members, which is common in black sororities as well as BQF underground culture. With these new advances, BQF organizations have developed gender neutral terminology that reflect their changing organizational perspective. However, one interviewee qualified his use of the term "soror" by saying he would never use it in any official or public capacity, but if he is relationally close to another member he sometimes uses "soror" just as some gay men say, "Hey girl, hey sis."

In the push to be made legible, uncovered and rendered to the state, BQF organizations have taken a disidentificatory approach to institutionalization-normalizing just enough to be made recognizable for security, but never fully residing in the state protocols. From there underground radical utopian, $\mathrm{BQF}$ formations and the black queer bodies who occupy these spaces, search and continue to search for different ways of being in the world and being in relation to one another than those already prescribed for the institutionally archived minoritized subject (Halberstam, 2011). On the surface, this may simply seem to be about achieving some sort of fraternity status; however, American fraternalism, including black fraternalism, as this project has attempted to illustrate, is a state standardizing mechanism of gender (in)difference rooted in a modern disciplinarity and interdisciplinarity. A (inter)disciplinarity and bureaucratization of diversity that Ferguson (2012) reminds us produces "closures that resulted from the state, academy, and capital's responses to prior social movements, closures that prevented the redistribution 
of material resources, deactivations that limited alternative sexual and gender formations in every way they could, all the while claiming that they-and we-would be satisfied" (p. 207). Thus, remixing on Audre Lorde, to be fully institutionalized for the BQF subject, is to attempt to (re)enter the master's house.

In other words, to fully rely on the academy, and its institutional logics of recognition, $\mathrm{BQF}$ organizations would have to comply with the idea that "minority difference can only be achieved through the forms that dominant institutions offer" (Ferguson, 2012, p. 226), the very forms that initially rejected their being. Trinh Minh-ha ([1989] 2006), Vietnamese filmmaker and postcolonial literary theorist, warns of the dangers of (re)entering the master's house, or employing dominant institutional ideology, for legitimacy in this period of power's archival articulation. In a manifesto to indigenous women writers in postcolonial literature, Minh-ha invokes the sentiments of Audre Lorde, "For the master's tools will never dismantle the master's house," and reminds indigenous female writers that though they may feel marginalized in their efforts, there are women writers who have resisted colonial and patriarchal structures to find strength in their unique style and approach. Thus, employing the master's tools gives a false sense of progress while continuing to perpetuate hegemonic ideology and structures. Minh-ha examines the apartheid language of 'separate development', which on the surface appeared to give native South Africans autonomy in their 'development', but instead, perpetuated an ideology of 'difference' that locked them into stratified divisions of control. In referring to this apartheid language, Minh-ha states, "It is no more than a tool of self-defense (for the oppressor) and conquest" (p. 247). Therefore, 
Minh-ha warns female native writers not to fall in to this "semantic trap" of appropriating dominant ideology which could lead to dividing women against each other.

Here, we can consider the "pull" and calls for BQF subjects to formulate legitimate Greek-lettered organizations, separate and distinctive from BGLOs but embedded within the university archive, akin to the "semantic trap" of a neo-colonial literary regime. In this case, potential black queer Greek-lettered organizations, charted on university campuses, would be faced with the pressure to conform to a type of organizational exceptionalism that mandates a degree of normalism and distinctions between exceptional and non-exceptional queers while their organizations would always contrast, or be the difference between, the cis-heteronormative BGLOs. Let alone, establishing black queer fraternities would essentially "out" its members, and the gender (in)difference, or normativity, that would come along with fraternalizing perpetuates a compulsive heterosexuality and homophobia. Minh-ha (2006 [1989]) makes similar points about the repressive nature of difference ideology found in the exoticism and tokenism of indigenous literature. Minh-ha argues native writers (telling native stories) are praised and categorized as a 'special' genre, which again may look and feel like progress, but ultimately it places native writers in a narrowly defined lane under constant surveillance of Western authorities.

When it came to the topic of forming publicly recognized campus-based groups, almost all the study participants spoke of issues of surveillance, including safety, social risk and concerns:

... This is what people don't understand about underground, the reason why it remained underground, black families are so cruel. They are getting better. But 
those kids couldn't go home with that... And then some of those kids wanted to be D9.

...I mean, can you imagine being, being on campus and trying to have an interest meeting and you know, and a respected male organization are blocking people from coming in.

... And when I joined, FAMU didn't even include sexuality or gender identity in their discrimination policy until 2013 or 14. So there was no protection for people...There were brothers who would show up to every probate, every set or class, whatever you want to call it, in their letters, decked out. Their house will be decorated, but they would never talk about it or wear it on campus because of fear of backlash.

Participants also discussed the incongruence between what they saw as their fundamental purpose as BQF organizations to be as accessible as possible for queer students of color and the institutional protocols of legitimacy and exceptionalism. For instance, most of these groups intentionally require a lower GPA membership requirement than what is expected for a campus-based fraternity. One study participant explains how most BQF organizations require a minimum 2.0 GPA because their target demographic is black and Latino queer students, who in many cases, have lower GPAs due to life circumstances, such as being kicked out of their home, no family support, inability to find employment, etc. However, as the participant goes on to say, “often times you see that they're still amazing individuals in these organizations that go on to have great careers."

Furthermore, BQF organizations that have attempted to charter chapters on college and university campuses have faced rejection even when they adopt institutional 
standards. One study participant discussed his organization's struggle for mainstream campus acceptance at length:

Our struggle with getting mainstream acceptance on the college campuses...we thought we had excellent inroads on historically black college campuses where there is a large consortium of LGBT people, many of whom are not looking for the more traditional experience. And so we assumed that we would be able to make some inroads there. I know I'd personally attempted to infiltrate Morgan State University when I was the regional director and we were kind of shut off at every turn. We almost made it on campus at Coppin State and then their director of Greek life left and we lost our support. Prairie View was very, very receptive to us in terms of whom we were, but that was because of who the students were on campus who had been initiated into the organization but they were not ever a recognized organization by the campus. But, you know, the students were very powerful students much like myself.

When I asked, what were the specific reasons campuses were not allowing your organization to charter chapters, the participant explained:

Statements that were made were very condescending. Some were we are exclusive when every fraternal organization is exclusive in one way or another. But the suggestion was that because we're a gay organization that we were exclusive and not accepting of straight men, which is why we changed kind of our tagline to be 'gay, bisexual, and progressive men'. So that straight men who were interested, even though we knew no straight man would ever be interested in joining our organization, we changed that to be more palatable to college 
campuses. What we found was that that was just an unfair barrier place in our way because it is true that divine nine organizations are very exclusive in whom they except and we were no different in that regard.

The participant's narrative illustrates the effects of how minority difference has been institutionalized within the academy. Cis-heteronormativity has been naturalized and bureaucratized, made invisible, to constitute an ideal black subjectivity. In the biopolitics of institutional representation, BGLOs are then rendered ideal and their exclusiveness often go unnoticed or is considered reasonable. Thus, that which goes unnoticed and unquestioned becomes the undue burden that $\mathrm{BQF}$ organizations often must meet to be campus recognized.

As a result, BQF organizations have mostly bypassed campus recognition for a more community-based approach. There are a few exceptions where chapters have been established on campuses, but campus charters remain little to no priority for BQF groups. As the above participant explains, "So what we have turned our kind of philosophy to is city based chapters, which is not unlike how we started and it is inclusive of every age from 18 , which is when you would be a traditional college freshmen into adulthood." Other study participants express similar sentiments:

...Just because of misinterpretation or things of that sort and that stops a lot of it [campus recognition]. And you know there is a lot to joining campuses and, and we feel that we're able to exist and be more efficient and less limited being a community-based organization... because we're able to do more without regulations. 
...It [campus recognition] wasn't a big deal...We didn't get our glory or gratification on campus. We let the girls have that. Our gratification and glory came from the bar scene.

Thus, BQF groups' disidentification with institutionalization, a formalizing without institutional incorporation, can be considered a deliberate strategy to remain stateless. In many ways, these groups have placed themselves in the in-between space of the community, between the scripted place of the academy and the unscripted world of the gay bar, what Neil Roberts (2015) might call freedom as marronage. Though the concept of marronage derives from a specific socio-historical context, Roberts considers its transhistorical and contemporary utility in African diasporic politics to encapsulate the "liminal and transitional social space between slavery and freedom" (p. 4). Roberts states, "Marronage is a flight from the negative, subhuman realm of necessity, bondage, and unfreedom toward the sphere of positive activity and human freedom" (p. 15). Therefore, marronage is an adequate term "to describe the activity of flight and the dialectical mechanisms operating during the flight process" (Roberts, 2015, p. 8) for BQF subjects as they move from the institutional regulations of the academy and the relative freedom of the underground scene.

Like many preceding queer theorists, including, but not limited to, Dean Spade (2008) and Jack Halberstam (2011), I find political scientist James C. Scott's work useful in making meaning of undisciplined queer practices in relation to the state and its efforts to universalize modern processes over localized, and often more effective, ways of being. Instead of employing Scott's (1999) Seeing Like a State, however, I want to explore his The Art of Not Being Governed (2009) to characterize BQF organizations' marronage 
status. Scott argues that in southeast Asia, much like regions of southwest China and the highlands of Latin America and Africa, there are indigenous people who occupy the highland periphery of nation-states, or what he calls shatter zones, "where the human shards of state formation and rivalry accumulated willy nilly, creating regions of bewildering ethnic and linguistic complexity" (p. 7). For Scott, these populations are not barbaric, primitive or backwards, but instead, refugees of early state-making in which "state expansion and collapse often had a ratchet effect" (p. 7). These ratchet effects were the result of wars, taxes, conscription, and conditions of servitude or slavery. Ultimately, statehood meant a type of permeant, fixed subjectivity over more loose-knit or fragmented arrangements.

Scott's observations are not much unlike the U.S. state expansion through the absorption and formation of minority difference and ideal subjectivity catalogued throughout this project. In this case, due to the hypervisibility of black sexuality and the interpellation of the state, $\mathrm{BQF}$ groups find themselves in a shatter zone of sorts, where they are in a constant state of refuge, forming eclectic ways of being while avoiding the confinement and regulation of the state's totality. Scott (2009) contends that besides moving away to avoid enslavement, these highland people practice a subversive state politics through their slash-and-burn agriculture and oral history tradition. Scott insists these methods are indicative of a population on the run from state control. Slash-andburn agriculture, a farming method where root crops are harvested in alternate areasmoving and returning to plots of land after its nutrients are depleted and restored - makes seizing crops difficult for the state. Furthermore, Scott suggests the highland people intentionally continue to utilize an oral history tradition for its flexibility. Scott states, 
"The very indeterminacy of social forms in the hills, the pliability of histories and genealogies, the baroque complexity of languages and populations is not just a puzzle for rulers, ethnographers, and historians; it is a constitutive feature of hill societies... it also seems reasonable to see this indeterminacy as an adaptive response to a context subject to radical, sudden, and unpredictable change" (p. 269). Oral history, unlike its written form, can adapt to the various circumstances subaltern populations find themselves.

In similar ways, $\mathrm{BQF}$ organizations have practiced their own forms of slash-andburn and oral history. What I have constituted as BQF formations/groups/organizations is a complex network of social bodies that originated in Tallahassee, Florida in the 1970s, but since then, have had many formations and reconfigurations, stops and starts, growth and expansion, halts and reconnections, mergers and accusations, to reach their current organizational forms. Of the BQF organizations I listed at the start of this chapter, which is by far not an exhaustive list—Delta Phi Upsilon (1994), Men of DISTINC (1997), KOSIS (1997), DASMOR (2000), The Academia Society (2006), Men With Purpose/Mu Omega Rho (2009), Zeta Alpha Delta (2013)—only four of these groups seem to currently be in operation. Furthermore, these publically established names and dates don't even begin to account for many of their previous underground iterations. BQF formations can easily be characterized as a slash-and-burn method of development, creating and recreating, when and where is conducive and needed, in order to flourish and avoid state surveillance and seizure.

This means these organizations and their development do not construct a linear, progressive history, and consequently, rely mostly on oral history. Here is how one participant attempts to describe the "history" of a BQF group and other formations: 
They have lineage back to 1981 even though their foundation is about 1998 or 1999, concretely, incorporated through the state of Florida. Because apparently there were bodies that were similarly orchestrating and existing at that time that they take ownership of... because there are people that know one another. So therefore it's kind of like, well, we were all doing the same concepts. We were all doing the same things. Therefore, this is all lineage of a similar type, you know... So you know, there's like a legendary tale to our organization, so to speak, and then there's the documented, what can be incorporated, what can be proven. So there's that. So that's like some organizations will say circa. Like our organization says circa 2007 because our main founder who changed the name in 2013, was initiated in 2007 through a body of similar structure that kind of changed their names and shifted as time went on.

Therefore, you can see how an oral history allows for these organizations to easily adapt to the continuous moves and shifts that is their genealogy. Also, without a historical paper trail, these organizations are less susceptible to surveillance and less reliant on state mediated forms of legitimacy. As Scott (2009) writes, "It is often and correctly noted that text-based civilizations have consistently seen the stateless people outside their grasp as peoples without history. But what we have encounter here is the practice of disavowing status-building histories in the name of preventing hierarchy and its frequent companion, state formation" (p. 276). Consequently, like other queer of color counterhistories, thinking particularly about Snorton’s (2017) racial history of trans identity, linear, or teleological, conceptions of history often speak to (and reinforce) privilege and access to dominant institutional structures. 
Thus, this $\mathrm{BQF}$ marronage constitutes a queer time and queer space indicative of the late twentieth and early twenty-first centuries political and cultural changes of postmodernism (Halberstam, 2005). Jack Halberstam (2005) posits that queer formulations of time and space evolve out of an inability or willful choice to function outside of normalized, heteronormative institutional logics in which dominant linear constructions of time are framed. Halberstam writes, "Within the life cycle of the Western human subject, long periods of stability are considered to be desirable, and people who live in rapid bursts are characterized as immature and even dangerous" (pp. 4-5). BQF culture's use of space and time has, thus, worked counter to the dominant Western norms of an American fraternal homosociality predicated on (bio)logical reproduction and capitalism. As such, BQF culture's alternative temporality in its contemporary marronage state corroborates Halberstam and other queer theorists claims about queer time and space as a useful frame of analysis for comprehending the dynamics of power and subversion within postmodernism — a subversion that's not necessarily symmetrical to authority but often lie in an in-between state.

Subsequently, black sexual hypervisibility, the MIAKA spectacle and BQF marronage illustrate a type of black femme fugitivity or flight, a flight Treva Ellison (2019) describes as "the re/appearances of queer femininity that disorganize and confound the categories we often use to make sense of the world" (p. 8). The practice of "slash-and-burn" and oral history by BQF organizations is, then, a radical act of black queer and trans recovery, or what Ellison calls flocking, "the possibility for Black trans and queer aesthetics through collective practice rather than carceral capture and coercion" (p. 13). In their disjunctive protocols, contemporary iterations of BQF formations 
reclaim and shade the very queer limits of black memory. Ellison states, "The queer limit of Black memory explains how maintaining the socio-spatial boundaries of racial Blackness is often accomplished by constructing certain modes of gender and sexual indeterminacy as impediments to Black racial progress" (p. 8). Therefore, these contemporary publically organized BQF organizations constitute an archive of their own - a counter institutional archive. The BQF archive, thus, enshrines the names of black femmes and queers whose queer failures of embodiment and institutionalization "offer models of contestation, rupture, and discontinuity for the political present" (Halberstam, 2011, p. 19). 


\section{CHAPTER 6: CONCLUSION: SHADE AS A BLACK POLITICS OF RESISTANCE?}

Indeed, I want to throw shade on normativity, sahay away from a politics of respectability, and get my life from a politics of deviance.

—Kaila Adia Story, On the Cusp of Deviance (2016)

There is something shady, a shadowy effect, about the genealogy of black fraternalism and minority difference in higher education. Shade, or its etymological sister, shadow, both derive from the Old English word sceadu and connote a form of darkness. Merriam-Webster defines shade as a "comparative darkness or obscurity owing to interception of the rays of light" and shadow being a "partial darkness or obscurity within a part of space from which rays from a source of light are cut off by an interposed opaque body." I find both conceptual iterations applicable in framing how power is rendered and bodies materialized in this study.

With a growing number of black bodies on college campuses at the turn of the twentieth century, black students sought affirmation, recognition and legitimacy in higher education and in the American landscape as proper gendered bodies and citizens through the formation of black fraternalism—conforming to the nationalist masculine homosocial archive of the American fraternal system. In doing so, the black fraternal body was formed over and against the plurality of black gender and sexuality (shade), forging new modes of representation, embodiment and confinement, particularly a type of repressive patriarchal femininity and femmephobia. As institutional models predicated on conceptions of Western manhood were challenged by the post-civil rights movement, 
black fraternalism, as an archive entity in its own right, would then be employed by the academy's archival regime to consolidate institutional forms of minority (in)difference and subjectivity. Thus, the reemergence of black fraternalism in the 1970s and 80s marked the foreclosure of critical universes while projecting a regulated, imagined minoritized community (shadow). As such, BQF formations-from the shadowsconstitute a critical institutional reading, or what Roderick Ferguson (2012) might consider "the practice of a creative negation, a practice that unravels the established standards of coherence and recognition" (p. 178). Indeed, BQF formations read against and beyond the institutional logics of minority difference predicated by black fraternalism to reorder and give new meaning to dominant text, symbols and structures "imprinted both by marginality and hegemonic institutionality all at the same time" (Ferguson, 2012, p. 179)—throwing shade.

What I am suggesting here, is that, shade might not only be a conceptual metaphor for understanding and analyzing how institutional power and minority absorption and affirmation operates, but shade might as well be an epistemological and institutional methodology of resistance. This latter deployment of shade draws on its use in black queer vernacular. In the introduction to his latest anthology in black queer studies, No Tea, No Shade, E. Patrick Johnson (2016) notes in black queer vernacular, to throw shade is to disrespect. As Dorian Corey details in the iconic documentary Paris is Burning, "shade comes from reading." According to Corey, "To read is to insult imaginatively, in opposition to the blunt gay-bashing taunts of the straight world." However, to throw shade, Corey explains, instead of “telling you you are ugly, I don't have to, because you already know." And, anyone who knows anything about throwing 
shade, knows that, for the best shade, the read is embedded in unassuming discoursetypically dressed in a complement. Shade, thus, transfigures that which is affirmedcalling attention to its inadequacy.

In a material and institutional context, shade might signify a contradictory performance where the political critique rests within a subversive iteration of the intelligible - as with BQF culture, illuminating the limits of institutional desire and representation of black life. As such, Ferguson's (2012) sentiments about the subversive practice of reading - "the naming, unnaming, and renaming of minority difference" (p. 179)—is shady:

Reading minority difference's archival history in this way allows us to refuse the fiction of minority innocence and compels us to develop methodologies for challenging institutional efforts to 'pin down' the meaning of minoritized lives, efforts that strive to put into law singular and univocal definitions of formations that are endlessly and vitally plural. (p. 179)

The ability to read normalizing institutional text for what it is and for what it could be-a form of disrespectful truth telling — shade is the disorienting of that which attempts to orient us towards conformity. Shade is a modifier of sorts- $\mathrm{BQF}$ formations shade institutional black fraternalism.

Shade here is in part constituted through a bi-directional looking. C. Riley Snorton (2014) envisions a framework for analyzing the function of racialized sexuality in contemporary media by overlapping Gayle Rubin's model of sexual hierarchies with Bentham's Panopticon. With this framework, Snorton argues "the margins structure the center through a specific form of looking where those closer to the center are surveilling 
the margins (and vice versa)" (p. 28), creating a biopolitical mode of looking delineated by the center overseeing marginal groups (and vice versa). Here, we can think of institutional black fraternalism, and the normative embodiment it represents, as those closer to the center, and $\mathrm{BQF}$ formations and their cultural incoherence, as those on the margins who structure the center.

In other words, the disqualified are indeed essential to what is considered the norm - they are used to build and uphold existing institutions of conformity. As Chandan Reddy (2011) suggests about the exclusion of alternative modes of subjectivity, "their historicity is inextricably tied to the limits that historically specific conditions of possibility establish for the production of culturally intelligible and sanctioned subjectivity" (p. 36). However, it's the looking back, the negotiation of the gaze, that informs BQF subjects' subversive acts, spaces and movements (development) through the shade/shadows, or what Snorton (2017) might consider as "viewed through the 'darkness of lightness'” (p. 144). Subsequently, BQF formations, like the mediated narratives of black trans personalities, present a countermythology, "ways to read the imbrications of race and gender as indexes of power's circulation and as instantiations of the ways discourse recursively presses flesh into bodies of meaning over time" (Snorton, 2017, p. 144). Furthermore, this mode of surveillance deflects attention away from the institutional structures propagating the separation and (dis)qualification. For BQF formations—shade, throwing shade, being shady—then, brings attention back to the propagation of institutional structures.

As a result, I want to think about how an understanding of shade — particularly, $\mathrm{BQF}$ formations and their institutional performance-in-deviance — might inform a black 
politics of resistance as Kaila Story (2016) contends in the chapter's epigraph. Story draws on Cathy Cohen (2004) to make her appeal, in which, Cohen argues for a queering of African American studies, particularly the study of black politics. Studies examining black political movements have largely focused on formal, clearly-defined organizations, protests, and political spaces over everyday contestation in the lives of ordinary black folks - hence, framing black politics by respectability, elites, and public opinion (Cohen, 2004). Cohen, thus, suggests a focus on those within black communities with limited agency - the so-called deviants - who in pursuit of "basic human goals such as pleasure, desire, recognition, and respect" (p. 30), often situate their lives, to various extents, in opposition to normalized institutional logics of gender, sex, and desire, despite societal consequences. Cohen states:

Scholars, especially those interested in the evolving nature of Black politics, must take seriously the possibility that in the space created by deviant discourse and practice, especially in Black communities, a new radical politics of deviance could emerge. It might take the shape of a radical politics of the personal, embedded in more recognized Black counter publics, where the most marginal individuals in Black communities, with an eye on the state and other regulatory systems, act with the limited agency available to them to secure small levels of autonomy in their lives. Ironically, through these attempts to find autonomy, these individuals, with relatively little access to dominant power, not only counter or challenge the presiding normative order with regard to family, sex, and desire, but also create new or counter normative frameworks by which to judge behavior. (p. 30) 
What Cohen highlights, and what I have attempted to show through this study examining institutionality and a black fraternalism that inform black gender ideology and politics, is that, how we think about gender and sexuality correlates with the type of research and politics we pursue. As such, BQF formations, and their shady endeavors, present a possibility for an alternative, more radical, black politics.

Though Cohen (2004) warns that deviance or defiant acts alone are not necessarily political without some intentionality and "the need for intervening mechanisms to transform deviant and defiant behavior into politically conscious acts" ( $\mathrm{p}$. 40), they do provide "a point of entry into a mobilized political movement" (p. 40). Here, I think the type of femme resistance and heterosociality found in BQF culture not only challenge prevailing paradigms of black politics, but provides "a point of entry" for thinking about a politics situated in a gender politics disassociated from a bio(logical) determinism — for as this study suggests, blackness and transness always already intersect: from the mis/un/gendering of black males (and subsequent ban from white fraternities) at the turn of the century to contemporary BQF formations exceeding the limits of institutional identity. As Snorton (2017) writes, "Here, trans - in each of its permutations - finds expression and continuous circulation within blackness, and blackness is transected by embodied procedures that fall under the sign of gender" (p. 2). To shade black politics then suggest a black politics that subvert the hierarchy and institutional logics reinforced by the disciplinary categories of "man" and "women." A black politics open to multiple possibilities of gender and relationships between those genders. A black politics that mobilize in support of black trans people, particularly trans women and femmes, some of the most vulnerable in our communities. A shady black 
politics would then transfigure institutional structures and employ its means to get all our lives.

\section{The Limits of Heterosociality and Gender Dissent}

I know I am being a little presumptuous in my development and deployment of shade. Nevertheless, my conceptualization of shade and its possible political implications is an attempt to illustrate how this project is situated in contemporary calls for new and alternative examinations of black politics - and thus, acts as "a point of entry" for further exploration, conversation and critique. With that, there are limitations to this study, and subsequently, this theorization. The heterosociality and femme resistance, forms of gender dissent, located in BQF culture has potential for radical transformation of masculine homosocial structures. They subvert the cisheteropatriarchal regimes of institutional minority indifference by "an active identification with women, against (gay) men's gender privileges" (Maddison, 2000, p. 194). In doing so, the black queer males who engage in BQF culture undermine the logics of rational cultural credibility and desire - a structural desire and affirmation predicated on nationalist idealization, exceptionalism and respectability politics that uphold systems of stratification.

However, heterosocial relationships require a delicate balance of social power to be truly transformative. Therefore, the ideological intent behind these relationships matter. For instance, if the queer males who disidentify with black sorority women "do not accede their male authority" (Maddison, 2000, p. 195), and thus, see themselves superior to women based on a gender difference or continue to espouse a belief in gender cultural intelligibility, the relationship is fraught and risks exploiting black women in 
similar ways as homosocial structures. Conversely, the black women who support BQF culture, also must suspend culturally intelligible beliefs of gender. Particularly, beliefs in a patriarchal femininity where their womanhood is defined by association to heterosexual male authority - making them "innate" arbitrators of femininity. In this case, as Stephen Maddison (2000) contends, "Gay men who female identify, are thus often cast, in heterosocial relationships, as unnatural women, inferior and subject to disenfranchisement by the 'proper' feminine performances of straight women" (p. 195). In other words, both the men and women in heterosocial relationships must be willing to contest their gender membership and the perimeters of the gendered roles ascribed to the categories "man" and "woman."

I witnessed hints of these limits of heterosociality in my interviews and observations with members of BQF organizations. Two participants discussed hearing about incidents where BQF members have charged ${ }^{38}$, or challenged, women in black sororities. Though these incidents seem to be isolated and associated with BQF culture's more underground past, it does suggest some sense of male entitlement. Maybe the most insightful indicator of a reluctance to de-naturalize gender is expressed in attitudes towards transgender membership. Only one of the study participants noted that their organization was in the process of changing their policies to explicitly accept transmen. The other participants, and the organizations they represent, were either opposed or indifferent about explicitly including trans members though most of their organizations

\footnotetext{
${ }^{38}$ In black Greek culture, to "charge" someone is to challenge a fellow member of a sorority/fraternity on the legitimacy of their membership, which holds implications for manhood/womanhood. This is typically done by asking a member obscure questions about the organization thought to only be known by members who pledge, or are "made."
} 
have members who are trans, particularly transwomen and femmes. However, those members typically joined before transitioning, while presenting as male.

For some BQF organizations, their reluctance to de-naturalize gender seem to correlate with their shift from underground to publicly recognized. As one participant explained, "the underground, during the club time, starting accepting drag queens, girls with high school diplomas, no collegiate life." However, in their more publically recognized form, some groups have adopted policies that limit gender performance and expression, such as not allowing members to wear organization paraphernalia if they present as a woman or are in drag. This is ironic given that BQF culture, particularly the significance of its underground origin, has proven that the institutional categories of "sorority" and "fraternity" can be employed to expand gender possibilities instead of limiting and reifying gendered norms and boundaries. But, as Maddison (2000) warns about the arrested possibility of heterosociality, "Our success, however, will always be hard won and plagued by assimilationist tendencies which draw us back towards patterns which are sponsored by dominant authorities" (p. 195). Because BQF organizations disidentify with institutional modals for legitimacy and security, these groups have given way, even if in partiality, to institutionalized standards. It can be argued that this assimilationist tendency also explains why some BQF groups now require college education for membership (though, as discussed in the previous chapter, the membership standards are still more accessible than campus-based fraternities).

Acknowledging the delicate power balancing act necessary within heterosocial relationships, specifically between gay men and straight women, Maddison (2000) contends that heterosocial partnerships with lesbians may be a more revolutionary 
approach. With straight women, homosocial structures produce tensions that must be carefully navigated in terms of challenging or consolidating a compulsive heterosexuality. In other words, the contrast between straight women's heterosexuality and gay men's homosexuality can easily fall into the trap of normalizing a binary gender and sexuality paradigm. Whereas with lesbians, Maddison states, “Gay men's relationships with lesbians are conducted under the mutual acknowledgement of queerness, such that the gender performance of each is equally and celebratedly unnatural" (p. 196). As you may recall, BQF culture is believed to have started through a partnership between a lesbian AKA and gay men, and since the formation of BQF culture, fraternity-inspired/patterned lesbian groups have also existed (as well as nonfraternity inspired/patterned lesbian groups). In fact, once the groups became public and more formalized, there was a unity board formed between the black fraternal gay organizations and lesbian organizations in Tallahassee called the Neo-Classical Council. However, it seems that the council and relationship between the gay and lesbian groups have disbanded, at least in part, due to disagreement on objectives and purpose. This raises another concern of Maddison's, “In heterosocial relationships with lesbians, gay men will be challenged where they are strong and often culpable, that is as subjects who often ventriloquise patriarchal values" (p. 197). Nevertheless, Maddison goes on to state, "The acknowledgement of the inauthenticity and contingency of gender performance would seem to be a precondition of heterosocial bonds with lesbians: we are all queers, and nobody can pretend that they are a real girl (or boy): other than our same-sex desire, that is what we share" (p. 197). 
The limitations of heterosociality outlined here provide guidance for future research and inquiry. More needs to be known about the black women who helped to start and/or support BQF culture and organizations. However, given the deviance associated with support of BQF formations, it may be nearly impossible to retrieve this information or talk with women who are/were involved. More broadly, there needs to be more research done about the history and significance of BGLO auxiliary/sweetheart groups. It is evident that the establishment of "sweetheart" groups played a role in BGLOs recovery and affirmation of minority difference in the post-civil rights academy and made space for the development of $\mathrm{BQF}$ formations.

As a queer of color critique of black fraternalism and institutionality, I did not attempt to document a definitive history of BQF formations; however, this endeavor would be worthwhile given that more attention is currently being paid to archiving black queer history and expanding the limits of black progressive memory. Conversely, this study primarily focused on black male-identified subjectivity, and thus, explored the construction of black fraternities, masculinity, and their queer counterparts, sororityinspired/patterned gay formations. However, this study raises questions about black female-identified subjectivity and the conception of black sororities, femininity, and their relationship to fraternity-inspired/pattern lesbian groups. Though I include these lesbian groups in what I have termed BQF culture and would argue there are genealogical similarities, a queer of color critique of black female-identified subjectivity, fraternalism, and the academy deserves a separate treatment from the one provided here. Encapsulating both genealogies into a single project would be daunting and likely distort the distinct structures and experiences of black women. 
Nevertheless, my hope is that this study is a springboard for the aforementioned projects. Besides, little is known about BQF culture and the growing number of black queer Greek-lettered/fraternal organizations, including but not limited to, how these groups will continue to navigate/negotiate institutionality and the impact these groups have on its members. Furthermore, the idealized projection of institutionalized black subjectivity is slowly fading. Since 2009 , there have been a small but increasing number of HBCUs that have opened LGBT resource centers, recognized LGBTQ/Ally groups, established LGBTQ advisory councils and introduced queer studies courses (Mobley \& Johnson, 2019). Furthermore, Spelman College and Bennett College (HBCU all-female institutions) officially changed their admissions policies in 2017 to admit transwomen and Morehouse College (HBCU all-male institution) recently announced they would start officially admitting transmen in 2020 . However, there is still much more work to be done. Including, or acknowledging, queer embodiment in black spaces within the academy, whether HBCU or PWI, is not enough. Inclusion alone, as Ferguson (2012) has shown, often reify normalizing power and reconstitute otherness. To not re-present a queer 'otherness', we must also shade — name, unname, and rename - the gendered entities and structures considered normal. 


\section{REFERENCES}

Ahmed, S. (2015). The cultural politics of emotion. New York, NY: Routledge.

Allen, W., \& Jewell, J. (2002). A backward glance forward: Past, present, and future perspectives on historically black colleges and universities. The Review of Higher Education, 25(3), 241-261.

Anderson, J. D. (1988). The education of blacks in the South, 1860-1935. Chapel Hill, NC: University of North Carolina Press.

Andersen, M., \& Collins, P. H. (2013). Why race, class, and gender still matter. In M. Andersen \& P. Hill Collins (Eds.), Race, class, and gender: An Anthology ( $8^{\text {th }}$ ed., pp. 1-14). Boston, MA: Cengage Learning.

Appiah, A. (1992). In my father's house: Africa in the philosophy of culture. New York, NY: Oxford University Press.

Bailey, M. (2013). Butch queens up in pumps: Gender, performance, and ballroom culture in Detroit. Ann Arbor, MI: The University of Michigan Press.

Beemyn, B. (2003). The silence is broken: A history of the first lesbian, gay, and bisexual college student groups. Journal of the History of Sexuality, 12(2), 205-223.

Bell, D. A. (1980). Brown v. Board of Education and the interest-convergence dilemma. Harvard Law Review 93, 518-533. 
Blockett, R. A. (2017). 'I think it's very much placed on us': Black queer men laboring to forge community at a predominantly White and (hetero) cisnormative research institution. International Journal of Qualitative Studies in Education, 30(8), 800816.

Bradley, S. (2008). The first and finest: The founders of alpha phi alpha fraternity. In G. Parks (Ed.), Black Greek-letter organizations in the twenty-first century: Our fight has just begun (pp. 19-40). Lexington, KY: University Press of Kentucky.

Brod, H. (1995). Pornography and the alienation of male sexuality. In L. May, R. Strikwerda, \& P. D. Hopkins (Eds.), Rethinking masculinity (pp. 237-53). Lanham, MD: Rowman \& Littlefield.

Brookfield, S. D. (2005). The power of critical theory: Liberating adult learning and teaching. San Francisco, CA: Jossey-Bass.

Bryson, R. J., \& Pruitt, E. (1999). History of the Southern Province: Kappa Alpha Psi Fraternity, Inc. Tallahassee, FL: Rose Printing.

Butler, J. (1990/1999). Gender trouble: Feminism and subversion of identity (2 ${ }^{\text {nd }}$ ed.). New York, NY: Routledge.

Butler, J. (1993). Bodies that matter: On the discursive limits of "sex". New York, NY: Routledge.

Butler, J. (1998). An affirmative view. In R. Post \& M. Rogin (Eds.), Rate and Representation: Affirmative Action (pp. 155-174). New York, NY: Zone.

Canaday, M. (2009). The straight state: Sexuality and citizenship in twentieth-century America. Princeton, NJ: Princeton University Press. 
Carter, B. A. (2013). "Nothing better or worse than being black, gay, and in the band": A qualitative examination of gay undergraduates participating in historically black college or university marching bands. Journal of Research in Music Education, 61(1), 26-43.

Centers for Disease Control and Prevention. (2016, February 23). Lifetime risk of HIV diagnosis [Press release]. Retrieved from https://www.cdc.gov/nchhstp/newsroom/2016/croi-press-release-risk.html.

Chi Theta charter line turns 50. (2017, April 30). Tallahassee Democrat. Retrieved from https://www.tallahassee.com/story/life/chronicle/2017/04/30/chi-theta-charterline-turns-50/101134812/.

Cohen, C. J. (1999). The boundaries of blackness: AIDS and the breakdown of black politics. Chicago, IL: University of Chicago Press.

Cohen, C. J. (2004). Deviance as resistance: A new research agenda for the study of black politics. Du Bois Review: Social Science Research on Race, 1(1), 27-45.

Collins, P. H. (1990/2000). Black feminist thought: Knowledge, consciousness, and the politics of empowerment ( $2^{\text {nd }}$ ed.). New York, NY: Routledge.

Collins, P. H. (2005). Black sexual politics: African Americans, gender, and the new racism. New York, NY: Routledge.

Connell, R. W. (2005). Masculinities. Berkeley, CA: University of California Press. Conquergood, D. (1991). Rethinking ethnography: Towards a critical cultural politics. Communications monographs, 58(2), 179-194. 
Crenshaw, K. (1989). Demarginalizing the intersection of race and sex: A black feminist critique of antidiscrimination doctrine, feminist theory and antiracist politics. University of Chicago Legal Forum, 139, 139-167.

Crenshaw, K. (1991). Mapping the margins: Intersectionality, identity politics, and violence against women of color. Stanford Law Review, 43, 1241-1299.

Cross, W. E. (1971, July). Negro-to-black conversion experience. Black World, pp. 1327.

Dancy, T. E. (2011). Becoming men in burning sands: Student identity, masculinity, and image construction in black Greek-letter collegiate fraternities. In M. W. Hughley \& G. S. Parks (Eds.), Black Greek-letter organizations 2.0: New directions in the study of African American fraternities and sororities (pp. 95-111). Jackson, MS: University Press of Mississippi.

De Lauretis, T. (1988). Sexual indifference and lesbian representation. Theatre Journal, $40(2), 155-177$.

Derrida, J. (1996). Archive fever: A Freudian impression. Chicago, IL: University of Chicago Press.

Derrida, J. (2004). Eyes of the university: Right to philosophy (Vol. 2). Stanford, CA: Stanford University Press.

DeSantis, A. D., \& Coleman, M. (2008). Attitudes about homosexuality in black fraternities. In G. S. Parks (ed.), Black Greek-lettered organizations in the twentyfirst century: Our fight has just begun (pp. 291-312). Lexington, KY: University Press of Kentucky. 
Designer Reco Chapple on being openly gay in black fraternity Kappa Alpha Psi. (2017, August 14). Retrieved from http://thejasminebrand.com/2017/08/14/designerreco-chapple-on-being-openly-gay-in-black-fraternity-kappa-alpha-psi/.

Du Bois, W. E. B. (1903). The souls of black folk. New York, NY: Bantam.

Edwards, E. R. (2012). Charisma and the fictions of black leadership. Minneapolis, MN: University of Minnesota Press.

Edwards, E. R. (2015). Sex after the black normal. Differences, 26(1), 141-167.

Ellison, T. C. (2019). Black femme praxis and the promise of black gender. The Black Scholar, 49(1), 6-16.

Epprecht, M. (2009). Sexuality, Africa, history. The American Historical Review, 114(5), $1258-1272$.

Fanon, F. (2006). National culture. In B. Ashcroft, G. Griffiths, \& H. Tiffin (Eds.), The Post-Colonial Studies Reader (pp. 119-122). New York, NY: Routledge. (Original work published in 1961)

Farrow, K. (2007, March 11). Black gay “sorority” causes controversy. Retrieved from http://www.newnownext.com/black-gay-sorority-causes-controversy/03/2007/.

Ferguson, R. A. (2004). Aberrations in black: Toward a queer of color critique. Minneapolis, MN: University of Minnesota Press.

Ferguson, R. A. (2012). The reorder of things: The university and its pedagogies of minority difference. Minneapolis, MN: University of Minnesota Press.

Ferguson, R. A. (2017). We demand: The university and student protests. Oakland, CA: University of California Press. 
Flyvbjerg, B. (2006). Five misunderstandings about case-study research. Qualitative Inquiry, 12(2), 219-245.

Foucault, M. (1970). The order of things: An archaeology of the human sciences. New York, NY: Pantheon Books.

Foucault, M. (1977). Discipline and punish: The birth of the prison. New York, NY: Pantheon Books.

Foucault, M. (1978). The history of sexuality: Volume 1. New York, NY: Random House. Fraternities and sororities: A dramatic comeback on campus. (1983, December). Ebony, 39(2), pp. 93-98.

Frazier, E. F. (1957). Black bourgeoisie. New York, NY: Free Press.

Gaines, K. K. (1996). Uplifting the race: Black leadership, politics, and culture in the twentieth century. Chapel Hill, NC: University of North Carolina Press.

Gasman, M., Nguyen, T. H., \& Kalam, S. (2013). Black undergraduates at historically black colleges and universities and multiple identities. In T. L. Strayhorn (Ed.), Living at the intersections: Social identities and black collegians (pp. 221-236). Charlotte, NC: Information Age Publishing.

Gates, H. L. (1988). The trope of a new negro and the reconstruction of the image of the black. Representations, 24, 129-155.

Gaudio, R. P. (2009). Man marries man in Nigeria?. In E. Lewin, \& W. L. Leap (Eds.), Out in public: Reinventing lesbian/gay anthropology in a globalizing world (pp. 273-291). Malden, MA: Wiley-Blackwell.

Gilroy, P. (1993). The black Atlantic: Modernity and double consciousness. New York, NY: Verso. 
Graves, J. L. (2001). The emperor's new clothes: Biological theories of race at the millennium. New Brunswick, N.J.: Rutgers University Press.

Grier-Reed, T. (2010). The African American student network: Creating sanctuaries and counterspaces for coping with racial microaggressions in higher education settings. Journal of Humanistic Counseling, Education and Development, 49, 181-188.

Halberstam, J. (1998). Female masculinity. Durham, NC: Duke University Press.

Halberstam, J. (2005). In a queer time and place: Transgender bodies, subcultural lives. New York, NY: NYU Press.

Halberstam, J. (2011). The queer art of failure. Durham, NC: Duke University Press.

Hamilton, C. V., \& Carmichael, S. (1967). Black power: Politics of liberation in America. New York, NY: Random House.

Harper, S. R., \& Gasman, M. (2008). Consequences of conservatism: Black male students and the politics of historically black colleges and universities. Journal of Negro Education, 77(4), 336-351.

Harris, J., \& Mitchell, V. C. (2008). A narrative critique of black Greek-letter organizations and social action. In G. S. Parks (ed.), Black Greek-lettered organizations in the twenty-first century: Our fight has just begun (pp. 143-168). Lexington, KY: University Press of Kentucky.

Hesse-Biber, S. (2014). Feminist approaches to in-depth interviewing. In S. N. HesseBiber (Ed.), Feminist Research Practice: A Primer (pp. 182-232). London: Sage. Higginbotham, E. (1993). Righteous discontent: The women's movement in the black Baptist church, 1880-1920. Cambridge, MA: Harvard University Press. 
Horkheimer, M. (1974). Eclipse of reason. New York, NY: Continuum. (Original work published in 1947)

Hoskin, R. A. (2019). Femmephobia: The role of anti-femininity and gender policing in LGBTQ+ people's experiences of discrimination. Sex Roles, 1-18.

Hughey, M. W., \& Parks, G. S. (2011). Public realism: Propounding a critical and empirical black “Greek” scholarship. In M. W. Hughey \& G. S. Parks (Eds.), Black Greek-letter organizations 2.0: New directions in the study of African American fraternities and sororities (pp. 3-23). Jackson, MS: University Press of Mississippi.

Hull, G., Bell-Scott, P., \& Smith, B. (Eds.). (1982). All the women are white, all the blacks are men, but some of us are brave: Black women's studies. New York City: Feminist Press at the City University of New York.

Ikpe, E. B. (2004). Human sexuality in Nigeria: A historical perspective. In Understanding Human Sexuality Seminar Series. (Vol. 1, pp. 10-38). Lagos, Nigeria: Africa Regional Sexuality Resources Centre.

Izugbara, C. O. (2004). Patriarchal ideology and discourses of sexuality in Nigeria. In Understanding Human Sexuality Seminar Series. (Vol. 2, pp. 1-34). Lagos, Nigeria: Africa Regional Sexuality Resources Centre.

Jackson, R. L. (2006). Scripting the black masculine body: Identity, discourse, and racial politics in popular media. Albany, NY: SUNY Press.

Johnson, E. P. (1998). Feeling the spirit in the dark: Expanding notions of the sacred in the African-American gay community. Callaloo, 21(2), 399-416. 
Johnson, E. P. (2003). Appropriating blackness: Performance and the politics of authenticity. Durham, NC: Duke University Press.

Johnson, E. P. (2005). "Quare" studies, or (almost) everything I know about queer studies I learned from my grandmother. In E. P. Johnson \& M. G. Henderson (Eds.), Black queer studies: A critical anthology (pp. 124-157). Durham, NC: Duke University Press.

Johnson, E. P. (2008). Sweet tea: Black gay men of the South. Durham, NC: University of North Carolina Press.

Johnson, E. P. (2016). Introduction. In E. P. Johnson (Ed.), No tea, no shade: New writings in black queer studies (pp. 1-26). Durham, NC: Duke University Press.

Johnson, E. P., \& Henderson, M. E. (2005). Introduction: Queering black studies/"quaring" queer studies. In E. P. Johnson, \& M. G. Henderson (Eds.), Black Queer Studies, (pp. 1-17). Durham, NC: Duke University Press.

Johnson, G. (2017, December 4). Learning to love myself as a black queer man in a black Greek letter organization. Retrieved from http://blackyouthproject.com/learninglove-black-queer-man-black-greek-letter-organization/.

Jones, R. L. (2004/2015). Black haze: Violence, sacrifice, and manhood in black Greekletter fraternities ( $2^{\text {nd }}$ ed.). Albany, NY: State University of New York Press.

Jones, S., \& Abes, E. (2013). Identity development of college students: Advancing frameworks for multiple dimensions of identity. San Francisco, CA: Jossey-Bass. Kant, I. (1979). The conflict of the faculties (M. J. Gregor, Trans.). Lincoln, NE: University of Nebraska Press. (Original work published in 1798) 
Kimbrough, W. M. (2003). Black Greek 101: The culture, customs, and challenges of black fraternities and sororities. Madison: Fairleigh Dickinson University Press.

Kohli, S. (2012, June 19). Alpha Kappa Alpha Sorority sued by MiAKA for discrimination. Retrieved from https://www.huffpost.com/entry/aka-sororitylawsuit_n_1609132.

Lake, T. (2007, March 20). Male ‘sorority' has black America ticked off. Retrieved from https://www.bet.com/news/news/2008/02/11/newsarticlethegaylifemiakasaka.htm 1 .

Lorde, A. (2007). Sexism: An American disease in blackface. In A. Lorde (Ed.), Sister outsider: Essays and speeches (pp. 60-65). Berkeley, CA: Crossing Press. (Original work published in 1979)

Lorde, A. (2007). Uses of the erotic: The erotic as power. In A. Lorde (Ed.), Sister outsider: Essays and speeches (pp. 53-59). Berkeley, CA: Crossing Press. (Original work published in 1978)

Maddison, S. (2000). Fags, hags and queer sisters: Gender dissent and heterosocial bonds in gay culture. New York, NY: St. Martin's Press.

Mahoney, A. D. (2019). The dying swan: Cultural nationalism and queer formations in Trinidad and Tobago. Interventions, 21(2), 235-254.

McClure, S. M. (2006). Improvising masculinity: African American fraternity membership in the construction of a black masculinity. Journal of African American Studies, 10(1), 57-73.

McCune, J. Q. (2014). Sexual discretion: Black masculinity and the politics of passing. Chicago, IL: University of Chicago Press. 
McDonald's did a commercial in 1989 where black fraternity pledgees recite their menu. (n.d.). Watch the Yard. Retrieved from https://www.watchtheyard.com/back-inthe-day/mcdonalds-fraternity-chant/.

Means, D. R. (2017). “Quaring” spirituality: The spiritual counterstories and spaces of black gay and bisexual male college students. Journal of College Student Development, 58(2), 229-246.

Means, D. R., \& Jaeger, A. J. (2013). Black in the rainbow: "Quaring” the black gay male student experience at historically black universities. Journal of African American Males in Education, 4(2), 124-141.

Mechling, J. (2008). Paddling and the repression of the feminine in male hazing. Thymos, 2(1), 60-75.

MIAKA: Men imitating AKA. (2007, February 28). Retrieved from https://loldarian.blogspot.com/2007/03/miaka-men-imitating-aka.html.

MIAKA threatens to file lawsuit against Alpha Kappa Alpha Sorority, Inc. for discrimination? (2012, June 6). Retrieved from https://kollegekidd.com/news/miaka-to-file-lawsuit-against-alpha-kappa-alphasorority-inc-for-discrimination/.

Mills, C. W. (1997). The racial contract. Ithaca, NY: Cornell University Press.

Miner, K., \& Jayaratne, T. (2014). Feminist survey research. In S. N. Hesse-Biber (Ed.), Feminist Research Practice: A Primer (pp. 296-329). London: Sage.

Minh-ha, T. T. (2006). Writing postcoloniality and feminism. In B. Ashcroft, G. Griffiths, \& H. Tiffin (Eds.), The Post-Colonial Studies Reader (pp. 246-249). New York, NY: Routledge. (Original work published in 1989) 
Mobley Jr, S. D., \& Johnson, J. M. (2019). "No pumps allowed”: The "problem” with gender expression and the Morehouse College "Appropriate Attire Policy." Journal of Homosexuality, 66(7), 867-895.

Mohanty, C. T. (2006). Feminist solidarity through anticapitalist struggles. In B. Ashcroft, G. Griffiths, \& H. Tiffin (Eds.), The Post-Colonial Studies Reader (pp. 485-498). New York, NY: Routledge. (Original work published in 2003)

Muñoz, J. E. (1999). Disidentifications: Queers of color and the performance of politics. Minneapolis, MN: University of Minnesota Press.

Nagel, J. (1998). Masculinity and nationalism: Gender and sexuality in the making of nations. Ethnic and Racial Studies, 21(2), 242-269.

Neal, M. A. (2013). Looking for Leroy: Illegible black masculinities. New York, NY: NYU Press.

Njoku, N., Butler, M., \& Beatty, C. C. (2017). Reimagining the historically black college and university $(\mathrm{HBCU})$ environment: Exposing race secrets and the binding chains of respectability and othermothering. International Journal of Qualitative Studies in Education, 30(8), 783-799.

Ochwada, H. (2005). Historians, nationalism and pan-Africanism: Myths and realities. In T. Mkandawire (Ed.), African intellectuals: Rethinking politics, language, gender and development (pp. 193-208). New York, NY: Zed Books.

Omi, M., \& Winant, H. (1994). Racial formation in the US: From the 1960s to the 1990s. New York, NY: Routledge.

Omi, M., \& Winant, H. (2015). Racial formation in the United States. New York, NY: Routledge. 
Palcic, J. L. (1979). The history of the Black Student Union at Florida State University, 1968-1978 (Doctoral dissertation). Retrieved from Florida State University, ProQuest Dissertations Publishing. (7926796)

Parks, G. (2008). Introduction: Towards a critical scholarship. In G. Parks (Ed.), Black Greek-letter organizations in the twenty-first century: Our fight has just begun (pp. 1-18). Lexington, KY: University Press of Kentucky.

Parks, G. (2015). Invictus: Hazing and the future of black Greek-letter organizations. Winston-Salem, NC: 4 Suns Press.

Patton, L. D. (2005). Power to the people! Black student protest and the emergence of black culture centers. In F. L. Hord (Ed.), Black culture centers: Politics of survival and identity (pp. 151-163). Chicago, IL: Third World Press.

Patton, L. D. (2011). Perspectives on identity, disclosure, and the campus environment among African American gay and bisexual men at one historically black college. Journal of College Student Development, 52(1), 77-100.

Patton, L. D. (2014). Preserving respectability or blatant disrespect? A critical discourse analysis of the Morehouse Appropriate Attire Policy and implications for intersectional approaches to examining campus policies. International Journal of Qualitative Studies in Education, 27(6), 724-746.

Patton, L. D., \& Simmons, S. L. (2008). Exploring complexities of multiple identities of lesbians in a black college environment. Negro Educational Review, 59(3-4), $197-$ 215.

Patton, M. Q. (2015). Qualitative research and evaluation methods. Thousand Oaks, CA: SAGE. 
Pelzer, D. L. (2016). Creating a new narrative: Reframing black masculinity for college men. Journal of Negro Education, 85(1), 16-27.

Pérez, H. (2015). A taste for brown bodies: Gay modernity and cosmopolitan desire. New York: NYU Press.

Perry, I. (2018). Vexy thing: On gender and liberation. Durham, NC: Duke University Press.

Phillips, T. C. (2003, November 4). Alpha Kappa Alpha names Mr. Miaka winner. The Alestle. Retrieved from http://www.alestlelive.com/article_b6ac9168-6c14-57f5825f-0cbad54ea6dc.html.

Pochmara, A. (2011). The making of the new negro: Black authorship, masculinity, and sexuality in the Harlem Renaissance. Amsterdam: Amsterdam University Press.

Puar, J. K. (2007). Terrorist assemblages: Homonationalism in queer times. Durham, NC: Duke University Press.

Ray, R., \& Spragling, K. W. (2012). “Am I not a man and a brother?” Authenticating the racial, religious, and masculine dimensions of brotherhood within Alpha Phi Alpha. In G. S. Parks, \& S. M. Bradley (Eds.), Alpha Phi Alpha: A legacy of greatness, the demands of transcendence (pp. 207-229). Lexington, KY:

University Press of Kentucky.

Reddy, C. (1997). Home, houses, nonidentity: 'Paris Is Burning.' In R. M. George (Ed.), Burning down the house: Recycling domesticity (pp. 355-379). Boulder, CO: Westview Press.

Reddy, C. (2011). Freedom with violence: Race, sexuality, and the U.S. state. Durham, NC: Duke University Press. 
Roberts, F. L. (2007, June 6). There's no place like home: A history of house ball culture. WireTap Magazine. Retrieved from https://sparkaction.org/content/theres-noplace-home-history-house-ball-culture.

Roberts, N. (2015). Freedom as marronage. Chicago, IL: University of Chicago Press. Rojas, F. (2007). From black power to black studies: How a radical social movement became an academic discipline. Baltimore, MD: JHU Press.

Ross, M. B. (2005). Beyond the Closet as Raceless Paradigm. In E. P. Johnson \& M. G. Henderson (Eds.), Black Queer Studies (pp. 161-189). Durham, NC: Duke University Press.

Ryan, E. G. (2012, June 20). Widely-reported story of gay men suing historically black sorority smells like bullshit. Retrieved from https://jezebel.com/widely-reportedstory-of-gay-men-suing-historically-bla-5919947.

Schwarz, A. C. (2003). Gay voices of the Harlem Renaissance. Bloomington, IN: Indiana University Press.

Scott, D. (2010). Extravagant abjection: Blackness, power, and sexuality in the African American literary imagination. New York, NY: NYU Press.

Scott, D. J. (2011). Factors that contribute to hazing practices by collegiate black Greeklettered fraternities during membership intake activities. In M. W. Hughey \& G. S. Parks (Eds.), Black Greek-letter organizations 2.0: New directions in the study of African American fraternities and sororities (pp. 235-250). Jackson, MS: University Press of Mississippi.

Scott, J. C. (1999). Seeing like a state: How certain schemes to improve the human condition have failed. New Haven, CT: Yale University Press. 
Scott, J. C. (2009). The art of not being governed: An anarchist history of upland Southeast Asia. New Haven, CT: Yale University Press.

Sedgwick, E. K. (1985/2015). Between men: English literature and male homosocial desire. New York, NY: Columbia University Press.

Sedgwick, E. K. (1990). Epistemology of the closet. Berkley, CA: University of California Press.

Shelton, C. L. (2008). Strategic essentialism and black Greek identity in the postmodern era. In G. Parks (Ed.), Black Greek-letter organizations in the twenty-first century: Our fight has just begun (pp. 213-232). Lexington, KY: University Press of Kentucky.

Shuford, B. C. (2011). Historical and philosophical development of multicultural student services. In D-L Stewart (Ed.), Multicultural student services on campus: Building bridges, re-visioning community (pp. 29-37). Sterling, VA: Stylus.

Smith, C. U. (Ed.). (1994). Student unrest on historically black campuses. Silver Spring, MD: Beckham House.

Snorton, C. R. (2014). Nobody is supposed to know: Black sexuality on the down low. Minneapolis, MN: University of Minnesota Press.

Snorton, C. R. (2017). Black on both sides: A racial history of trans identity. Minneapolis, MN: University of Minnesota Press.

Solorzano, D. G., Ceja, M., \& Yosso, T. (2000). Critical race theory, racial microaggressions, and campus racial climate: The experiences of African American college students. The Journal of Negro Education, 69, 60-73. 
Somerville, S. B. (2000). Queering the color line: Race and the invention of homosexuality in American culture. Durham, NC: Duke University Press.

Spade, D. (2008). Documenting gender. Hastings Law Journal, 59, 731-842.

Squire, D. D., \& Mobley, S. D. (2015). Negotiating race and sexual orientation in the college choice process of black gay males. The Urban Review, 47(3), 466-491.

Stake, R. E. (2005). Qualitative case studies. In N. K. Denzin \& Y. S. Lincoln (Eds.), The Sage handbook of qualitative research (3rd ed., pp. 443-466). Thousand Oaks, CA: Sage.

Star Jones responds to MIAKA controversy. (2012, June 11). Ebony. Retrieved from https://www.ebony.com/news/star-jones-responds-to-miaka-controversy/.

Stein, M. N. (2015). Measuring manhood: Race and the science of masculinity, 18301934. Minneapolis, MN: University of Minnesota Press.

Stombler, M., \& Padavic, I. (2005). Sister acts: Resistance in sweetheart and little sister programs. In T. L. Brown, G. S. Parks, \& C. M. Phillips (Eds.), African American fraternities and sororities: The legacy and the vision (pp. 233-268). Lexington, KY: University Press of Kentucky.

Story, K. A. (2016). On the cusp of deviance: Respectability politics and the cultural marketplace of sameness. In E. P. Johnson (Ed.), No tea, no shade: New writings in black queer studies (pp. 362-379). Durham, NC: Duke University Press.

Story, K. A. (2017). Fear of a black femme: The existential conundrum of embodying a black femme identity while being a professor of black, queer, and feminist studies. Journal of lesbian studies, 21(4), 407-419. 
Strayhorn, T. L., Blakewood, A. M., \& DeVita, J. M. (2008). Factors affecting the college choice of African American gay male undergraduates: Implications for retention. NASPA Journal, 11(1), 88-108.

Strayhorn, T. L., \& Mullins, T. G. (2012). Investigating black gay male undergraduates' experiences in campus residence halls. Journal of College \& University Student Housing, 39(1), 140-161.

Strayhorn, T. L., \& Tillman-Kelly, D. L. (2013). Queering masculinity: Manhood and black gay men in college. Spectrum: A Journal on Black Men, 1(2), 83-110.

Syrett, N. L. (2009). The company he keeps: A history of white college fraternities. Chapel Hill, NC: University of North Carolina Press.

Torbenson, C. L. (2009). From the beginning: A history of college fraternities and sororities. In C. L. Torbenson \& G. S. Parks (Eds.), Brothers and sisters: Diversity in college fraternities and sororities (pp. 15-45). Maddison, NJ: Fairleigh Dickinson University Press.

Wallace, M. (1978). Black macho and the myth of the superwoman. New York, NY: The Dial Press.

Washington, M. H., \& Nuñez, C. L. (2012). Education, racial uplift, and the rise of the Greek letter tradition. In T. L. Brown, G. S. Parks, \& C. M. Phillips (Eds.), African American fraternities and sororities: The legacy and the vision $\left(2^{\text {nd }} \mathrm{ed}\right.$., pp 141-182). Lexington, KY: University Press of Kentucky.

Weber, L. (1998). A conceptual framework for understanding race, class, gender, and sexuality. Psychology of Women Quarterly, 22(1), 13-32. 
West-Savali, K. (2012, August 16). Musing on the MiAKA men myth: Was the MiAKA lawsuit against AKA just an urban legend? Retrieved from https://thegrio.com/2012/08/16/musing-on-the-miaka-men-myth-was-the-miakalaw-suit-against-aka-just-an-urban-legend/.

Whaley, D. E. (2010). Disciplining women: Alpha Kappa Alpha, black counterpublics, and the cultural politics of black sororities. Albany, NY: SUNY Press.

Wilder, C. S. (2013). Ebony and ivy: Race, slavery, and the troubled history of America's universities. New York, NY: Bloomsbury Press.

Williamson, J. A. (2003). Black power on campus: The University of Illinois, 1965-75. Champaign, IL: University of Illinois Press.

Yeung, K. (2009). Challenging the heterosexual model of brotherhood: The gay fraternity's dilemma. In C. L. Torbenson, \& G. S. Parks (Eds.), Brothers and sisters: Diversity in college fraternities and sororities (pp. 184-209). Maddison, NJ: Fairleigh Dickinson University Press.

Yeung, K., \& Stombler, M. (2000). Gay and Greek: The identity paradox of gay fraternities. Social Problems, 47(1), 134-152.

Yeung, K, Stombler, M., \& Wharton, R. (2006). Making men in gay fraternities: Resisting and reproducing multiple dimensions of hegemonic masculinity. Gender and Society, 20(1), 5-31.

Zuberi, T. (2001). Thicker than blood: How racial statistics lie. Minneapolis, MN: University of Minnesota Press. 
Appendix A

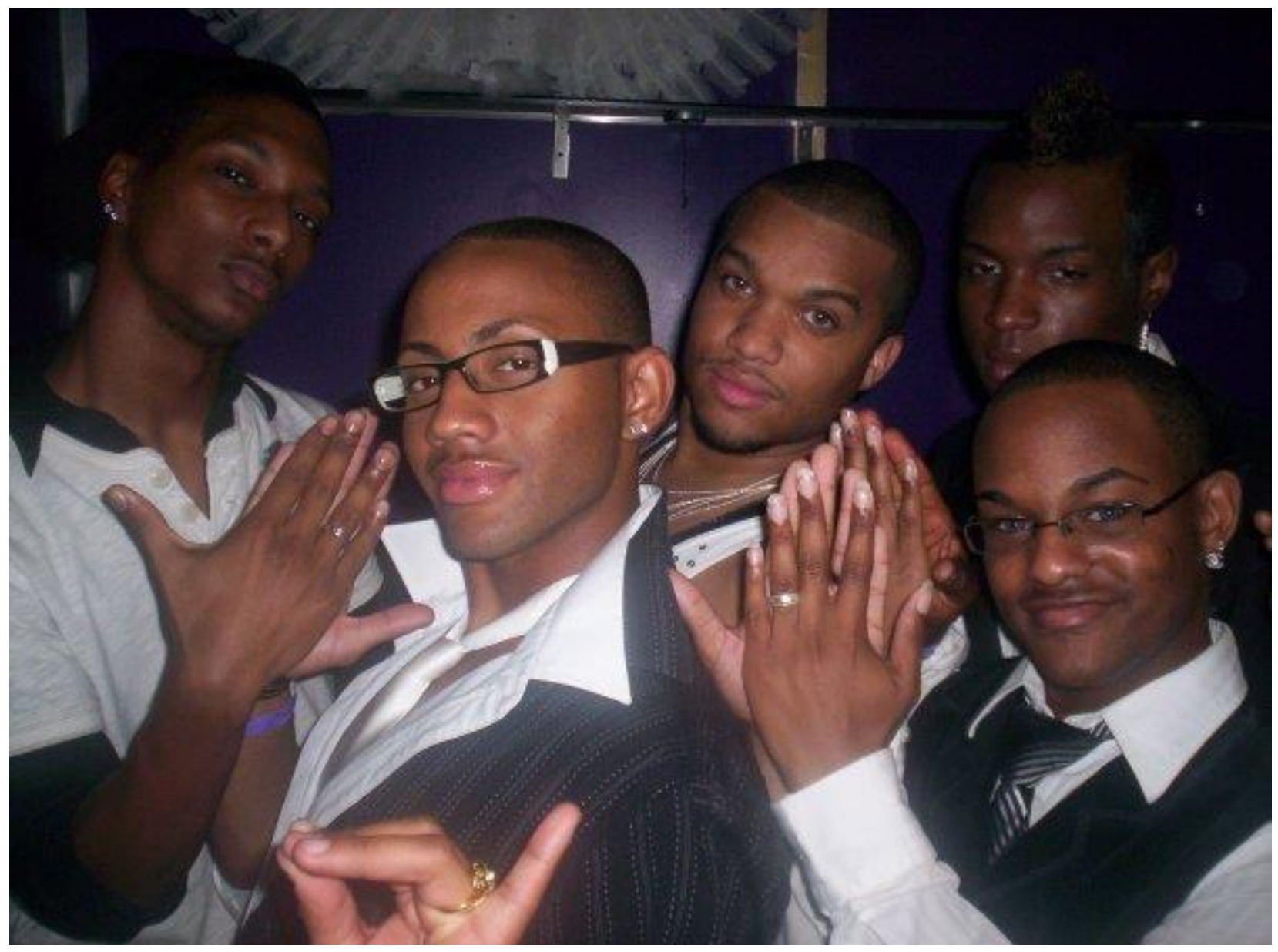

Figure 4. One of the MIAKA pictures that surfaced in 2007 and resurfaced in 2012 on

the KollegeKidd website. This picture circulated widely in the press and social media.

Retrieved from http://kollegekidd.com/news/miaka-to-file-lawsuit-against-alpha-kappa-

alpha-sorority-inc-for-discrimination/. 
Appendix B

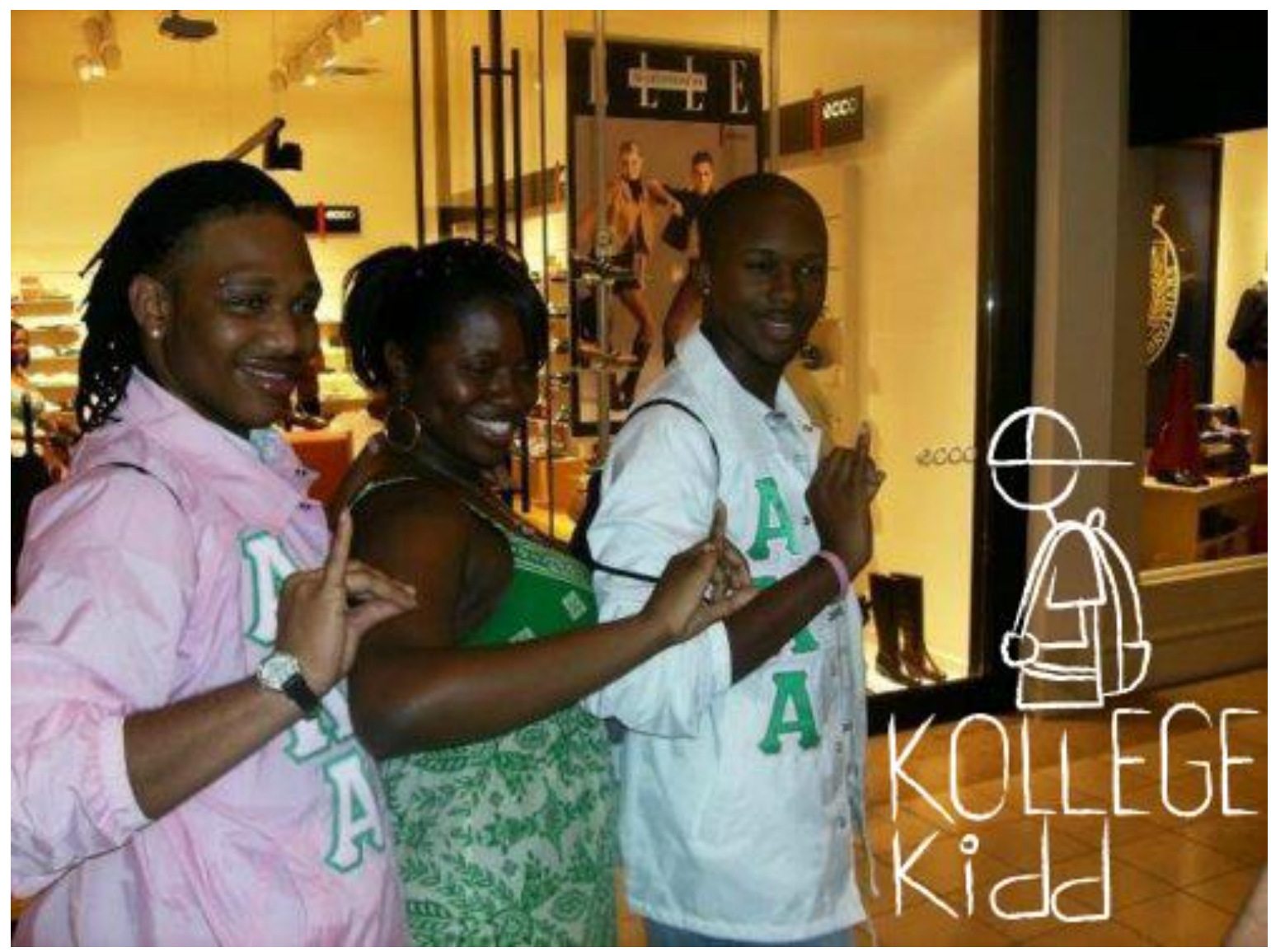

Figure 5. One of the MIAKA pictures that surfaced in 2012 on the KollegeKidd website.

Interestingly, this picture did not get circulated as much as other photos of MIAKAs. I assume this is due to its heterosocial implications which would challenge the narrative of "MIAKAs as deviant thefts" as well as gendered (bio)logics of femininity.

Consequently, the picture resulted in KollegeKidd and its audience questioning the authenticity of the picture and its subjects' identity. Some wondered about the female presenting AKA: “Is she a 'real' AKA? Is she a 'real' woman?" Retrieved from http://kollegekidd.com/news/real-or-fake-alpha-kappa-alpha-member-poses-withmiakas/. 


\section{CURRICULUM VITAE}

\section{Antron Demel Mahoney}

Department of Pan-African Studies, University of Louisville

Strickler Hall 445, Louisville, Kentucky 40292

Phone: (803) 316-2450 Email: antron.mahoney@louisville.edu

\section{EDUCATION}

University of Louisville, Louisville, Kentucky

June 2019

Ph.D., Pan-African Studies

Graduate Certificate in Women's \& Gender Studies

Dissertation: Queering Black Greek-lettered Fraternities, Masculinity and Manhood:

A Queer of Color Critique of Institutionality in Higher Education

Committee: W. Carson Byrd, Anne Caldwell, Ricky L. Jones, Kaila Story (Chair)

University of North Carolina at Greensboro, Greensboro, North Carolina May 2007

M.Ed., Curriculum and Instruction

Concentration in Higher Education

Bethune-Cookman College, Daytona Beach, Florida May 2005

B.S., Business Education, Suma cum laude

\section{RESEARCH INSTERESTS}

My research and scholarship interests include critical explorations of embodiment and freedom. As such, I explore race, gender, and sexuality theories and politics in the context of social movements and leadership-specifically, examining experiences and performances (inter)relating to African American/African diaspora, black masculine/male identities, black feminist/queer praxis, U.S. higher education, and media studies.

\section{PROFESSIONAL EXPERIENCE}

Graduate Assistant

Department of Pan-African Studies

August 2015-Present

University of Louisville (UofL), Louisville, Kentucky

Graduate Intern

January 2016-June 2016

Anne Braden Institute for Social Justice Research (ABI)

University of Louisville (UofL), Louisville, Kentucky

Assistant Director for Leadership Development-promoted

Center for Leadership and Social Change (department merger with Multicultural Affairs)

June 2012-July 2015

Florida State University (FSU), Tallahassee, Florida

Student Development Program Coordinator

June 2010-June 2012

Center for Leadership and Civic Education

Florida State University (FSU), Tallahassee, Florida

Service House Hall Director/Community Involvement Coordinator

Department of Residence Life and Student Housing

June 2007-May 2010 
Office of Leadership and Community Involvement

Southern Methodist University (SMU), Dallas, Texas

Community Outreach Graduate Assistant

Office of Leadership and Service-Learning (OLSL)

January 2006-May 2007

University of North Carolina at Greensboro (UNCG), Greensboro, North Carolina

\section{PUBLICATIONS}

Ovink, S. M., Brunn-Bevel, R. J., Byrd, W. C., \& Mahoney, A. D. (2019). Always Crossing Boundaries, Always Existing in Multiple Bubbles: Intersected Experiences and Positions on College Campuses. In W. C. Byrd, S. M. Ovink, \& R. J. Brunn-Bevel (Eds.), Intersectionality and Higher Education: Identity and Inequality on College Campuses.

Mahoney, A. D. (2019). The Dying Swan: Cultural Nationalism and Queer Formations in Trinidad and Tobago. Interventions: International Journal of Postcolonial Studies, 21(2), 235-254. DOI: 10.1080/1369801X.2018.1547209

Mahoney, A. D. (2017). Being at the heart of the matter: Culturally relevant leadership learning, emotions and storytelling. Journal of Leadership Studies, 11(3), 55-60.

Mahoney, A. D. (2016). Culturally responsive integrative learning environments: A critical displacement approach. In T. Bertrand Jones, K. Guthrie, \& L. Osteen (Eds.), New directions in student leadership \#152: Developing culturally relevant leadership learning (pp. 47-59). San Francisco, CA: Jossey-Bass.

Mahoney, A. D. (2013). Strategies for change: Understanding the social change model. In W. Wagner, D. Ostick, \& Associates (Eds.), Exploring leadership, facilitation and activity guide: For college students who want to make a difference (pp. 224-228). San Francisco, CA: Jossey-Bass.

${ }^{* *}$ Adapted for Wagner, W., \& Ostick, D. (2013). Exploring leadership: For college students who want to make a difference, student workbook. San Francisco, CA: Jossey-Bass.

Works in Progress

Mahoney, A. D, \& Harris, H. B. (forthcoming). When the Spirit Says Dance: A Queer of Color Critique of Black Justice Discourse in Anti-Transgender Policy Rhetoric. Maryland Law Journal of Race, Religion, Gender and Class.

\section{TEACHING EXPERIENCE}

University of Louisville-Sole Instructor

2018-2019 PAS 325: Black Male Identity (3-credit hour undergraduate course)

University of Louisville-Graduate Teaching Assistant for Dr. Ricky L. Jones

2017-2018 PAS 200: Introduction to Pan-African Studies (3-credit hour undergraduate course)-Co-Instructor

2017-2018 PAS 324: Politics, Political Violence and Resistance (3-credit hour undergraduate course)-CoInstructor

2016-2017 PAS 325: Black Male Identity (3-credit hour undergraduate course)-Co-Instructor

2016-2017 PAS 327: Politics of the Black Community (3-credit hour undergraduate course)

2015-2016 PAS 205: Race, Color and Consciousness (3-credit hour undergraduate course)

2015-2016 PAS 326: Black Political Thought (3-credit hour undergraduate course)

Florida State University-Sole Instructor

2011-2015 LDR 2213: Leadership for Social Justice (3-credit hour undergraduate course)—Developed this course

2010-2012 HUM1921: Social Justice Colloquium (1-credit hour undergraduate course)

2010-2012 LDR 2101: Leadership Theory and Practice (3-credit hour undergraduate course)

Southern Methodist University-Co-Instructor with Dr. Carol Clyde

2009-2010 WELL 2170: Volunteer Activities (1-credit hour service-learning course)-Developed this course

University of North Carolina at Greensboro-Graduate Teaching Assistant for Dr. Cathy Hamilton

2006-2007 RPM 401: Strategic Community Leadership (3-credit hour undergraduate service-learning course)

2006-2007 RPM 201: Introduction to Community Leadership (3-credit hour undergraduate service-learning 
course)

\section{SELECTED PROFESSIONAL PRESENTATIONS}

\section{Peer-reviewed Conference Papers}

Mahoney, A. D. (2019, November). Becoming Men: Black Greek Fraternal Archive and Homosociality. Accepted for inclusion in the National Women's Studies Association Annual Conference, San Francisco, CA.

Mahoney, A. D. (2017, March). Coming Out in Space: Black Greek-lettered Fraternities and Sexual Discretion. Presented at the annual American College Personnel Association Conference, Columbus, $\mathrm{OH}$.

Invited Presentations/Workshops/Talks

Mahoney, A. D. (2019, January). The Imperative of Black Queer Counter Spaces, Stories and Politics. Presented at The Academia Society, Inc. annual Founders' Day Convocation, Atlanta, GA.

Mahoney, A. D. (2017, June). Data Collection with Vulnerable Populations: A Black Queer Approach. Presented in EDAD 995 Doctoral Seminar: Approaches to Qualitative Data Collection at the University of NebraskaLincoln, Lincoln, NE.

Mahoney, A. D. (2016, November). Introduction of the Speaker: Angela Davis: 'WWADD?'. Presented at the annual University of Louisville Anne Braden Memorial Lecture, Louisville, KY.

Mahoney, A. D. (2016, September). How to Create LGBTQ Workplace Allies. Presented at the Diversity in the Workplace Conference, Louisville, KY.

Abuznaid, A., Coonan, T., Donoso, D., \& Mahoney, A. D. (2016, February). Morals to Movements: Activism Informed by Knowledge and Pain. Presented at the annual Dalton Institute on College Student Values, Tallahassee, $\mathrm{FL}$.

Mahoney, A. D. (2014, June). Leadership Development in Collegiate Recreation: Creating Space, Building Capacity. Presented at the annual National Intramural-Recreational Sports Association Summit, Tallahassee, FL.

Campbell, J., Kamau, D., Hobbs, C., Mahoney, A.D., \& Tolson, F. (2013, October). Race and the Law. Presented by the FSU Division of Student Affairs, Tallahassee, FL.

Mahoney, A. D. (2013, January). The Sounds of Leadership: Developing the Capacity for Change. Presented at the annual Vietnam Education Foundation Conference, Tallahassee, FL.

Chanton, J., Isaac, M., Mahoney, A. D. \& Opel, A. (2011, November). Beyond Green: Exploring the Three Pillars of Sustainability. Sponsored by the Florida Climate Institute and FSU Sustainable Campus Initiative, Tallahassee, FL.

Mahoney, A.D. (2011, October). Discover, Develop, and Apply Your Strengths. Presented at the University of West Florida Student Government Association Leadership Retreat, Pensacola, FL.

\section{Conference Presentations/Workshops}

Mahoney, A. D. (2016, November). Black Queer Men: (re)Defining Black Masculinity and Manhood. Presented at the annual Come Together Kentucky Conference, Louisville, KY.

Hernandez, M., Mahoney, A. D., Mills, S. \& Osteen, L. (2015, May). Merging Matters: Exploring Gains and Losses at the Intersection of Structure and Identity. Presented at the annual National Conference on Race and Ethnicity in American Higher Education, Washington, DC.

Hernandez, E., \& Mahoney, A. D. (2014, January). Bowing Down: Queen Bey (Beyoncé) and Contemporary Feminism. Presented at the annual FSU Multicultural Leadership Summit, Tallahassee, FL.

Mahoney, A. D. (2013, January). Life-Affirming Leadership: Using Affirmation as a Tool for Change. Presented at the annual FSU Multicultural Leadership Summit, Tallahassee, FL.

Bunch, N., Byrne, V., \& Mahoney, A. D. (2012, March). Creating Positive Sustainable Change through a Service Leadership Co-Curricular Program. Presented at the annual American College Personnel Association Conference, Louisville, KY.

Cusker, C., Mack, D., Mahoney, A. D., \& Martin-Scoufield, A. (2010, March). Bias Incidents: Innovative Ideas for 
Addressing Hate in our Halls. Presented at the annual American College Personnel Association Conference, Boston, MA.

Mack, D., Mahoney, A. D., \& Martin-Scoufield, A. (2010, March). Fostering Inclusivity and Diversity: A Comprehensive Developmental Framework. Presented at the annual American College Personnel Association Conference, Boston, MA

Anderson, C., Gibson, R., Mahoney, A. D., O'Banner, D., \& Schofield, A. (2010, March). Diversity Action Team: Leadership Strategy for Effective Change. Presented at the annual National Association of Student Personnel Administrators Conference, Chicago, IL.

Mahoney, A. D. \& Martin-Scoufield, A. (2008, June). The Dream Team: Collaborating with Student Staff to Mutually Create a Winning Working Relationship. Presented at the annual Association of College \& University Housing Officers-International Conference, Orlando, FL.

Mahoney, A. D. \& Martin-Scoufield, A. (2008, February). The Service House Combo Meal: Satisfy Your Hunger for A Service Themed Community (Poster Session). Presented at the annual Southwest Association of College \& University Housing Officers Conference, Frisco, TX.

Kowalski, L., Mahoney, A. D., \& O'Banner, D. (2007, July). Facilitating Relationships with Academic Affairs Partners. Presented at the North Texas LIST Conference, Arlington, TX.

Mahoney, A. D., Hollister, C., \& Turner, M. (2006, November). Campus Community Connection: Enhancing Campus, Community, and Government Partnerships. Presented at the annual North Carolina Campus Compact Student Conference, Raleigh, NC.

\section{CERTIFICATIONS AND HONORS}

2017

2015-Present

2015-Present

2014

2014

2014

2014

2013

2013

2013

2011

2010

2009

2009

2008

2008

2007

2005

2005

2005
Jan Carew Awardee for Best Essay by a UofL Pan-African Studies Graduate Student University of Louisville Diversity Scholars Fellowship

LeaderShape® Institute Co-Lead Facilitator National Association of Student Personnel Administrators-FL Mid-Manager of the Year International Colloquium on Black Males in Education Participant FSU Better Together Award for Collaborative Programming TEDActive Attendee

FSU Social Justice Ally Training

FSU Seminole Allies and Safe Zone Facilitator

FSU Uphold the Garnet and Gold Award

FSU LeaderShape® Institute Cluster Facilitator

Kappa Alpha Psi Southwestern Province Guide Right Achievement Award

DFW LeaderShape® Institute Cluster Facilitator

SMU LGBT Allies Training

StrengthQuest ${ }^{\mathrm{TM}}$ Educator Training Seminar

SMU Student Life Star Performer Award

Break Away® Alternative Break Citizenship School Participant

Southern Education Foundation (SEF) Leadership Initiative Fellow

Florida Teacher Certification Exam (Secondary Education)-Passed

Bethune-Cookman College School of Business Student of the Year

\section{SELECTED UNIVERSITY COMMITTEES AND SERVICE}

University of Louisville

Department of Pan-African Studies

2016-2019 Member, Pan-African Graduate Student Association

2015-2016 Representative, Graduate Student Council

Florida State University

Center for Leadership and Social Change

2013-2015 Member, FSU Mentoring Institute Planning Team

2012-2015 Member, ServScript Advisory Committee

2011-2015 Chair, Professional Development Committee

2010-2015 Chair, Service Scholar Advisory Board

2010 Coordinator, FSU United Way Campaign 
University-wide

2014

2013-2015

2013-2015

2013-2015

2012-2015

2012-2013

2011

2010-2012

2010
2013-2015

Chair, Seminole Allies \& Safe Zone Coordinator Search Committee

Member, Student Affairs Diversity and Inclusion Committee

Member, Student Affairs Social Justice Programming Committee

Member, Black Male Institute Taskforce

Member, Fraternity and Sorority Life Taskforce

Member, Student Affairs Professional Development Committee

Member, Student Fee Committee

Member, Martin Luther King, Jr. Commemorative Celebration Committee

Member, University First-year Common Reading Book Selection Committee

Facilitator, University President's Retreat

Southern Methodist University

Department of Residence Life and Student Housing

2009-2010 Member, Sustainability Outreach and Education Committee

2008-2010 Chair, Diversity Action Team

2008-2009 Member, Professional Development Committee

$2008 \quad$ Chair, Social Committee

2008

Member, Professional Staff Training Committee

2007-2008

University-wide

2007-2010

$2007-2010$

2008-2009
Member, SMU/Paul Quinn College Martin Luther King, Jr. Week Committee Member, Student Affairs Faculty and University Partnerships Committee Member, StrengthQuest Advisory Committee

\section{COMMUNITY AND PROFESSIONAL LEADERSHIP}

2017-2018

2016-2017

$2012-2015$

2011-2015

2011-2012

2011-2012

2009-2011

$2009-2010$

2008

2006-2007

2006-2007

2006-2007

2005-2007
Vice President, UofL Multicultural Association of Graduate Students, Louisville, Kentucky Parliamentarian, UofL Multicultural Association of Graduate Students, Louisville, Kentucky Advisor, Kappa Delta Chi Sorority, Inc., Tallahassee, Florida Advisor, FSU Student United Way, Tallahassee, Florida Mentor, James A. Shanks Middle School Male Mentoring Program, Quincy, Florida Mentor, Big Brothers Big Sisters of the Big Bend, Tallahassee, Florida Co-Chair, Pan African Network Mentoring Program, ACPA-College Student Educators International Advisory Team/Mentor, Kappa League Youth Leadership Development Program, Dallas, Texas

Parliamentarian, National Pan-Hellenic Council of Dallas, Dallas, Texas President (Charter member), Black Graduate Student Association, University of North Carolina at Greensboro

Member, Greensboro Collegiate Council, Greensboro, North Carolina Member, Phi Kappa Chapter of Alpha Phi Omega National Service Fraternity, University of North Carolina at Greensboro

Peer Mentor, Guilford County Family Life Council Wise Guys Mentor, Greensboro, North Carolina

2005

Volunteer, Greensboro Truth and Reconciliation Commission, Greensboro, North

Carolina 